Development of an Advanced Continuous Mild Gasification Process for the Production of Coproducts

Task 4

System Integration Studies: Char Upgrading

\title{
Tonical Report
}

M.C. Jha

R.L. McCormick

R.F. Hogsett

R.M. Rowe

K.R. Anast

December 1991

Work Performed Under Contract No.: DE-AC21-87MC24268

For

U.S. Department of Energy

Office of Fossil Energy

Morgantown Energy Technology Center

Morgantown, West Virginia

By

Western Research Institute

Laramie, Wyoming

and

AMAX Research \& Development Center

Golden, Colorado 


\section{DISCLAIMER}

This report was prepared as an account of work sponsored by an agency of the United States Government. Neither the United States Government nor any agency thereof, nor any of their employees makes any warranty, express or implied, or assumes any legal liability or responsibility for the accuracy, completeness or usefulness of any information, apparatus, product, or process disclosed, or represents that its use would not infringe privately owned rights. Reference herein to any specific commercial product, process, or service by trade name, trademark, manufacturer, or otherwise, does not necessarily constitute or imply its endorsement, recommendation, or favoring by the United States Government or any agency thereof. The views and opinions of authors expressed herein do not necessarily state or reflect those of the United States Government or any agency thereof.

This report has been reproduced directly from the best available copy.

Available to DOE and DOE contractors from the Office of Scientific and Technical Infu-mation, P.O. Box 62, Oak Ridge, TN 37831; prices available from (615)576-8401, FTS 626-8401.

Available to the public from the National Technical Information Service, U.S. Department of Commerce, 5285 Port Royal Rd., Springfield, VA 22161. 
Development of an Advanced Continuous Mild Gasification

Process for the Production of Coproducts

\section{Task 4}

System Integration Studies: Char Upgrading

Topical Report

M.C. Jha

R.L. McCormick

R.F. Hogsett

R.M. Rcwe

K.R. Anast

Work Performed Under Contract No.: DE-AC21-87MC24268

For

U.S. Department of Energy

Office of Fossil Energy

Morgantown Energy Technology Center

P.O. Box 880

Morgantown, West Virginia 26507-0880

By
Western Research Institute

P.O. Box 3395, University Station

Laramie, Wyoming 82071-3395

and

AMAX Research \& Development Center

5950 McIntyre Street

Golden, Colorado 80403-7499

December 1991 


\begin{abstract}
Under Contract No. DE-AC21-87MC24268 from DOE/METC, Amax Research \& Development Center of Golden, Colorado (Amax R\&D), worked with Western Research Institute of Laramie, Wyoming (WRI), on "Development of an Advanced, Continuous Mild Gasification Process for the Production of Coproducts". The project was divided into four tasks:

Task 1. Literature Survey and Market Assessment

Task 2. Bench-Scale Mild Gasification Study

Task 3. Bench-Scale Char Upgrading/Utilization Study

Task 4. System Integration Studies

This document describes the results of Task 4 under which a 50 pound/hour char-to-carbon (CTC) process research unit (PRU) was designed in the second half of 1989, with construction completed in June 1990. The CTC PRU at Golden was operated for nearly one year during which 35 runs were completed for a total of nearly 800 hours of operation. Char methar-tion and carbon production reactor development activities are detailed in this report, as well as the results of integrated runs of the CTC process. Evaluation of the process and the carbon product produced is also included.

It was concluded that carbon could be produced from mild gasification char utilizing the CTC process. Char methanation and membrane separation steps performed reasonably well and can be scaled up with confidence. However, the novel indirectly heated reactor system for methane cracking did not work satisfactorily due to materials of construction and heat transfer problems, which adversely affected the quantity and quality of the carbon product. Alternative reactor designs are recommended.
\end{abstract}




\section{ACKNOWLEDGEMENTS}

Amax Research \& Development Center would like to acknowledge Mr. Norm Merriam and the staff at Western Research Institute in Laramie, Wyoming, for their assistance in this project. The United States Department of Energy, Morgantown Energy Technology Center, is also acknowledged for their assistance and financial support. The support and interest of Amax Coal Industries is greatly appreciated. Amax Coal purchased virtually all of the processing equipment used in this test work. AMAX Inc. has also shown interest in the project and provided support by the purchase of analytical instruments. This interest and support is greatly appreciated.

We would like to thank BEI Engineers and Constructors of Lakewood, Colorado, for their assistance in the design of the process research unit (PRU) used in this work. TIC of Steamboat Springs, Colorado, built the PRU and their assistance is acknowledged.

Roger Nichting of the Materials Processing Department at Amax R\&D provided expertise and performed test work with regard to materials of construction.

The PRU was operated by a highly skilled and dedicated group of technicians: Tony Blandon, Dave Meyer, and Mario Robles. They were assisted by Mike Danz, Steve Smith, and Don Thompson. Wendy Kennedy word processed this final report and all of the reports prepared for this project. 


\section{TABLE OF CONTENTS}

Page

ABSTRACT $\ldots \ldots \ldots \ldots \ldots \ldots \ldots \ldots \ldots \ldots \ldots \ldots \ldots$

ACKNOWLEDGEMENTS $\ldots \ldots \ldots \ldots \ldots \ldots \ldots \ldots$

LIST OF TABLES $\ldots \ldots \ldots \ldots \ldots \ldots \ldots \ldots \ldots$ vi

LIST OF FIGURES $\ldots \ldots \ldots \ldots \ldots \ldots \ldots \ldots \ldots \ldots$

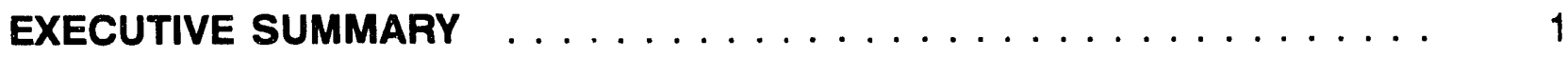

INTRODUCTION $\ldots \ldots \ldots \ldots \ldots \ldots \ldots \ldots \ldots \ldots \ldots$

PROCESS DESCRIPTION $\ldots \ldots \ldots \ldots \ldots \ldots$

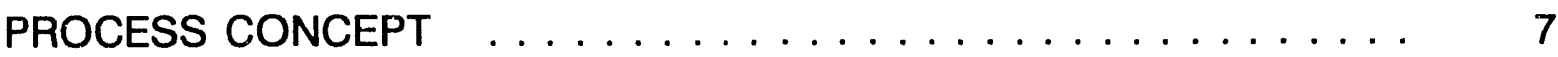

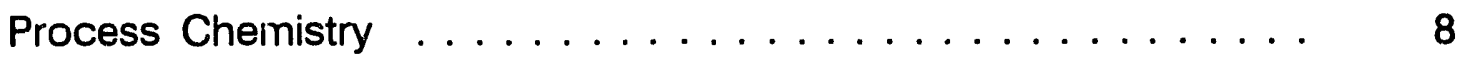

PRU Process Flow Diagram ................... 10

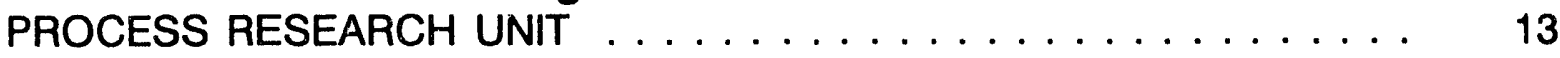

Methanation Reactor $\ldots \ldots \ldots \ldots \ldots \ldots \ldots$

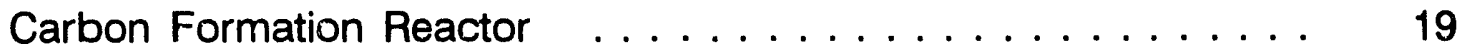

Gas Separation Membrane .................... 21

Process Gas Analysis . . . . . . . . . . . . . . . . . . . 22

Computer Control and Data Acquisition ............. 23

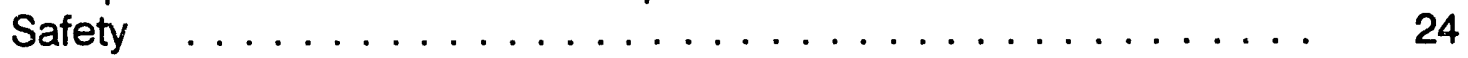

Materials of Construction .................. 25

PROCESS RESEARCH UNIT OPERATING PROCEDURES $\ldots \ldots \ldots$

PROCESS RESEARCH UNIT OPERATION RESULTS $\ldots \ldots \ldots \ldots$

CHRONOLOGY OF PRU TESTS AND UNIT MODIFICATIONS $\ldots \ldots$

Run $\mathrm{S}-1 \ldots \ldots \ldots \ldots \ldots \ldots \ldots \ldots$

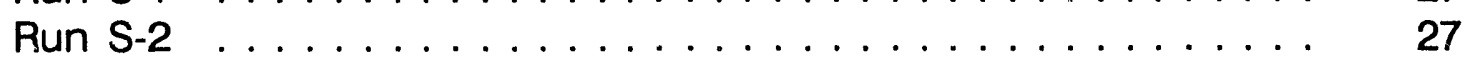

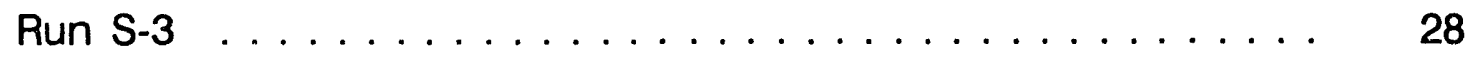

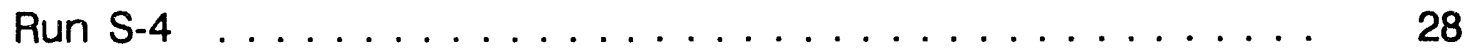

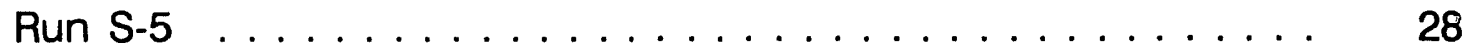

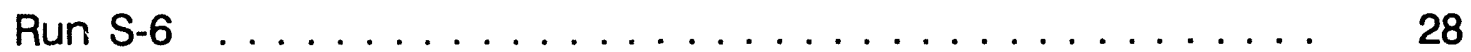

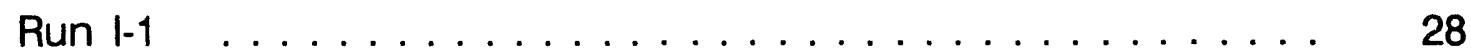

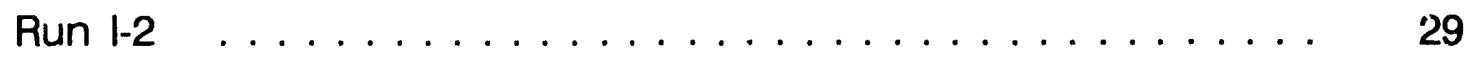

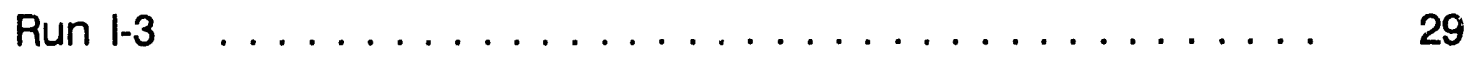

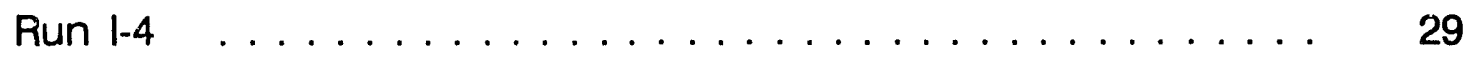




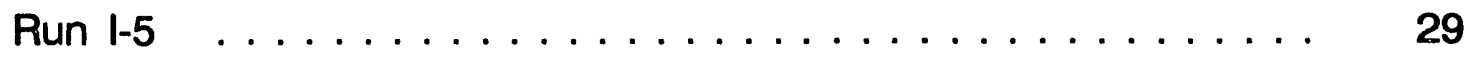

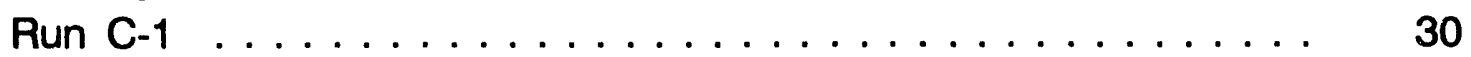

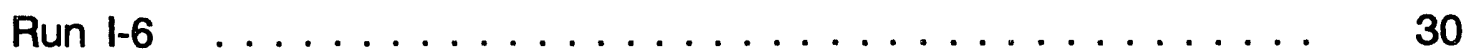

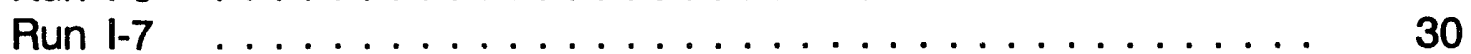

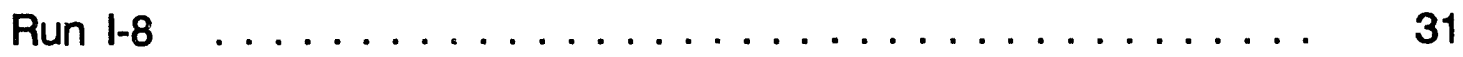

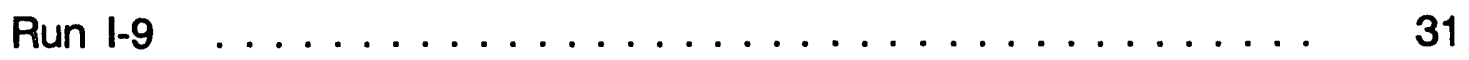

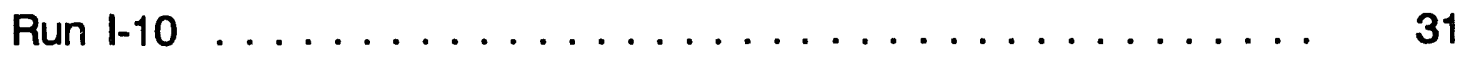

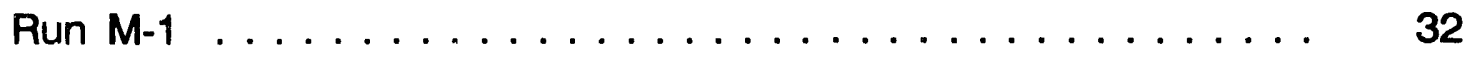

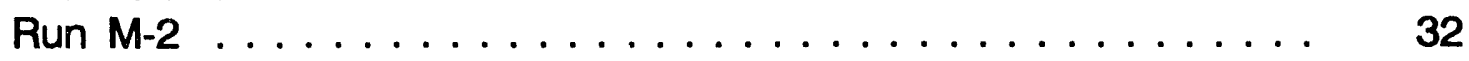

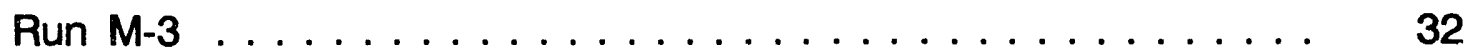

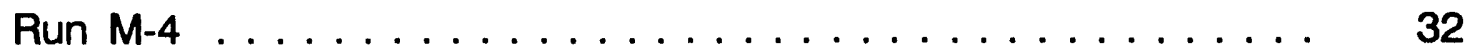

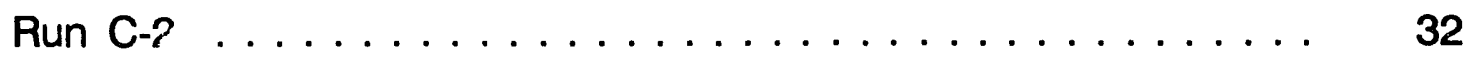

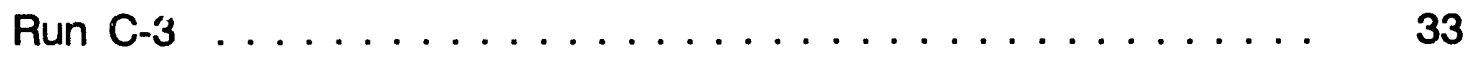

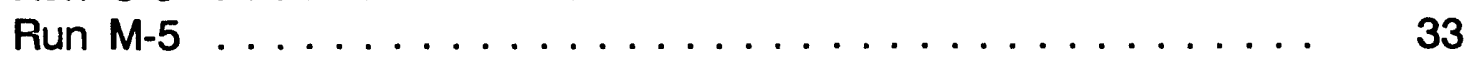

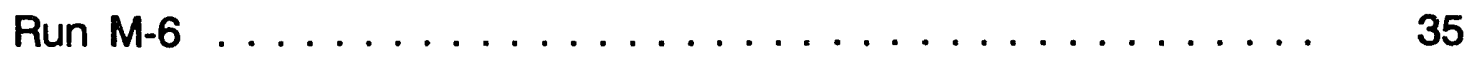

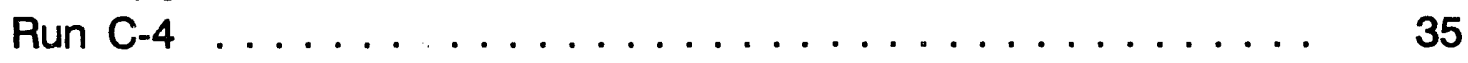

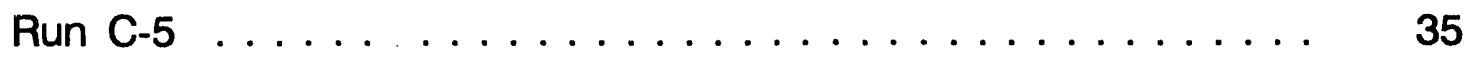

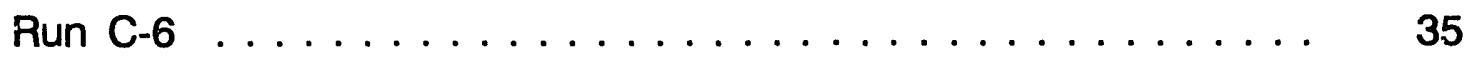

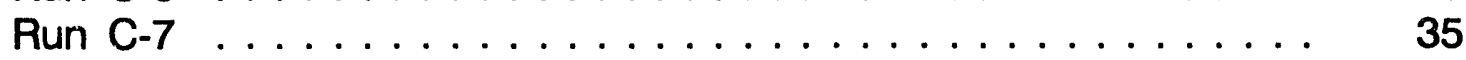

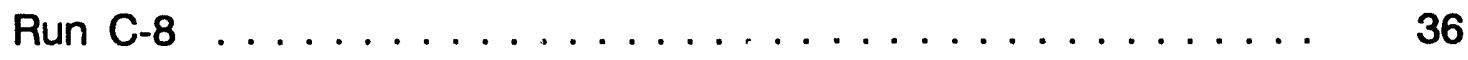

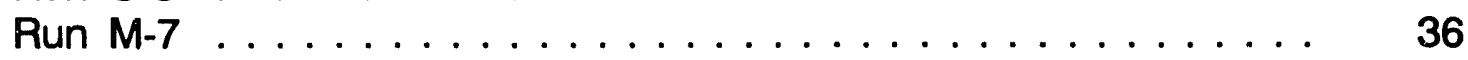

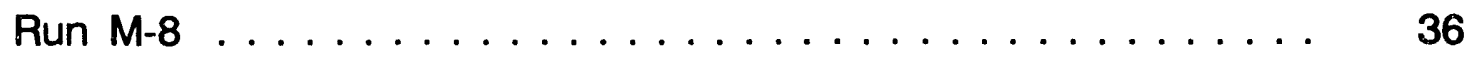

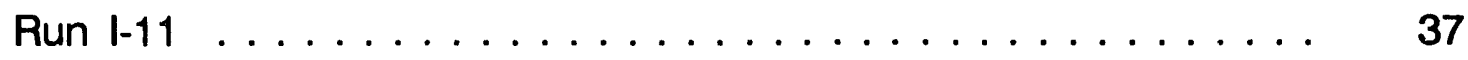

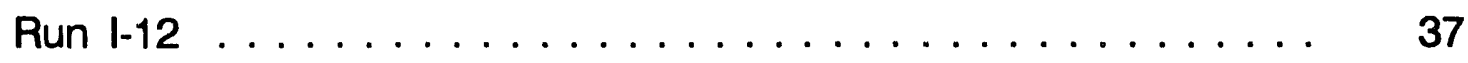

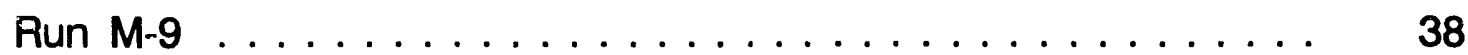

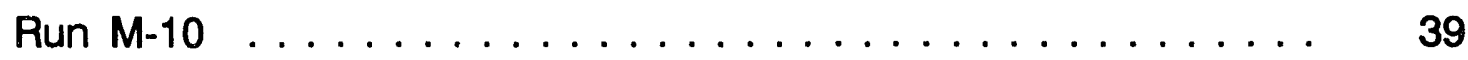

COLD FLOW TEST RESULTS $\ldots \ldots \ldots \ldots \ldots \ldots \ldots \ldots \ldots . \ldots . \ldots$

Methanation Reactor Simulation ............. 40

Carbon Formation Reactor Simulation . . . . . . . . . . 44

DETAILED TEST DATA FROM SELECTED RUNS $\ldots \ldots \ldots \ldots \ldots$.

Run C-2 Results $\ldots \ldots \ldots \ldots \ldots \ldots \ldots \ldots \ldots \ldots \ldots \ldots$

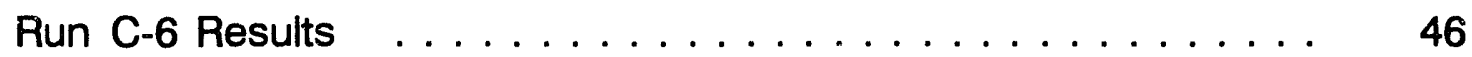

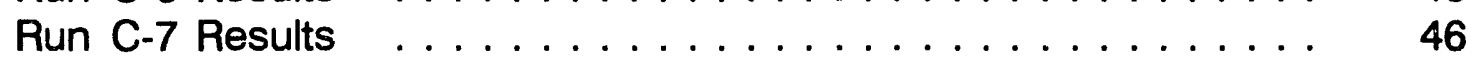

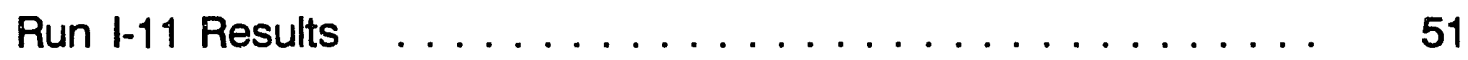

Run $\mathrm{M}-10$ Results $\ldots \ldots \ldots \ldots \ldots \ldots \ldots \ldots$

PRODUCT CHARACTERIZATION RESULTS $\ldots \ldots \ldots \ldots \ldots \ldots .69$

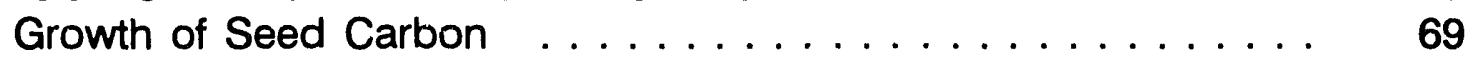

Fine Carbon From Baghouse $\ldots \ldots \ldots \ldots \ldots \ldots \ldots$

Pyrolytic Carbon From Heat Transfer Surfaces . . . . . . . . 74

MATERIALS PERFORMANCE RESULTS $\ldots \ldots \ldots \ldots \ldots \ldots \ldots$ 
TABLE OF CONTENTS

(Continued)

Page

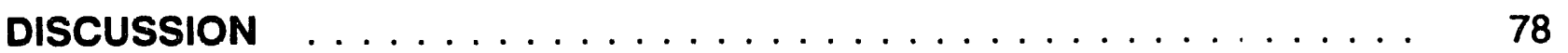

GAS SEPARATION SYSTEM PERFORMANCE $\ldots \ldots \ldots \ldots \ldots$

METHANATION SYSTEM PERFORMANCE $\ldots \ldots \ldots \ldots \ldots \ldots \ldots 78$

CARBON FORMATION SYSTEM PERFORMANCE $\ldots \ldots \ldots \ldots \ldots$

INTEGRATED SYSTEM PERFORMANCE $\ldots \ldots \ldots \ldots \ldots \ldots \ldots .81$

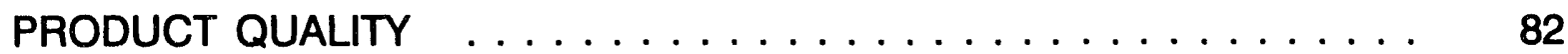

PERFORMANCE OF MATERIALS OF CONSTRUCTION ....... 83

PERFORMANCE OF CONTROL SYSTEM AND INSTRUMENTATION . $\quad 85$

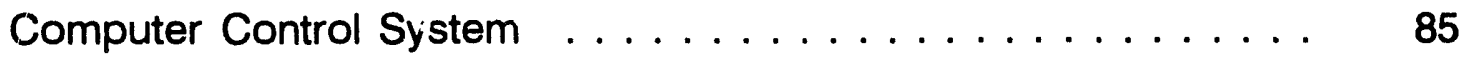

Instrumentation $\ldots \ldots \ldots \ldots \ldots \ldots \ldots \ldots \ldots \ldots$

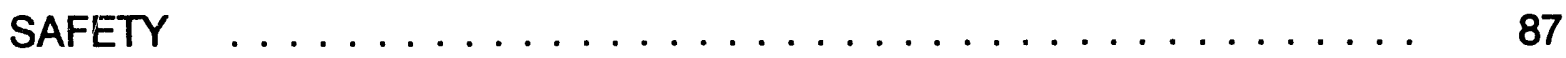

CONCLUSIONS $\ldots \ldots \ldots \ldots \ldots \ldots \ldots \ldots \ldots \ldots \ldots$

RECOMMENDATIONS $\ldots \ldots \ldots \ldots \ldots \ldots \ldots \ldots \ldots \ldots \ldots$

REFERENCES $\ldots \ldots \ldots \ldots \ldots \ldots \ldots \ldots \ldots \ldots \ldots \ldots \ldots \ldots \ldots$

APPENDIX A
OPERATION METHOD DETAILS $\ldots \ldots \ldots \ldots \ldots \ldots \ldots \ldots$

APPENDIX B

METHANATION REACTOR DATA ANALYSIS AND MODELING $\ldots \ldots 102$

APPENDIX C

CALCULATION OF CARBON REACTOR HEAT TRANSFER

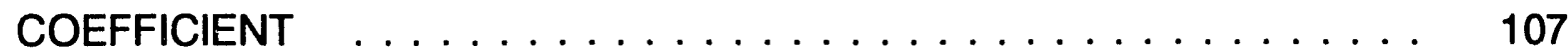




\section{LIST OF TABLES}

Page

Table 1. Analytical Results for Eagle Butte Coal and Mild Gasification Char .................... 12

Table 2. Particle Size Distribution for Mild Gasification Char (MG-122) $\ldots \ldots \ldots \ldots \ldots \ldots \ldots \ldots \ldots \ldots \ldots \ldots$

Table 3. Materials of Construction Used in the PRU . . . . . . . 25

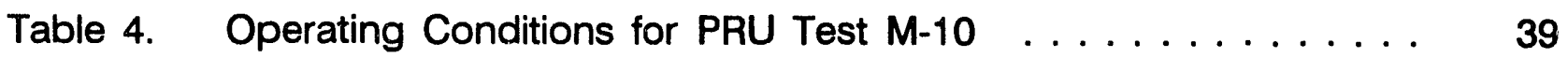

Table 5. Comparison of the Properties of Ambient Air and Process Gases . . . . . . . . . . . . . . . . . 40

Table 6. Analytical Data for Spent Chars from Run $M-10 \ldots 68$

Table 7. Average Values of Carbon Conversion for Run

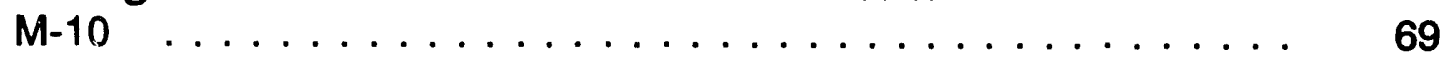

Table 8. Analytical Data on Seed Carbons $\ldots \ldots \ldots \ldots \ldots \ldots$

Table 9. Analysis of Fine Carbon Product from Run C-7 . . . . . . 73

Table 10. Analytical Results for Fine Carbon Size

Fractions from Run $\mathrm{C}-7 \ldots \ldots \ldots \ldots \ldots \ldots \ldots$

Table 11. Analytical Results for Forms of Pyrolytic

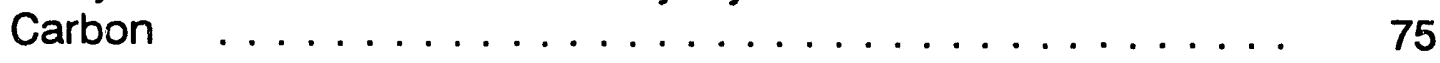

Table 12. Char/Hydrogen Ratios and Other Pertinent Data from Run $\mathrm{M}-10$

Table 13. Kinetic and Mass Transfer Parameters Extracted from

Run $\mathbf{M - 1 0}$ 


\section{LIST OF FIGURES}

Page

Figure 1. Block flow diagram of overall mild gasification and char-to-carbon process. . . . . . . . . . . . . 5

Figure 2. Simplified flow diagram for char-to-carbon process. $\ldots \ldots \ldots 7$

Figure 3. Heat of reaction as a function of temperature. . . . . . . 9

Figure 4. Equilibrium gas composition as a function of temperature and pressure. . ..............

Figure 5. Conversion versus time plots for bench-scale methanation of mild gasification char. . . . . . . . . 10

Figure 6. Conceptual flowsheet for char-to-carbon process with gas separation and high pressure carbon formation.

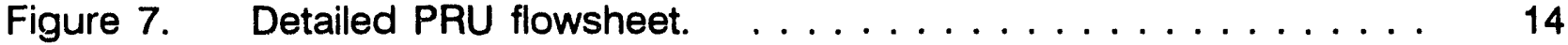

Figure 8. Photograph of PRU area. $\ldots \ldots \ldots \ldots \ldots \ldots \ldots$

Figure 9. Scale drawing of methanation reactor :essel. $\ldots \ldots \ldots 17$

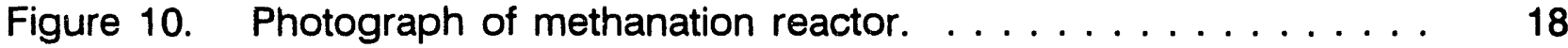

Figure 11. Scale drawing of carbon formation reactor. . . . . . . . 20

Figure 12. Photograph of carbon reactor. $\ldots \ldots \ldots \ldots \ldots \ldots \ldots$

Figure 13. Simplified process flow diayram showing location

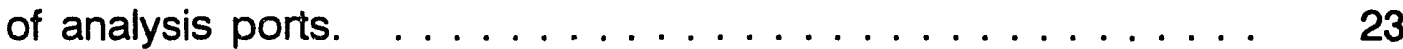

Figure 14. Scale diawing of modified carbon reactor. . . . . . . . . 34

Figure 15. Photograph showing large carbon deposit on carbon formation reactor heat transfer surfaces after Run I-12. . . . . 38

Figure 16. Photograph of methanation unit cold flow model. . . . . . . 41

Figure 17. Results of methanation reactor cold flow tracer study (32-pound bed inventory and mean residence time of 40 minutes). 


\section{LIST OF FIGURES}

(Continued)

Page

Figure 18. Results of methanation reactor cold flow tracer study (24-pound bed inventory and mean residence time of 30 minutes).

Figure 19. Results of methanation reactor cold flow tracer study (14-pound bed inventory and mean residence time of 28 minutes)

Figure 20. Photograph of carbon formation unit cold flow model.

Figure 21. a) Glow bar temperatures and b) carbon reactor bed temperatures for Run C-2.

Figure 22. Carbon reactor feed gas flow rate for Run C-2. . . . . . .

Figure 23. Mean carbon reactor heat transfer coefficient for

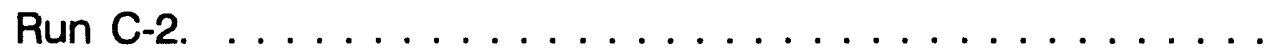

Figure 24. a) Glow bar temperatures and b) carbon reactor bed temperatures for Run C-6.

Figure 25. Carbon reactor feed gas flow rate for Run C-6.

Figure 26. Overall carbon reactor heat transfer coefficients for Run C-6.

Figure 27. a) Glow bar temperatures and b) carbon reactor bed temperatures for Run C-7.

Figure 28. Carbon reactor feed gas flow rate for Run C-7. . . . . . . 53

Figure 29. a) Carbon reactor gas compositions and b) carbon reactor methane conversion for Run C-7. . . . . . . . . . . . . .

Figure 30. Overall carbon reactor heat transfer coefficients for Run C-7.

Figure 31. a) Membrane gas compositions and b) membrane efficiency for Run I-11. 


\section{LIST OF FIGURES}

(Continued)

Page

Figure 32. Methane reactor bed temperature for Run $\mathrm{I}-11 . \ldots \ldots$

Figure 33. Methane reactor feed gas flow rate for Run I-11. . . . . . . 58

Figure 34. Methane reactor gas compositions for Run I-11. . . . . . 59

Figure 35. a) Glow bar temperatures and b) carbon reactor bed temperatures for Run $1-11 . \ldots \ldots \ldots \ldots \ldots \ldots$

Figure 36. Carbon reactor feed gas flow rate for Run $1-11 . \ldots 62$

Figure 37. Carbon reactor gas compositions for Run I-11. . . . . . . 62

Figure 38. Overall carbon reactor heat transfer coefficients for Run $1-11 . \ldots \ldots \ldots \ldots \ldots \ldots \ldots \ldots \ldots \ldots \ldots \ldots \ldots \ldots$

Figure 39. a) Membrane gas composition and b) membrane efficiency for Run $\mathrm{M}-10 . \quad \ldots \ldots \ldots \ldots \ldots \ldots \ldots \ldots \ldots$. . . . . . . . 64

Figure 40. Methane reactor bed temperature for Run $M-10 . \ldots \ldots 6$

Figure 41. Methane reactor feed gas flow rate for Run $M-10$. . . . . 66

Figure 42. a) Methane reactor gas compositions and b) char carbon conversions for Run M-10. . . . . . . . . . . . . . . 67

Figure 43. Particle size distributions for original seed carbon and seed carbon withdrawn from the reactor after

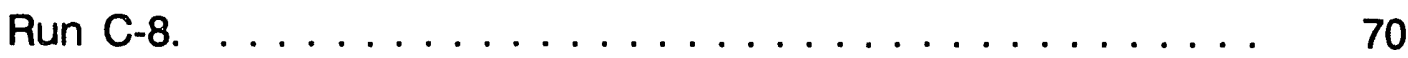

Figure 44. Photomicrographs of a) original seed carbon and b) seed carbon withdrawn from the reactor after Run C-8.

Figure 45. Photomicrographs of cross sections of a) original seed carbon and b) seed carbon withdrawn from the reactor after Run C-8.

Figure 46. Energy dispersive X-ray spectra for a) pyrolytic carbon taken from the glow bar muffle surface and b) pyrolytic carbon roughly 1 inch from the glow bar muffle surface. 


\section{LIST OF FIGURES}

(Continued)

Page

Figure 47. Photomicrograph of pyrolytic carbon fragment showing

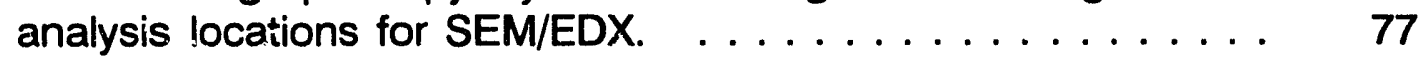

Figure 48. High temperature tensile strength of Incoloy $800 \mathrm{HT}$. . . . . 84

Figure 49. Results of high temperature creep measurement for Incoloy $\mathbf{8 0 0 \mathrm { HT }} . \ldots \ldots \ldots \ldots \ldots \ldots \ldots \ldots \ldots . \ldots \ldots$ 


\section{EXECUTIVE SUMMARY}

Under Contract No. DE-AC21-87MC24268 from DOE/METC, Amax Research \& Development Center of Golden, Colorado (AMAX), has been working with Western Research Institute of Laramie, Wyoming (WRI), on "Development of an Advanced, Continuous Mild Gasification Process for the Production of Coproducts". The project was divided into four tasks:

Task 1. Literature Survey and Markeic Assessment

Task 2. Bench-Scale Mild Gasification Study

Task 3. Bench-Scale Char Upgrading Study

Task 4. System Integration Studies

Task 1 was completed in early 1988. It was concluded that the commercial feasibility of the technology would critically depend on upgrading of products, particularly char, to higher-value products. Pure carbon, to be used as carbon black or anode carbon in the short range and as a premium fuel in the long range, was identified as the preferred product.

Under Task 2, WRI developed an inclined fluidized-bed process for drying and mild gasification of subbituminous coal. Under Task 3, AMAX developed a char-to-carbon (CTC) process for upgrading the mild gasification char to pure carbon and activated carbon. Detailed results from these studies have been presented as topical reports.

Following successful bench-scale test work, a 100 pound/hour coal mild gasification process research unit (PRU) was designed, built, and operated at WRI during 1989 - 1990 under Task 4. A companion 50 pound/hour char-to-carbon (CTC) PRU was designed, built, and operated at Amax R\&D. This topical report presents the results from CTC PRU work.

The CTC process consists of two steps. In the first step, most of the carbon present in the char is converted to methane by the following reaction:

$$
\mathrm{C}+2 \mathrm{H}_{2} \rightarrow \mathrm{CH}_{4}
$$

All of the ash and most of the sulfur impurities are left behind in the spent char. In the second step of the process, methane is decomposed at a higher temperature to produce pure carbon and hydrogen according to the reverse reaction:

$$
\mathrm{CH}_{4} \rightarrow \mathrm{C}+2 \mathrm{H}_{2}
$$

Hydrogen is recycled to the first step. Thus, the process does not consume an external reagent. Other impurities present in the char, nitrogen, hydrogen, and oxygen are gasified during methanation but do not affect the purity of the carbon produced and are removed from the system as a bleed gas used for fuel value. 
AMAX optimized process conditions for both steps by bench-scale testing and process integration to minimize the process cost. The methanation reaction takes place at 1,300 to $1,500^{\circ} \mathrm{F}$ and 200 to 300 psia in an excess of hydrogen. About 70 percent char conversion is obtained in less than 2 hours residence time.

The spent char has a high specific surface area and a very porous structure. It is upgraded to activated carbon by recovering a relatively ash-free portion by gravity separation or acid leaching.

The carbon formation reaction takes place in an indirectly heated continuous reactor at 1,600 to $1,800^{\circ} \mathrm{F}$ and 50 to 100 psia in the presence of carbon seed. Under these conditions, metal heat transfer surfaces can be used for indirect heating, and both coarse and fine carbon can be produced for different markets.

Relatively close temperature and pressure conditions between the two steps improve the thermal and mechanical energy efficiency of the process. However, they reduce the thermodynamic driving force, resulting in low single-pass conversion efficiency. To overcome this problem, which would otherwise require a large amount of hydrogen recirculating load, a membrane gas separation unit is used.

The PRU was designed during the second half of 1989 with assistance from BEI Engineers and Constructors of Lakewood, Colorado, and constructed during the first half of 1990 with assistance from The Industrial Company of Steamboat Springs, Colorado. It consists of a char methanation fluid-bed reactor, an indirectly heated carbon formation fluid-bed reactor, a gas separation membrane, two compressors, several heat exchangers, filters, systems for feeding and discharging solids, and systems for supplying start-up gases to the process. The plant is entirely computer controlled, and process gas analysis is performed with a mass spectrometer.

The PRU was operated for nearly cne year (July 1990 - July 1991) during which 35 runs were completed, for a total of nearly 800 hours of operation. These runs included:

- Six shakedown runs during which the primary goal was to calibrate the instruments, develop start-up and shut-down procedures.

- Ten methanation runs during which the primary focus was on the methane reactor and its modifications. The membrane was included in the flowsheet so that unreacted hydrogen could be recovered and reused. The methane-rich gas product was simply burned in the flare.

- Eight carbon formation runs during which the primary focus was the carbon formation reactor and its modifications. Bottled methane gas mixed with hydrogen from the tank was used in these runs.

- Eleven integrated runs Juring which both the reactors were operated and emphasis was on demoristrating the proof of concept for the process, as well 
as on developing a better understanding of the process control. The longest runs lasted for up to 3 days.

The PRU operation provided the proof of concept for the CTC process. Mild gasification char was successfully converted to methane in the methanation reactor, and after gas separation in a membrane, it was decomposed to carbon in the carbon formation reactor. The two reactions occurred at designed temperature and pressure conditions.

However, the percent conversion was well below the design in both reactors, mostly due to the lack of adequate residence time at proper temperature. Heat losses were significantly higher than allowed for in the design. The fluidization quality was also poor, as was seen in cold flow models.

The carbon product was contaminated by chromium, iron, and nickel metals due to erosion and corrosion of metal tubes used as muffle for glow bars which provided heat to the carbon formation reactor. This materials of construction problem led to the poor performance of the carbon reactor and its shutdown due to safety concerns. Scaling of these surfaces resulted in poor heat transfer coefficients and was the primary cause for the low carbon yields obtained.

Other systems, including the membrane, cyclones, baghouse, heat exchangers, and compressors, worked well. The solids feeding and discharging systems had to be modified. Most of the instruments, with the exception of turbine flowmeters, worked well.

The plant is highly computerized for data logging, as well as process control. This system worked well and was primarily responsible for the safe operation of the plant involving explosive and toxic gases.

It is recommended that the PRU test program be continued, after the required modifications, to accomplish the following goals:

- Process optimization.

- Production of enough product for market evaluation.

Such an operation will also confirm the 20 ton/day integrated process development unit (PDU) design. The PDU is a prerequisite to the commercialization of this technology.

Specific recommendations for the PRU modification are to:

- Install an alternative carbon formation reactor system based on known commercial technology and aimed at producing only fine carbon. Thermal black and plasma technology are the obvious candidates.

- Modify the methanation reactor to provide longer residence time and better fluidization, along with continuous feed and discharge systems. 


\section{INTRODUCTIC:A}

Under Contract No. DE-AC21-87MC24268 from DOE/METC, Amax Research \& Development Center of Golden, Colorado (Amax R\&D), worked with Western Research Institute of Laramie, Wyoming (WRI), on "Development of an Advanced, Continuous Mild Gasification Process for the Production of Coproducts". The project was divided into four tasks:

Task 1. Literature Survey and Market Assessment

Task 2. Bench-Scale Mild Gasification Study

Task 3. Bench-Scale Char Upgrading/Utilization Study

Task 4. System Integration Studies

Task 1 was completed in January 1988. The results of these studies have been presented at METC ${ }^{1}$ and in a topical report. ${ }^{2}$ The results indicated that the mild gasification liquid products may have significant value in several niche markets. These include utilizing the $700^{\circ} \mathrm{F}+$ fraction as anode binder pitch. The lighter fractions can be used as a coal dedusting agent and as a diesel fuel additive or substitute to operate heary mine equipment.

The studies performed under Task 1 indicated that while the liquids are valuable products, the economic viability of the mild gasification process depends mainly on the value of the char. Char is the major product in terms of tonnage, and therefore, it is crucial that the char be marketed at a premium. Several energy and non-energy applications for char were investigated as a part of the work described in the topical report.

It was concluded that the most attractive approach would be to convert char to carbon. This solid, pure product can be marketed in the metals and energy markets. Three specific markets have been targeted, based on the market size and price that the product carbon may command in these markets. These markets are:

- Carbon anodes for aluminum production.

- Carbon black for the rubber industry.

- Carbon as a premium fuel.

Task 2, the bench-scale mild gasification study, was completed by WRI early in 1989, and the results are described in a topical report. ${ }^{3}$ Task 3 , the bench-scale char upgrading study, was performed by Amax R\&D and completed in mid-1989. These results have also been presented in a topical report. ${ }^{4}$ The char-to-carbon (CTC) process developed in Task 3 involves two steps, the conversion of carbon in the char to methane, followed by the conversion of methane to high purity carbon and hydrogen. This hydrogen is then recycled to convert more char to methane. Under Task 3, these two steps were studied separately. Details of the overall process have been presented by Jha and Cha, ${ }^{5}$ and a block flow diagram is shown 
in Figure 1. The char upgrading process has been described by McCormick and Jha, ${ }^{6}$ and process details and test results have been presented at METC. ${ }^{7,8}$ The use of carbon as a premium fuel has been discussed by Woessner and Jha. ${ }^{9}$ AMAX has applied for several patents covering various aspects of the process. ${ }^{10-14}$

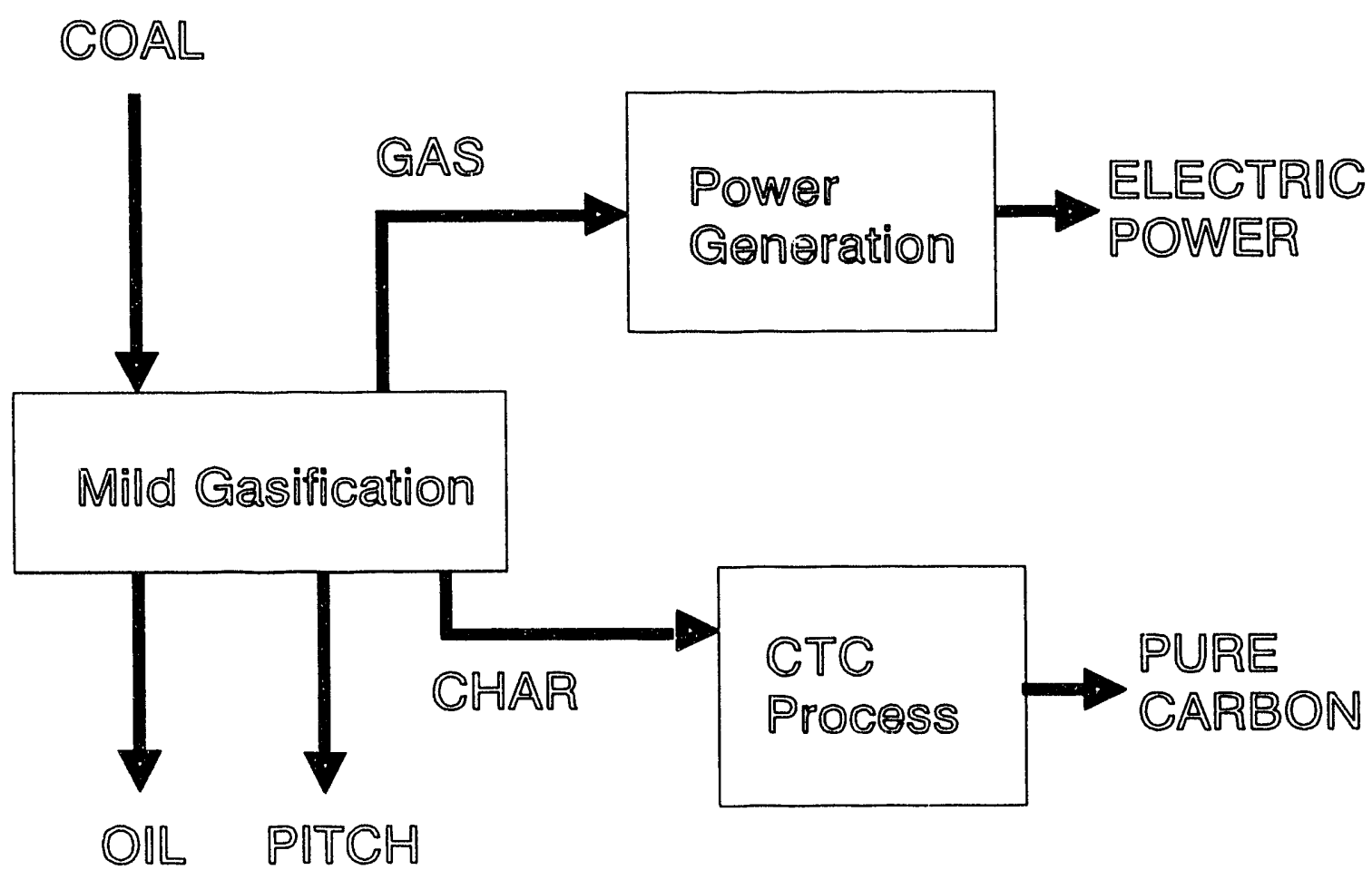

Figure 1. Block flow diagram of overall mild gasification and char-to-carbon process.

In Task 4, the overall process was studied in two integrated, continuous process research units (PRUs). A 100 pound/hour mild gasification PRU, located at WRI, began operating in the third quarter of 1989. Operation of the mild gasification PRU was completed in 1990, and the results have been presented in a topical report. $^{15}$

A companion 50 pound/hour CTC PRU was designed in the second half of 1989 and construction was completed in June 1990. AMAX Inc. and Amax Coal Industries provided the funds for purchase of equipment and instruments. The CTC PRU at Golden was operated for nearly one year. This document describes the results of the CTC-PRU studies. In particular, char methanation and carbon production reactor development activities are detailed, aj well as the results of integrated runs of the CTC process. Evaluation of the process and the carbon product produced is also included. 
Task 4 also included an updated cost estimate and economic analysis for a 1,000 ton/day commercial demonstration plant as Task 4.6 and conceptual design for a 1 ton/hour process development unit (PDU) as Task 4.7. Separate topical reports have been issued for these tasks. ${ }^{16,17}$ 


\section{PROCESS DESCRIPTION}

The char-to-carbon process being developed in this project involves two steps, the conversion of carbon in the char to methane, followed by the conversion of methane to high purity carbon and hydrogen. The hydrogen is then recycled to convert more char to methane. In this chapter, a detailed discussion of the process concept is presented. This is followed by a description of the CTC PRU and its important unit operations.

\section{PROCESS CONCEPT}

The CTC process is being developed for conversion of the carbon in mild gasification c'.'. ar to pure carbon and activated carbon. Mild gasification char is produced by low temrerature devolatilization of coal. The char contains 75 to 85 weight percent carbon, as well as ash, hydrogen, sulfur, nitrogen, and oxygen. The CTC process removes 50 to 75 percent of this carbon from the char and recovers it as pure carbon. A simplified flow diagram showing the two main steps in the process is shown in Figure 2. The carbon in char is converted to methane by reaction with hydrogen in Reactor 1 . This methane is then decomposed to product hydrogen for recycle and the pure carbon product in Reactor 2.

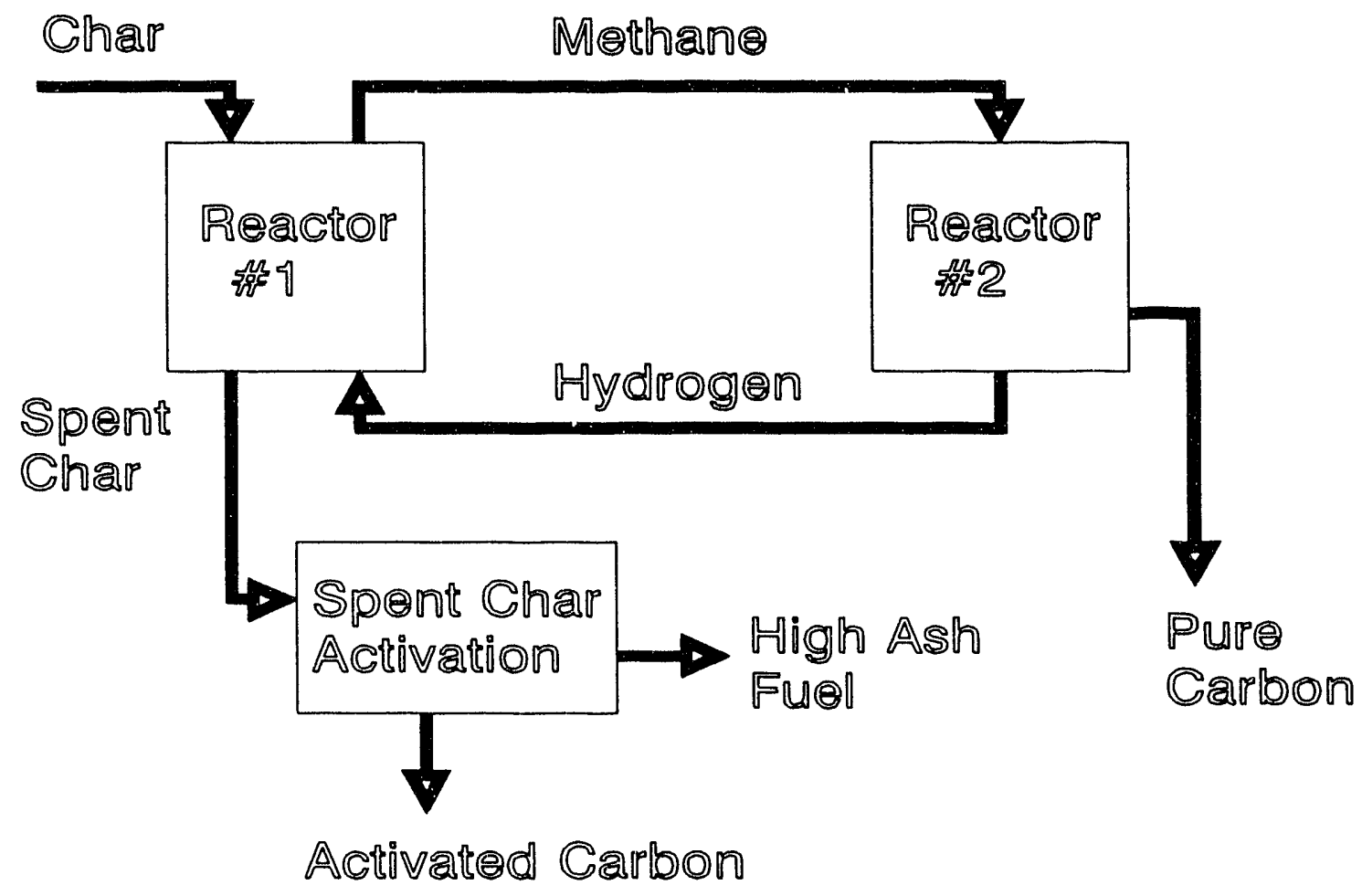

Figure 2. Simplified flow diagram for char-to-carbon process. 
The pure carbon can be used as a high purity substitute for petroleum coke in the manufacture of carbon anodes used in aluminum production. The carbon might also see application as a substitute for thermal black in rubber compounding. The largest market in the long term will be as a premium fuel for power production. ${ }^{9}$

The spent char contains 65 to 75 weight percent carbon and 20 to 25 weight percent ash. This material can be upgraded to lower its ash content, producing a high quality activated carbon and a low grade fuel.

\section{Process Chemistry}

The chemical reaction which is being exploited in this process is the reaction of carbon and hydrogen to produce methane and the reverse reaction to produce carbon and hydrogen:

$$
\begin{array}{ll}
\mathrm{C}+2 \mathrm{H}_{2} \rightarrow \mathrm{CH}_{4} & \left(800-1,500^{\circ} \mathrm{F}\right) \\
\mathrm{CH}_{4} \rightarrow \mathrm{C}+2 \mathrm{H}_{2} & \text { (above 1,650 } \\
&
\end{array}
$$

The first reaction is exothermic and the reverse reaction is endothermic. The heat of reaction is a weak function of temperature, as shown in Figure 3 . In the temperature range of interest, the heat of reaction is about $42,000 \mathrm{Btu} / \mathrm{lbmole}$ or 24 $\mathrm{kcal} / \mathrm{gmole}$.

Equilibrium gas compositions for this system are shown in Figure 4. The figure indicates that methane formation is favored thermodynamically at high pressure and low temperature. At low temperatures, reaction rates tend to be very slow so that in practice, this reaction must be performed at $1,300^{\circ} \mathrm{F}$ or above. Also, the pressure at which this reaction can be conducted is constrained by pressure vessel cost and the cost of gas compression.

Bench-scale tests indicated that acceptably high rates of methane formation could be achieved at 1,300 to $1,475^{\circ} \mathrm{F}$ and 200 to 300 psig. ${ }^{4}$ Temperature had a significant effect on the ultimate carbon conversion which could be achieved, however. ${ }^{6}$ This effect is shown in Figure 5 where total conversion as a function of time for fixed-bed char methanation runs is plotted as a function of time. An optimum reaction temperature of $1,380^{\circ} \mathrm{F}$ was selected based on these considerations.

Conventional thermal black processes for decomposing $\mathrm{CH}_{4}$ to carbon and $\mathrm{H}_{2}$ operate at atmospheric pressure and at temperatures between 2,300 and $2,800^{\circ} \mathrm{F}$. At these conditions, thermodynamics favor an equilibrium gas composition very low in residual $\mathrm{CH}_{4}$. In the CTC process concept, the carbon production reactor is indirectly heated to avoid contamination of the recycle hydrogen products. However, materials of construction and fabrication techniques required for a continuous, indirectly heated reactor at these thermodynamically and kinetically 


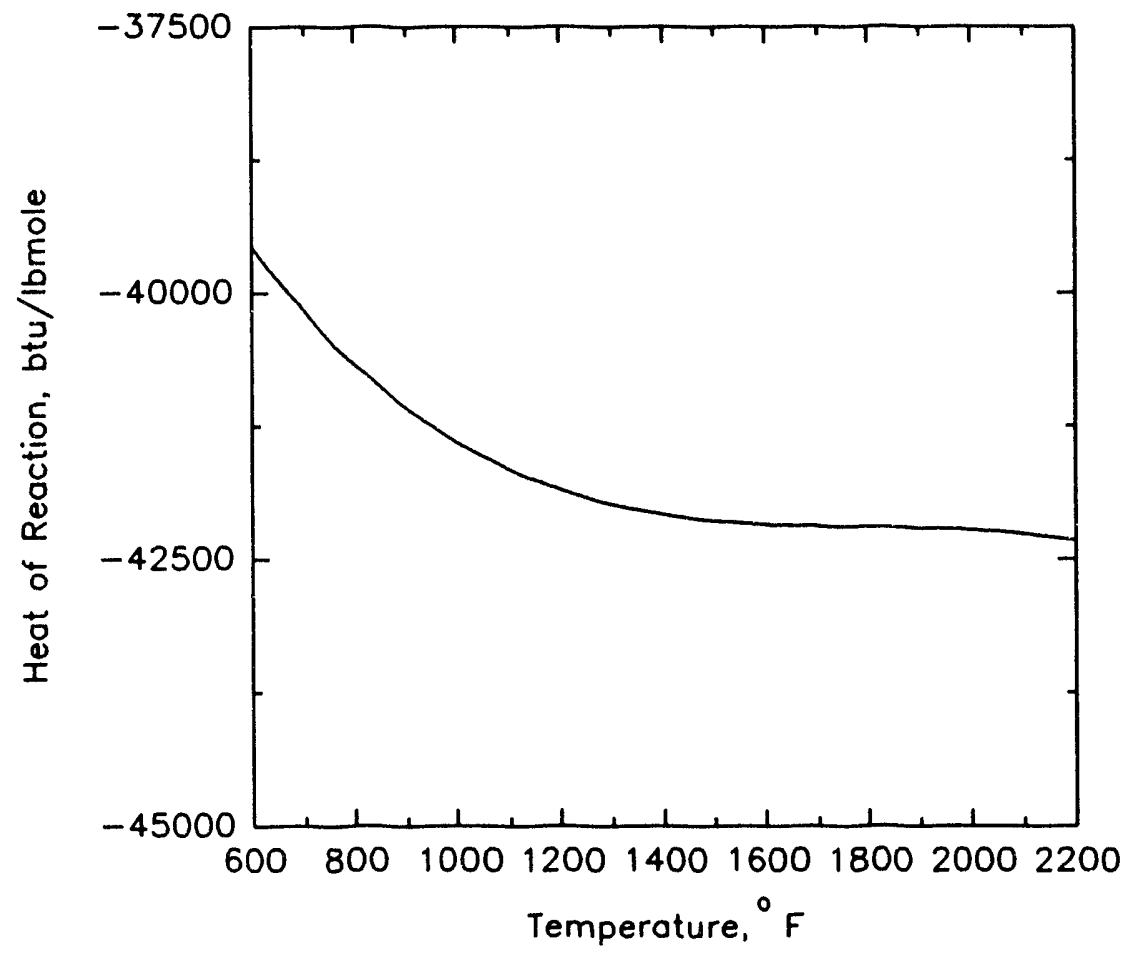

Figure 3. Heat of reaction as a function of temperature.

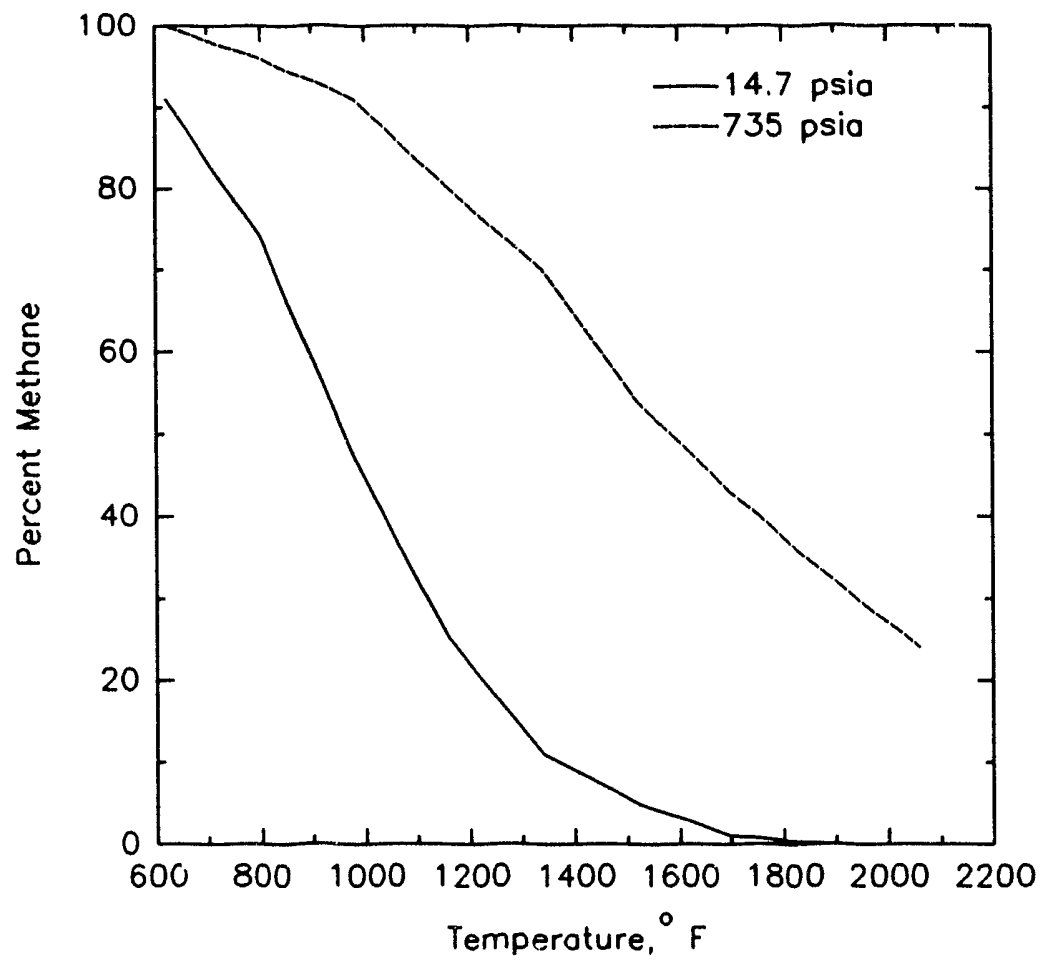

Figure 4. Equilibrium gas composition as a function of temperature and pressure. 
favorable conditions are not available in a practical sense. At temperatures below $2,000^{\circ} \mathrm{F}$, thermodynamics are still favorable, but reaction rates are very slow at atmospheric pressure.

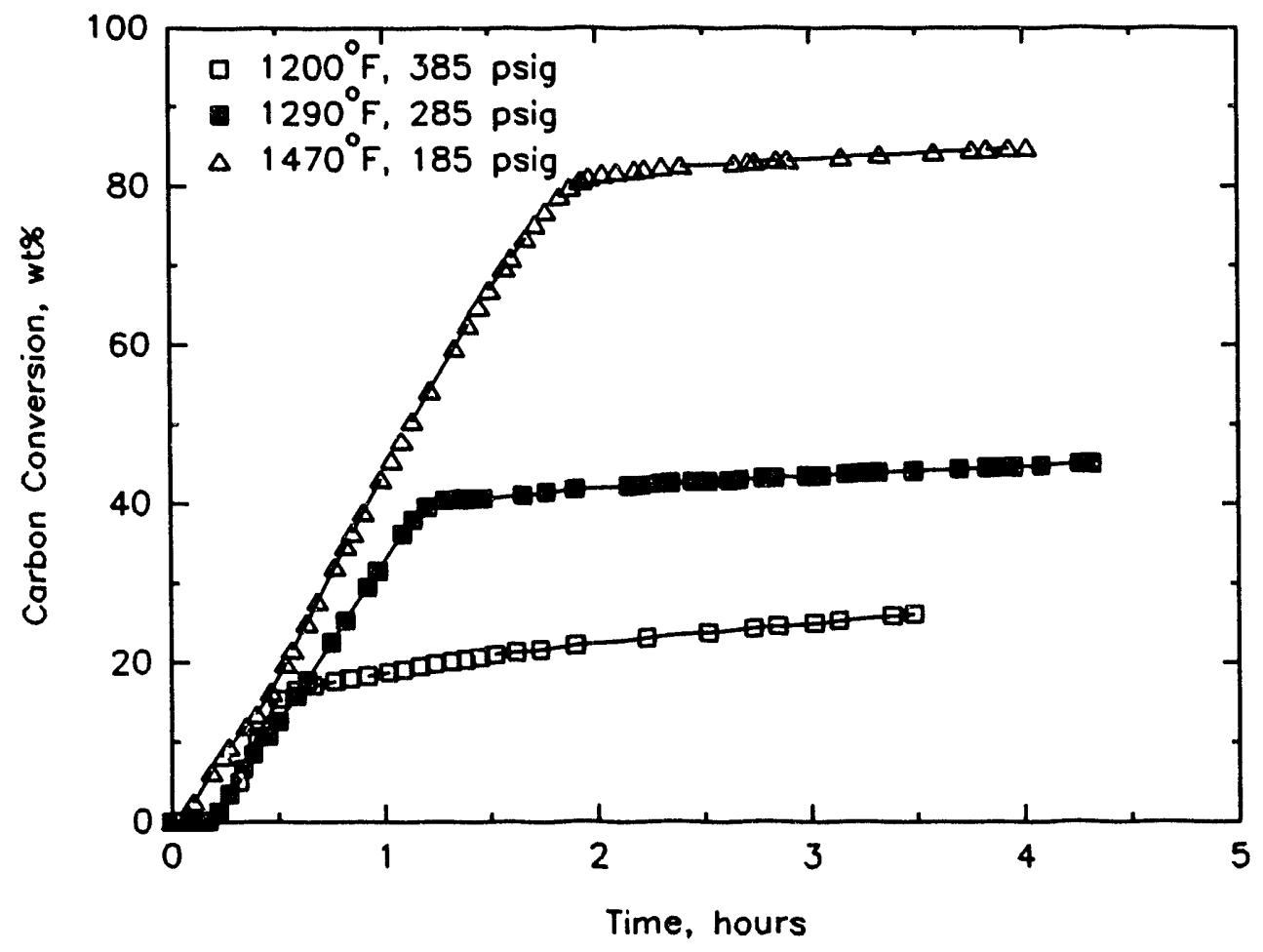

Figure 5. Conversion versus time plots for bench-scale methanation of mild gasification char.

During bench-scale testing, reaction conditions were optimized at 1,500 to $1,800^{\circ} \mathrm{F}$ and 50 to 150 psia. $^{12}$ At these conditions, particularly in the presence of carbon seed particles to act as nucleation sites for the formation of new carbon, reaction rates are reasonably fast and materials of construction and fabrication techniques for the reactor are available. These conditions do, however, raise the equilibrium methane content in the residual gas to about 20 to 30 volume percent. From the standpoint of integrating these two reactors into a single process, it is desirable to operate them at similar pressures and temperatures in order to achieve a high thermal and mechanical energy efficiency. Chemical conversion efficiency on a single-pass basis will, however, be low, resulting in recycle of excessive hydrogen. To correct this problem, a gas separation membrane was included in the flowsheet. ${ }^{14}$

\section{PRU Process Flow Diagram}

A conceptual flowsheet for the char-to-carbon PRU is shown in Figure 6. The feed char to the PRU was produced in the mild gasification PRU operated by 
Western Research Institute (WRI) at Laramie, Wyoming. Feed coal to the mild gasification PRU was Powder River Basin coal from AMAX's Eagle Butte Mine near Gillette, Wyoming. Table 1 lists analytical data for the starting coal and a typical mild gasification char. A particle size distribution for this char is shown in Table 2.

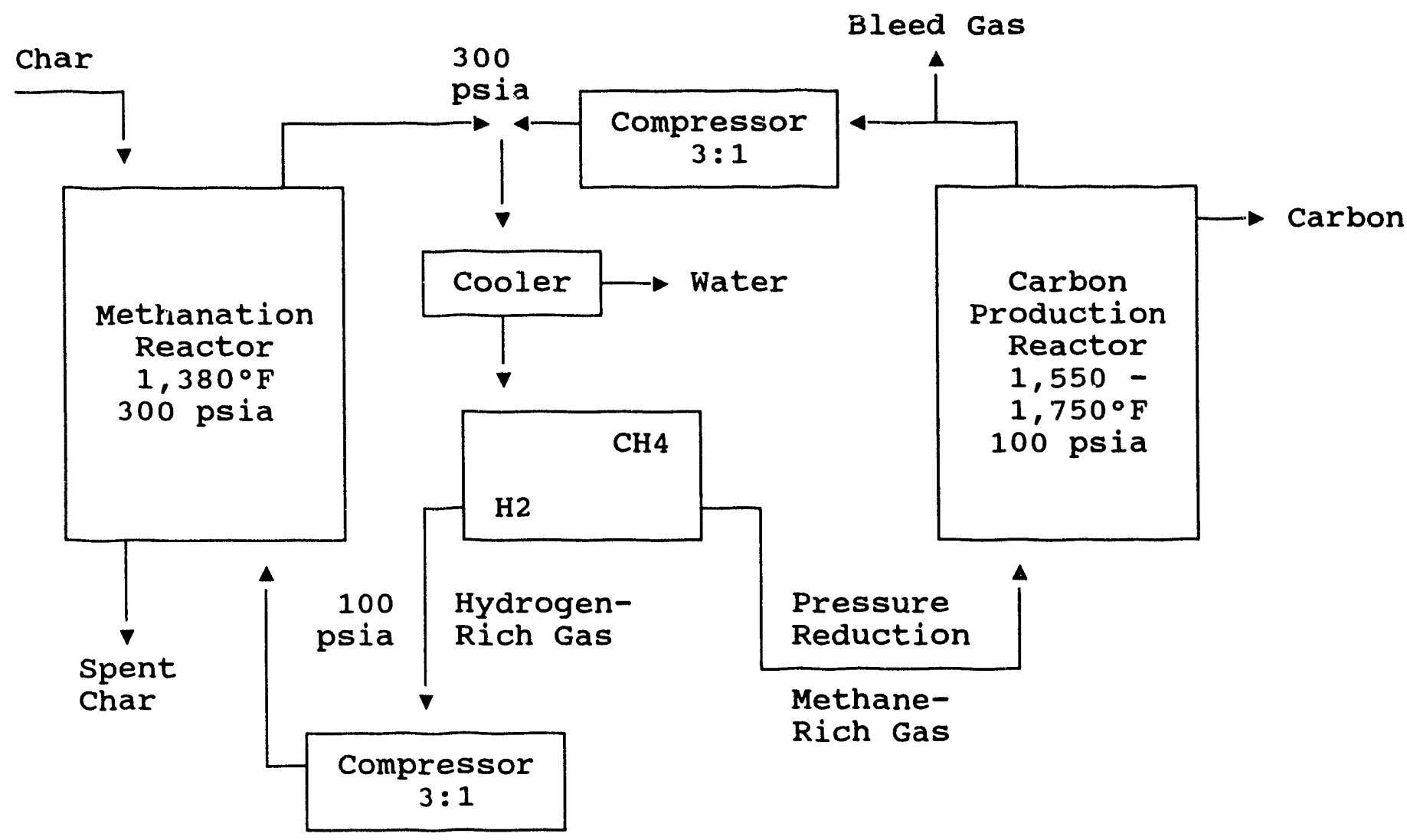

Figure 6. Conceptual flowsheet for char-to-carbon process with gas separation and high pressure carbon formation.

In the first step, char is converted to methane by reaction with hydrogen at 300 psia and $1,380^{\circ} \mathrm{F}$. The reactor pressure was selected as a practical upper limit based on pressure vessel and compression costs. The product gas contains 30 to 40 percent methane. This concentration is fixed by reaction equilibria at the conditions selected for the methanation reactor. Because the char contains hydrogen which is gasified, the process is a net producer of hydrogen. Gas is bled from the hydrogen recycle loop to maintain a constant volume, remove product hydrogen, and control the concentration of impurities. 
Table 1. Analytical Results for Eagle

Butte Coal and Mild Gasification Char

\begin{tabular}{|c|c|c|}
\hline & $\begin{array}{c}\text { Eagle } \\
\text { Butte Coal }\end{array}$ & $\begin{array}{c}\text { MG-122 } \\
\text { Char }\end{array}$ \\
\hline \multicolumn{3}{|l|}{ Proximate Analysis, Weight \% } \\
\hline Moisture & 30.0 & 2.7 \\
\hline Volatiles & 30.5 & 18.1 \\
\hline Ash & 4.5 & 9.0 \\
\hline Fixed Carbon & 35.0 & 70.2 \\
\hline \multicolumn{3}{|l|}{ Ultimate Analysis, Weight \% daf } \\
\hline Carbon & 75.7 & 87.6 \\
\hline Hydrogen & 4.4 & 2.9 \\
\hline Nitrogen & 0.9 & 0.8 \\
\hline Sulfur & 0.4 & 0.6 \\
\hline Oxygen & 18.6 & 8.1 \\
\hline Micropore Surface Area, $\mathrm{m}^{2} / \mathrm{g}$ & -- & 361 \\
\hline
\end{tabular}

Table 2. Particle Size Distribution for Mild Gasification Char (MG-122)

U. S. Mesh $\quad \begin{gathered}\text { Cumulative } \\ \text { Percent Passed }\end{gathered}$

$10 \quad 98.0$

$12 \quad 92.3$

$14 \quad 84.5$

$16 \quad 74.2$

$20 \quad 64.7$

$28 \quad 47.5$

$35 \quad 31.8$

$48 \quad 19.8$

$65 \quad 11.2$

$100 \quad 5.8$

$150 \quad 1.6$

Pan -.-

The impurity present in the highest concentration in char is oxygen. In the methanation reactor, most of this oxygen is gasified as water. The water can then 
react with carbon in the high temperature carbon formation reactor to produce carbon monoxide. Because char oxygen content is relatively high (around 8 weight percent), the carbon monoxide level in the loop will also be high (up to 30 volume percent) unless oxygen is actively rejected. This is accomplished by cooling the gas to condense water.

The gas then passes through a gas separation membrane where relatively pure hydrogen (95 to 99 percent) permeates the membrane at about 100 psia. This hydrogen is then compressed in a single-stage compressor and recycled to the methanation reactor. The methane (55 to 65 percent purity) is rejected from the membrane, along with most of the impurities, at 290 psia and reduced in pressure before being fed to the carbon formation reactor at 100 psia.

In the carbon formation reactor, the methane decomposes to carbon and hydrogen at $1,650^{\circ} \mathrm{F}$ and 100 psia. Bench-scale data suggested that the reaction can be conducted under conditions of fine particle nucleation or by the growth of carbon seed particles in a fluidized bed. ${ }^{12}$ Heat for this reaction is supplied through internal electric heating elements at the PRU scale. At larger scale, heat pipes might be used instead of the electric heating elements.

The gas exiting the reactor may contain as much as 20 to 30 percent unconverted methane. This composition is determined by reaction equilibria at the conditions required for an indirectly heated reactor. This gas is compressed in another single-stage compressor, mixed with the methanation reactor product gas, and fed to the membrane.

\section{PROCESS RESEARCH UNIT}

To verify the process concept described above and obtain data for scale-up, Amax R\&D designed, built, and operated a 50 pound/hour CTC PRU. The CTC PRU was designed to achieve specific goals related to process development. These goals were to:

- Validate process design, rnodels, and control strategy.

- Develop start-up, shut down, and operational procedures.

- Optimize process conditions.

- Produce product for market evaluation.

- Obtain data for scale-up to a 1 ton/hour process development unit (PDU).

In this section, a detailed description of the PRU is presented, including details on each of the major unit operations.

The detailed design of the PRU was performed by BEI Engineers of Lakewood, Colorado. The process flowsheet is shown in Figure 7, which also lists the design flow rates and composition for various streams in the plant. In addition to those systems shown in Figure 7, a hydrogen supply system consisting of a 
Figure 7. Detailed PRU flowsheet. 


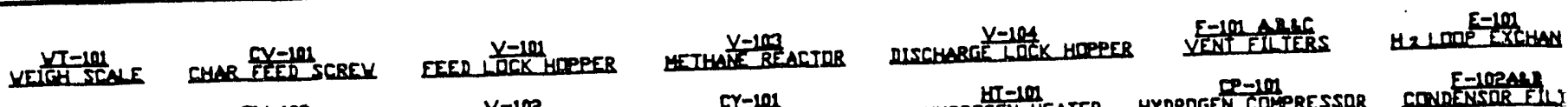

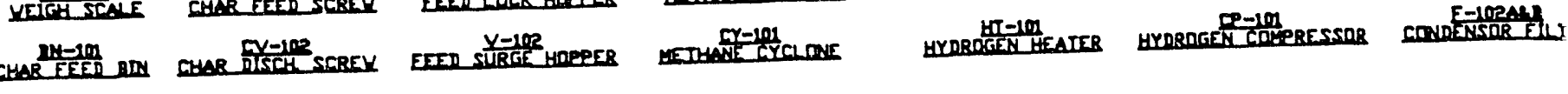

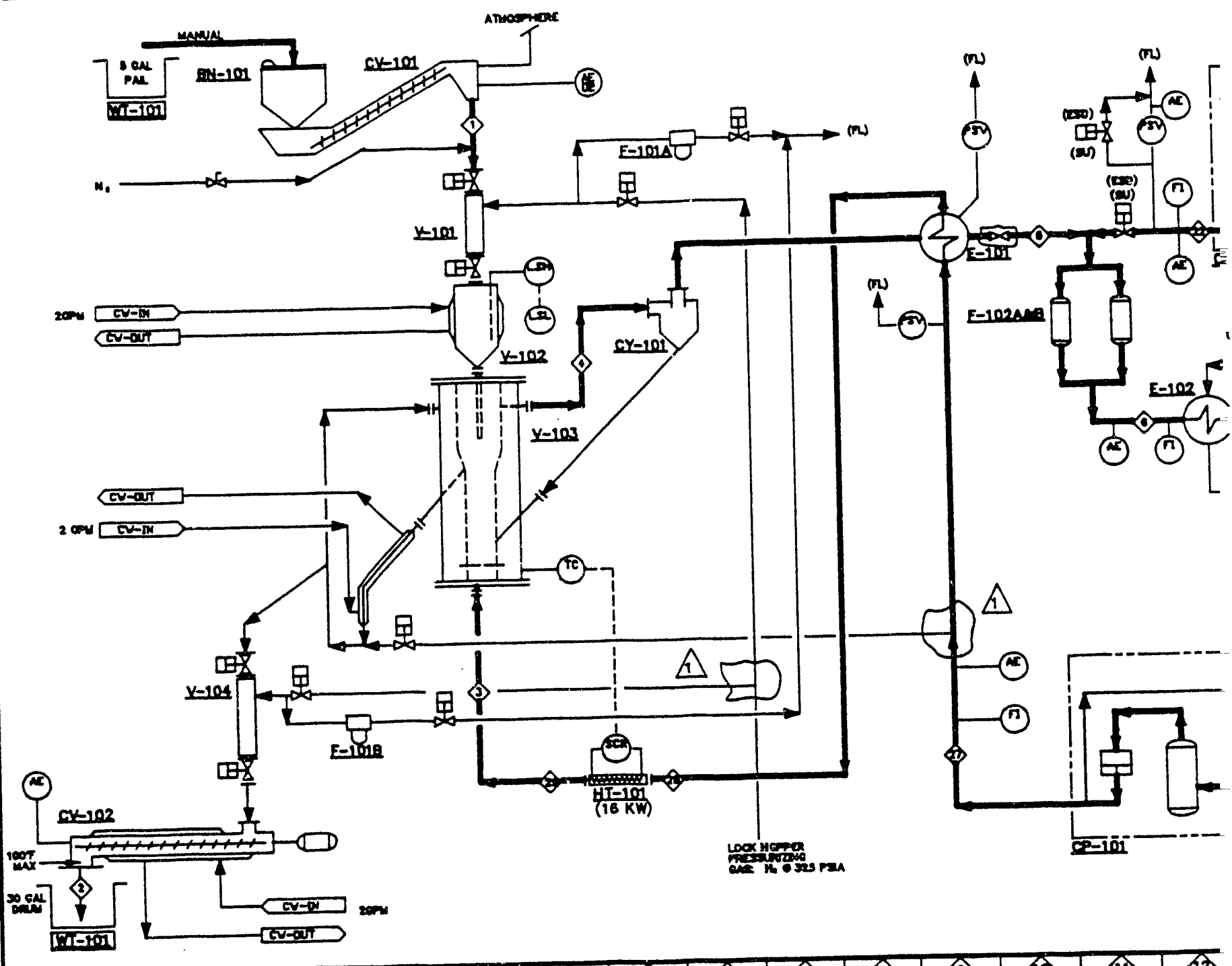

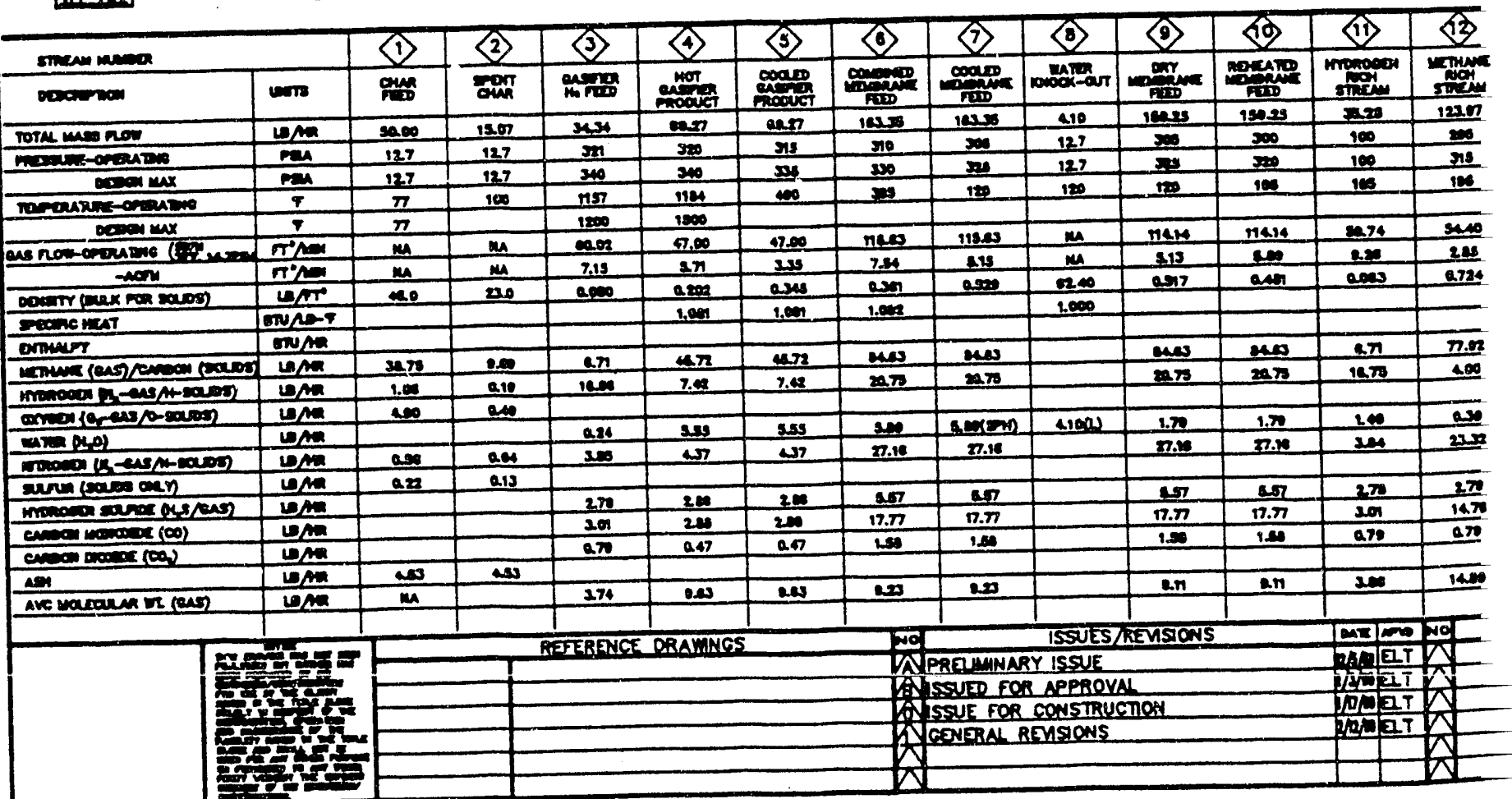




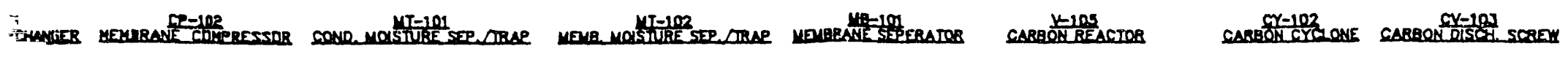

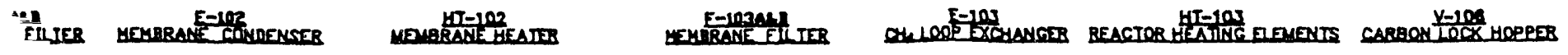
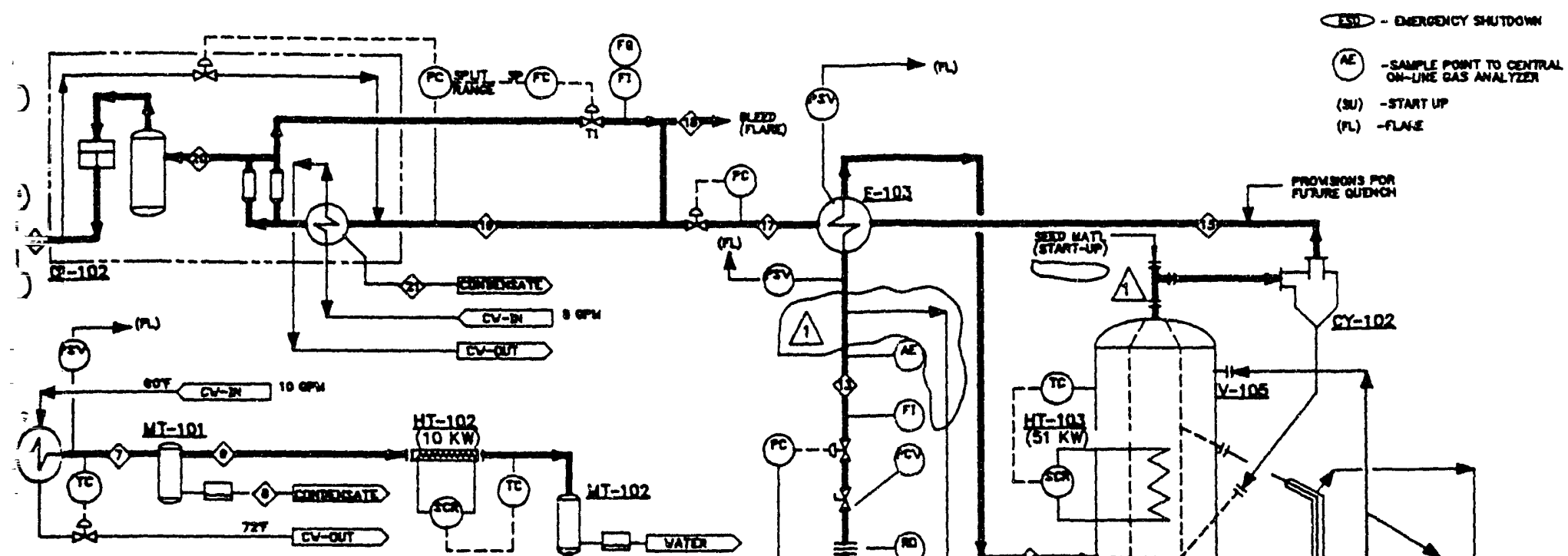

15-103
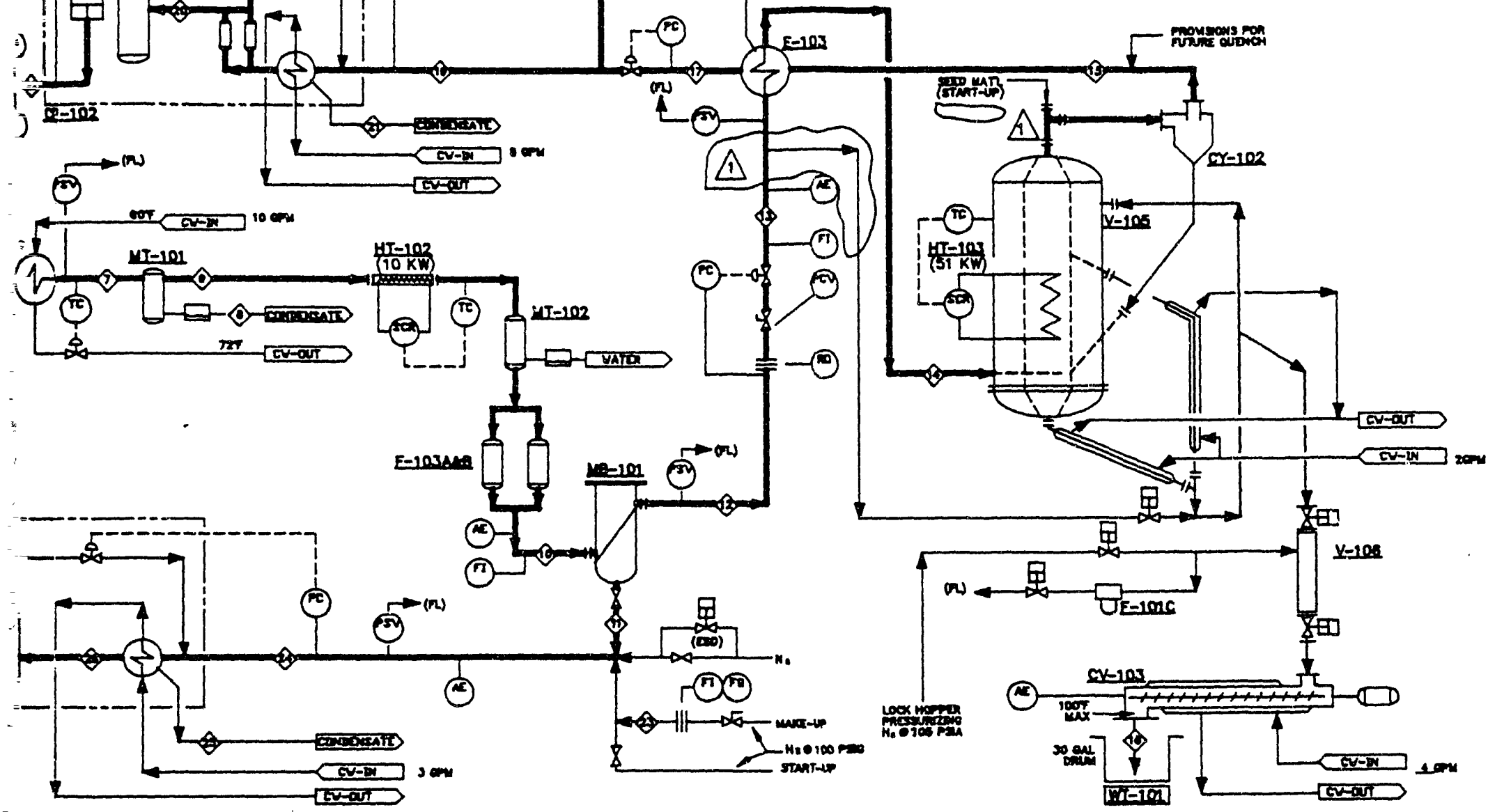

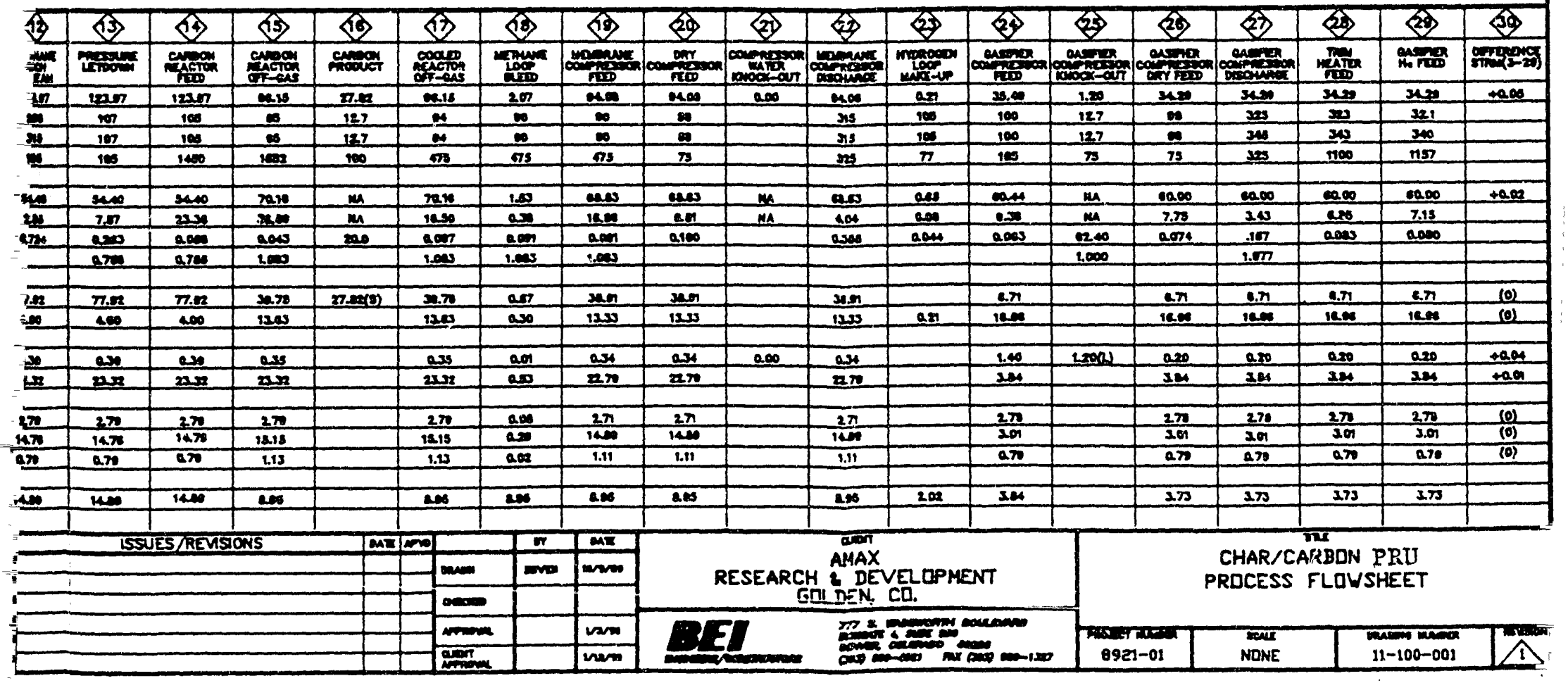


hydrogen tube trailer and associated gas regulators and piping was installed outside the battery limits of the plant. Also, a nitrogen purge system consisting of a liquid nitrogen tank and associated regulators and piping was installed. Flammable gases could be vented to a flare system set up outside the plant battery limits. A photograph of the PRU area is shown in Figure 8 to provide an indication of the scale of the undertaking.

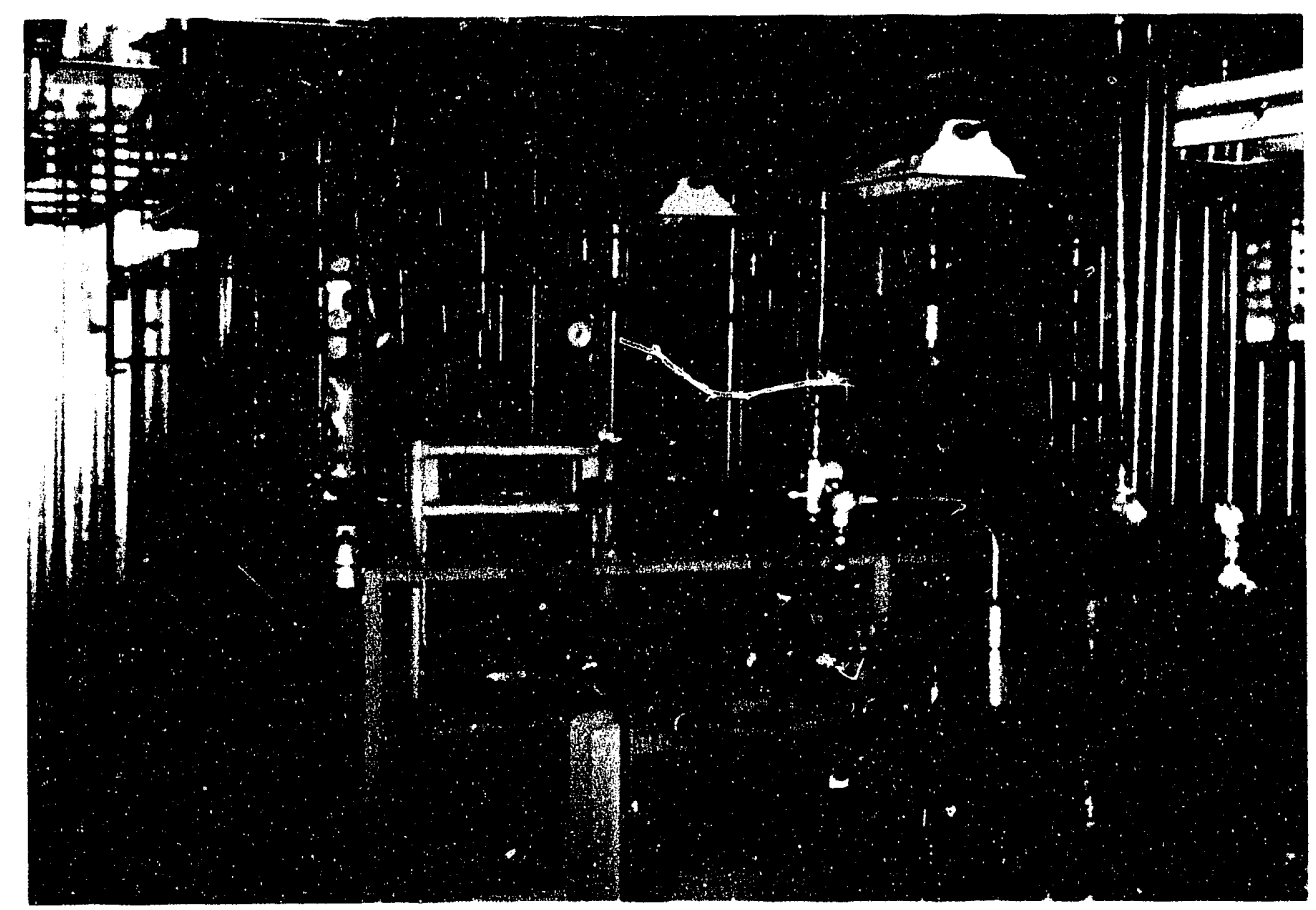

Figure 8. Photograph of PRU area.

Referring to Figure 7, mild gasification char is manually weighed and dumped into a feed bin (BN-101). From here char is conveyed by a screw feeder to the feed lock hopper and batch fed into the methanation unit at a nominal feed rate of 50 pounds/hour. Spent char exits the reactor through a discharge leg, J-valve, and lock hopper system (V-104) and is conveyed in a water cooled screw to a nitrogen purged drum. Gas exiting the reactor passes through a cyclone and then a shelland-tube heat exchanger where feed gas is preheated by cooling the exit gas.

The cooled methane reactor exit gas is then mixed with the carbon reactor exit gas and passed through a set of filters to remove any solids not collected in the cyclones. The gas is then further cooled to condense water (E-102) which is removed in a separator. The gas is then heated to well above the dew point, passes through a final set of filters, and fed to the gas separation membrane (MB- 
101). The gas separation membrane produces a hydrogen-rich stream at about 90 psig and a methane-rich stream at about 290 psig.

The hydrogen-rich gas stream from gas separation is compressed to above $300 \mathrm{psig}$ in CP-101. This compressed gas is then preheated by heat exchange with the methanation product gas and then heated further in an electric circulation heater (HT-101) before being fed to the methanation reactor.

The methane-rich gas stream is reduced in pressure to about $100 \mathrm{psig}$ and then passed through a shell-and-tube heat exchanger where it is preheated by the carbon reactor product gas. The preheated gas then enters the carbon reactor through sparge tubes. In the carbon reactor, methane is cracked to form carbon and hydrogen. The coarse carbon product is discharged from the bottom of the reactor into a J-valve and lock hopper system (V-108). Medium sized carbon particles can be removed as a bed overflow to the J-valve and lock hopper system. Gas exiting the reactor passes through a cyclone where fines are collected and returned to the bed. The hot exit gas then preheats the feed gas and is fed to a compressor, CP-102. Here the gas is compressed to above 300 psig and then mixed with the methanation reactor product gas. Before compression, excess gas is bled out of the system.

\section{Methanation Reactor}

The design char feed rate into the methanation reactor is 40 to 60 pounds/hour. Methanation is performed in a fluid bed designed to operate at 1,200 to $1,550^{\circ} \mathrm{F}, 200$ to $400 \mathrm{psia}$, and 30 to 90 minutes residence time for the solids. A drawing of the methanation reactor is shown in Figure 9, and a photograph is shown in Figure 10. It consists of a lower, 5-inch diameter zone which operates as a slugging bed and an expanded top zone of 10 -inch diameter which is not fluidized and acts as a moving bed. The purpose of this arrangement was to minimize entrainment and freeboard requirement. The bed discharges out the side of the 5-inch zone to a J'valve and lock hopper system. The design was later modified so that the discharge pipe was a bed overflow and served to control bed level at the top of the 5-inch zone. This resulted in reduced capacity but led to major improvements in operability. Figure 9 also shows the location of thermocouples in the bed.

The incoming fluidizing gas is about 95 to 99 percent $\mathrm{H}_{2}$, with the balance being $\mathrm{CH}_{4}, \mathrm{~N}_{2}, \mathrm{CO}$, and other impurities. The inlet gas flow rate is measured with a turbine flowmeter. The unit is designed to produce gas consisting of 30 to 40 percent $\mathrm{CH}_{4}, 60$ to 50 percent $\mathrm{H}_{2}$, and 5 to 10 percent other gas species as impurities after passing through a high pressure cyclone to return entrained solids to the reactor bed. The reactor is designed as an equilibrium reactor so that thermodynamics dictate the $\mathrm{CH}_{4}$-to- $\mathrm{H}_{2}$ ratio in the product gas, depending on reactor temperature and pressure conditions. A lower temperature in the reactor 


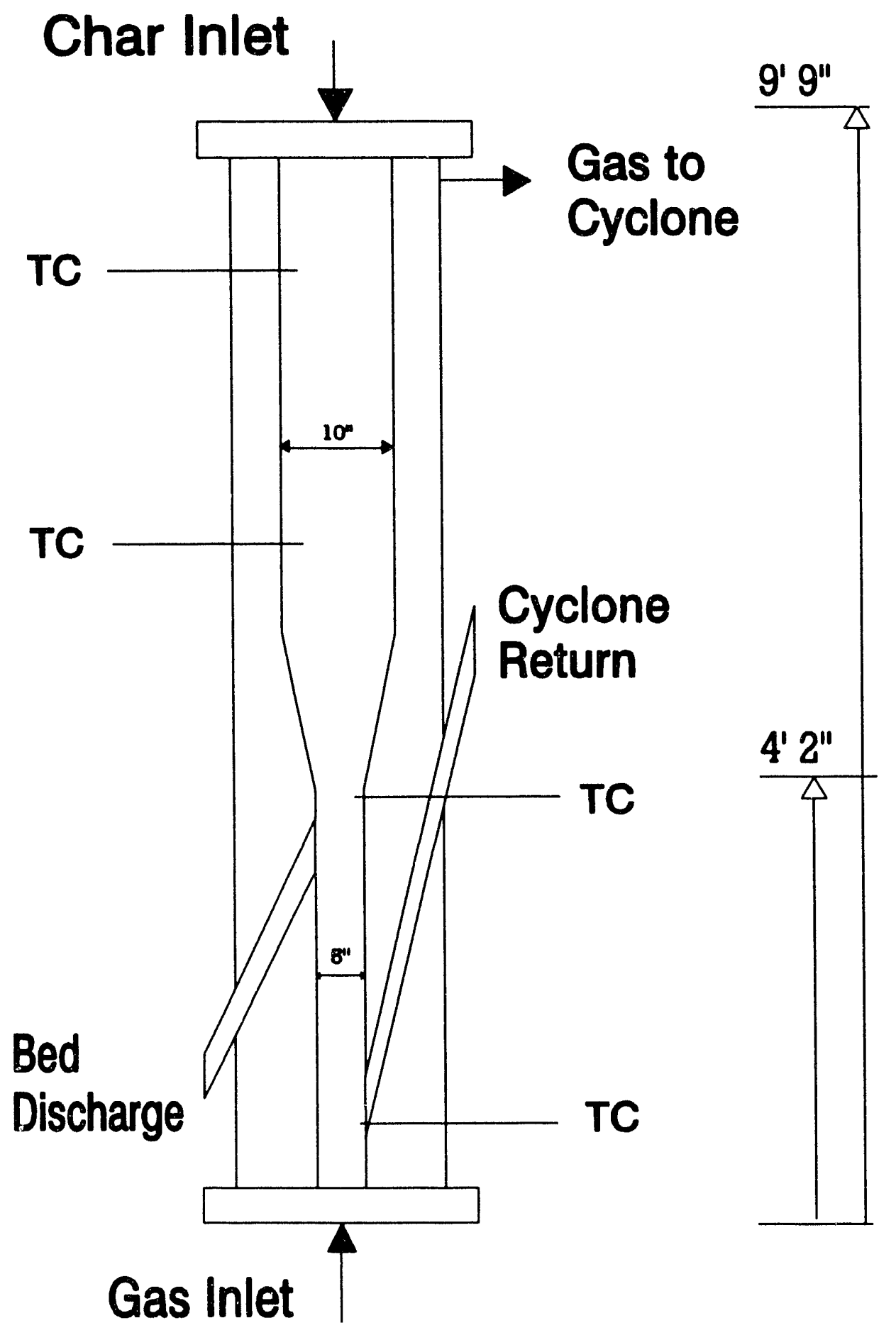

Figure 9. Scale drawing of methanation reactor vessel. 
would favor higher $\mathrm{CH}_{4}$ concentration, but at the expense of a slower reaction rate, leading to reduced $\mathrm{CH}_{4}$ yield.

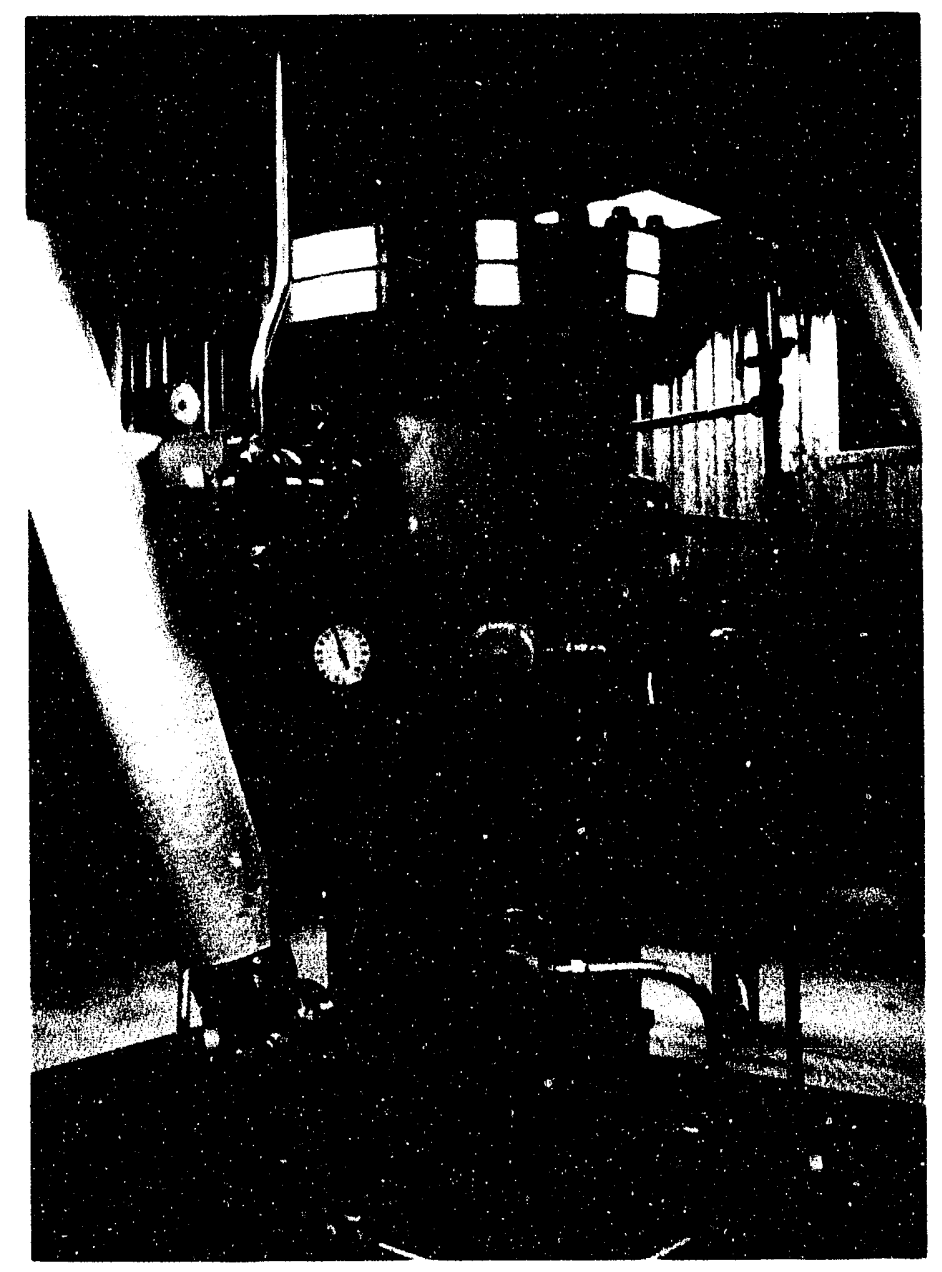

Figure 10. Photograph of methanation reactor.

Char is fed through a double valve lock hopper system, cycling at about a 5minute frequency in the original design. This system was substantially modified to improve operability, and the modifications are described in the results section. Spent char was to be removed from the reactor on a variable time frequency such that level control was maintained in the fluid bed. This did not prove to be practical, and the discharge system was modified to control bed level by bed overflow as described in the results section. A lock hopper system similar to the feed system is used to remove the spent char from the reactor. This system was also substantially modified during the PRU studies. After exiting the lock hopper system, the spent char is cooled in a water jacketed screw and transportea to ? sealed bin under a blanket of $\mathrm{N}_{2}$. 
As designed, fluidizing gas enters the reactor at a temperature about $300^{\circ} \mathrm{F}$ lower than reactor operating conditions. The amount of sensible heat required to heat the fluidizing gas to reactor conditions, plus the amount required to heat up the feed char, was expected to balance with the heat released in the exothermic reaction. In ractice, heat losses were much higher than design, and oxygen had to be injected to heat the reactor by burning a small fraction of the char or hydrogen. This modification was developed during the PRU runs and is described in the results section. The fluid-bed reactor was assumed to be well mixed and operated at nearly isothermal conditions when fluidized.

\section{Carbon Formation Reactor}

The approach outlined earlier for carbon formation was implemented in the PRU in a fluid-bed reactor where the fluidized particles could function as seed carbon and as a heat transfer medium. The fluid-bed was designed for flexibility in the particle size range and distribution of the carbon product. A drawing of the design for this reactor is shown in Figure 11 and a photograph is shown in Figure 12.

Gas enters the bed through sparge tubes and inlet flow is monitored with a turbine flowmeter. Immersed in the bed are twelve horizontal muffle tubes containing SiC glow bars. These electric heating elements supplied the endothermic heat of reaction and sensible heat requirements through roughly $14 \mathrm{ft}^{2}$ of heat transfer surface area. Heat transfer coefficients were not high enough with this arrangement, however, and the unit was later modified to have vertical, finned tubes enclosing the glow bars yielding $64 \mathrm{ft}^{2}$ of heat transfer surface area, inclucling the fins. The unit was also modified to have a gas distribution plate to improve the quality of fluidization. In both designs, the glow bars and their electrical connections are enclosed in an air tight, nitrogen purged box which was constantly monitored for any leakage of process gases.

Originally, carbon was to be removed via bed overflow through a lock hopper system, cooled in a water jacketed screw, and packed in drums. Also, by operating the reactor at higher gas velocities, finer carbon particles could be removed with a cyclone and lock hopper system. A third alternative was to remove only the largest particles of carbon from the bottom of the bed by using a bottom discharge and letting coarse carbon pass downward below the fluidizing zone. This was accomplished by using sparge pipes for gas distribution rather than a distribution plate. The open spaces between the sparge pipes allowed those particles large enough to defluidized to settle in the reactor and pass out. By using these three discharge methods, either separately or in combination, the product size distribution was expected to range from sub-micron to about 250 microns. In practice, only fine carbon could be removed from the reactor, and this was collected in a baghouse which was added to the PRU flowsheet after the initial shake-down runs. 


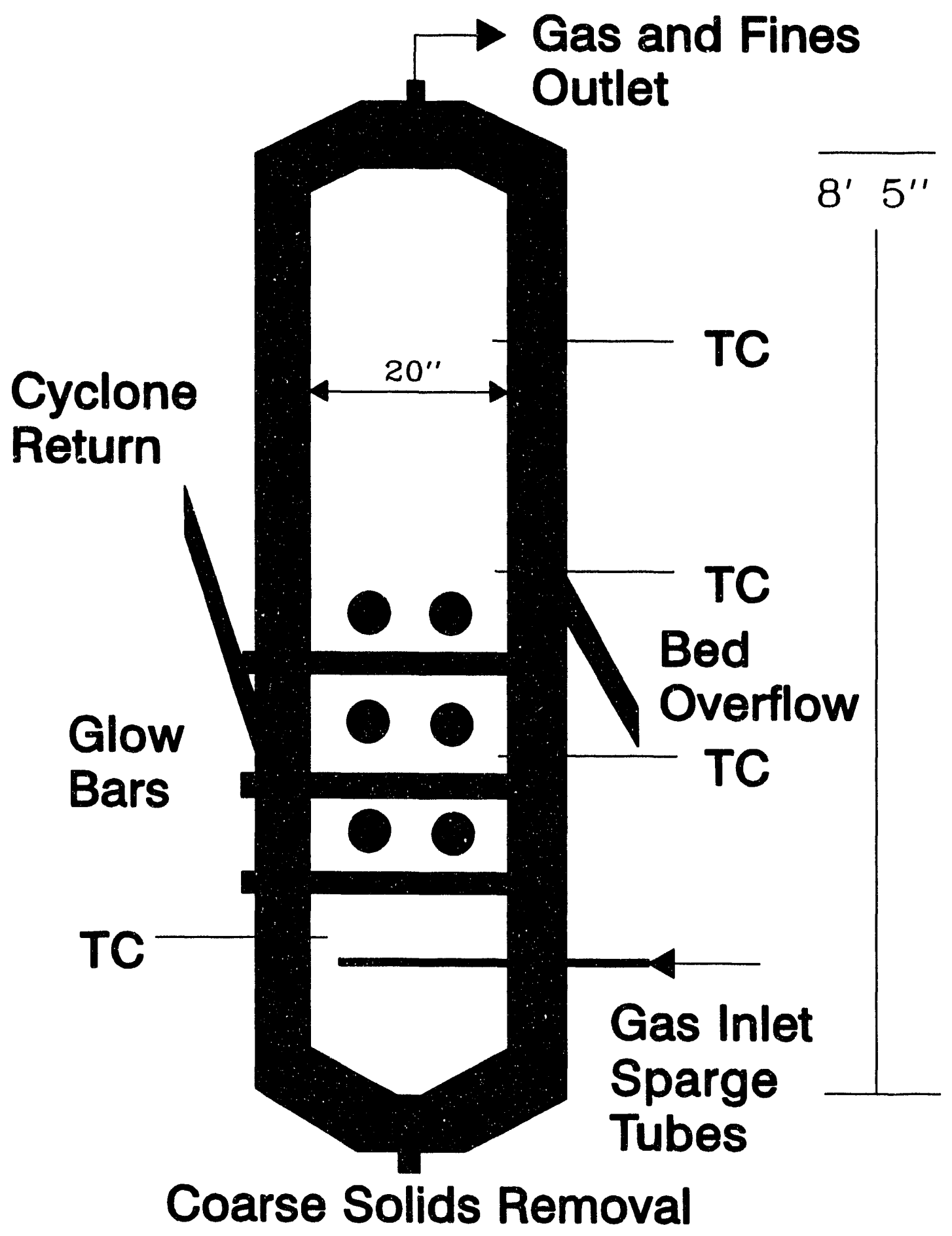

Figure 11. Scale drawing of carbon formation reactor. 


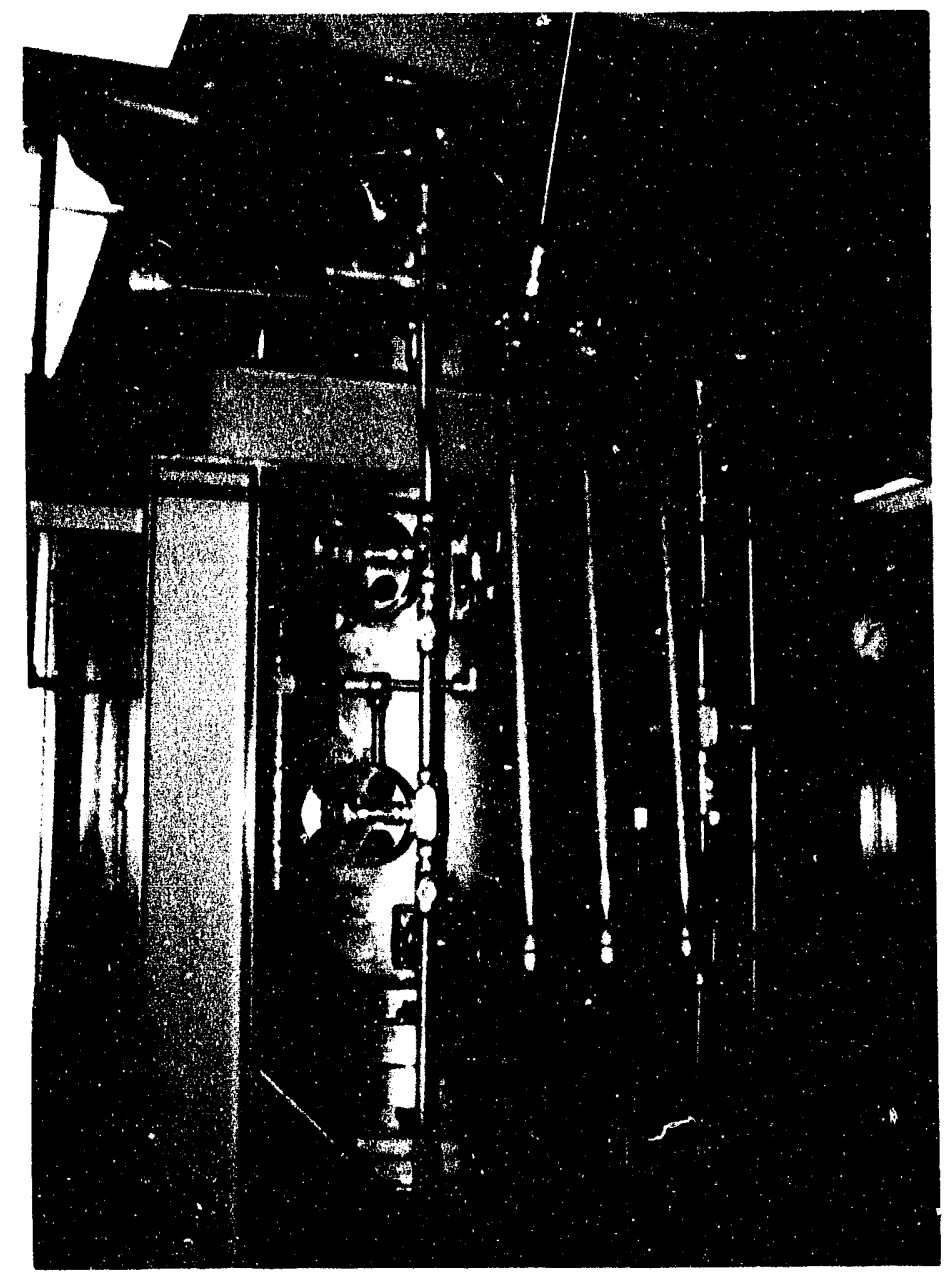

Figure 12. Photograph of carbon reactor.

\section{Gas Separation Membrane}

Gases exiting from both reaction steps are combined into a common mixed $\mathrm{H}_{2} / \mathrm{CH}_{4}$ gas stream and fed to a gas separation membrane to separate the mixed gas into hydrogen-rich and methane-rich streams. Design gas composition for the membrane feed gas ranged from 55 to 65 percent $\mathrm{H}_{2}$ and 35 to 25 percent $\mathrm{CH}_{4}$, with the balance being impurities. When the membrane is operated at an inlet pressure of 300 psia, the hydrogen-rich stream should range from 90 to 95 percent $\mathrm{H}_{2}$, while the methane-rich stream should range from 60 to 65 percent $\mathrm{CH}_{4}$. Most of the impurities should concentrate in the methane-rich stream. The hydrogen-rich stream discharges at 80 to $100 \mathrm{psia}$, while the methane-rich stream discharges at 290 psia. The most important variable in terms of membrane performance is the difference in $\mathrm{H}_{2}$ partial pressure between the feed stream and hydrogen-rich discharge stream. Increasing the pressure drop improves separation efficiency, as does increasing the $\mathrm{H}_{2}$ content of the feed stream. 
The membrane material is degraded by liquid water, so gases must always be above the dew point. A condensing cooler is used to lower the mixed gas temperature down to $100^{\circ} \mathrm{F}$ which, at 300 psia, results in efficient condensation of water. If oxygen is not removed as water, it will convert to $\mathrm{CO}$ in the carbon formation reactor and be bled out with excess hydrogen. Conversion of oxygen to CO ultimately results in a greater loss of carbon from the process than would otherwise occur and higher impurity concentrations in the recirculating gas.

Therefore, water removal before membrane separation results in significant benefits to the process in terms of carbon yield, removal of impurities from the recirculating gas, and volume of gas which must be recirculated.

After condensation of water, the gas in then reheated to $190^{\circ} \mathrm{F}$ and filtered before being sent to the membrane. The membrane system performed as designed and no changes had to be made.

\section{Process Gas Analysis}

Gas streams from throughout the process were sampled and analyzed using a Questor high speed prucess analyzer manufactured by Extrel Corporation. The location of analysis ports is shown in the simplified flow diagram of Figure 13. The Questor process analyzer utilizes a quadrupole mass spectrometer, 16 port sampling valve, and control computer system to moi: ${ }^{2} \mathrm{r}$ process gas streams for several different components. The components monitored were:

- $\mathrm{CH}_{4}$
- $\mathrm{H}_{2}$
- $\mathrm{CO}_{2}$
- $\mathrm{N}_{2}$
- $\mathrm{O}_{2}$
$\mathrm{H}_{2} \mathrm{~S}$

Qualitative scans of the entire 200 mass unit range of the instrument were made periodically to alert us to the presence of any other gases which might form in the process.

Gases were sampled through $1 / 16$-inch diameter lines attached to the process line using a 50-micron filter and a fine metering valve. For sampling of gases at near atmospheric pressure (vent system and nitrogen purged screws and enclosures), explosion proof vacuum pumps were employed to pump the gas to the instrument. Gas flow rates in the sample lines were adjusted to allow response times of a few minutes.

The Questor sampling system utilizes a very small diameter capillary through which gas is bled into the mass spectrometer's vacuum chamber. This capillary 
can potentially plug with fine char, carbon particles, or volatile matter. To minimize problems with inlet plugging, the system was modified to include a second filter just before the inlet and a heater to prevent condensation of volatiles. Even with these modifications, inlet plugging was an occasional problem.

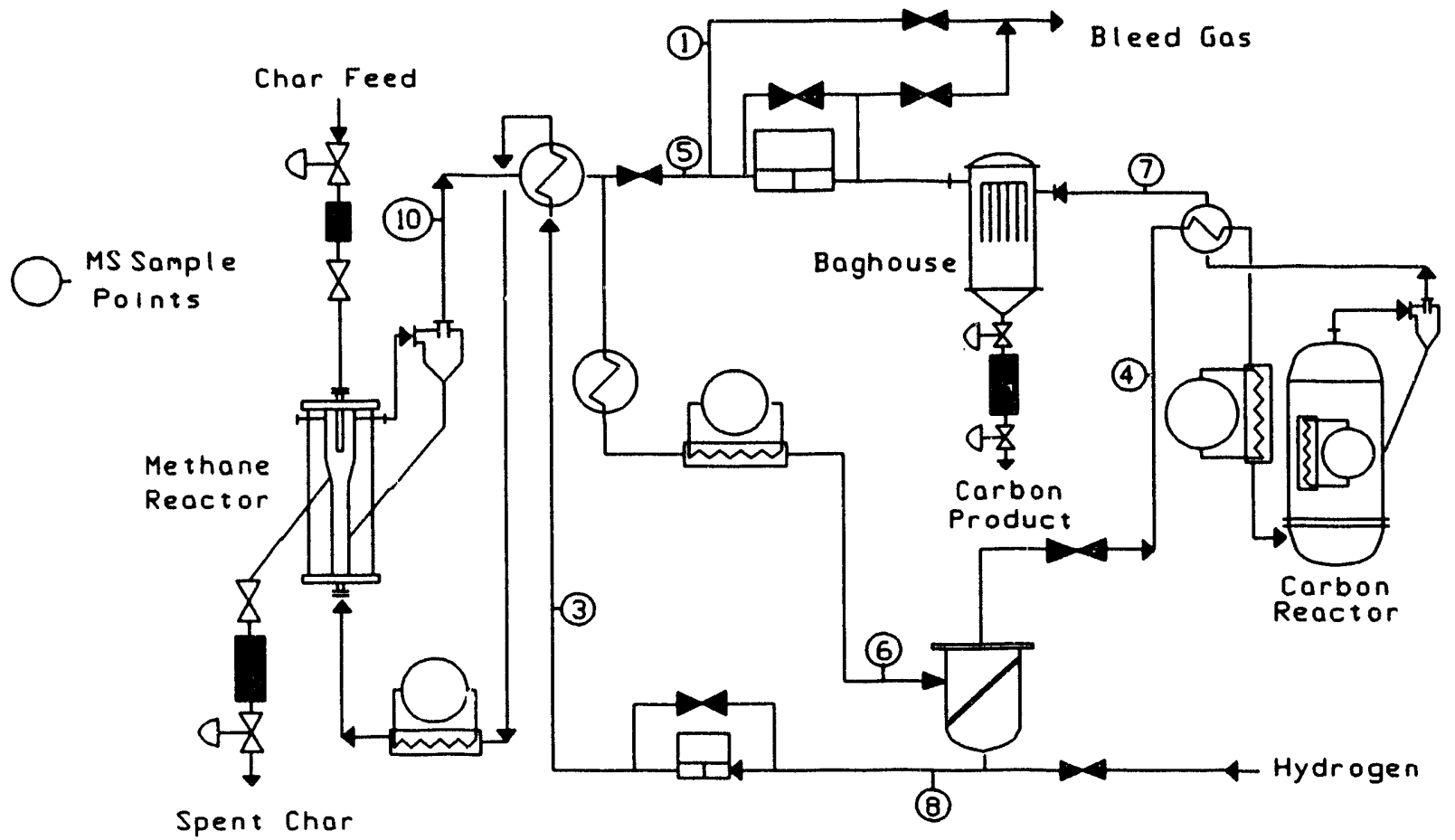

Figure 13. Simplified process flow diagram showing location of analysis ports.

\section{Computer Control and Data Acquisition}

PRU process control was accomplished using a dedicated computer control system. Basic system components were an NEC personal computer and monitor, Analog Devices computer interface hardware, Analog Devices digital and analog interface modules, and Genesis Control Series ${ }^{\mathrm{TM}}$ process control software. A second control computer was connected via local area network to facilitate user monitoring of the PRU operation. In addition, serial connection was made to the mass spectrometer to facilitate integration of analytical data into the control system. A battery driven uninterruptible power supply provided backup power for up to 45 minutes in the event of a power failure.

A total of 108 analog and 77 digital process control signals comprised the system. Of the analog signals, 94 were inputs (temperatures, pressures, gas flow 
rates, mass spectrometer data, and combustible gas detector data) and 14 were outputs (heater controllers and valve positioners). Of the digital signals, 46 were inputs (limit and flow switches) and 31 were outputs (on/off and open/close signals).

Primary PID control was accomplished through system software and included the following major control loops:

- Methane Compressor

- Hydrogen Compressor

- Methane Reactor Pressure

- Carbon Reactor Pressure

- Methane Reactor Heater

- Carbon Reactor Heater

- Membrane Condenser

- Membrane Heater

- Hydrogen Make-Up Gas Flow

- Process Gas Bleed Flow

- Emergency Shut Down

In addition, all process data logging was accomplished by process control software. All control algorithms, user interface screens, and data logging and reporting methods were developed at Amax R\&D and implemented through the process control system.

\section{Safety}

The CTC process utilizes highly flammable gases at high pressure and temperature, and therefore, safety has been a primary concern during PRU operation. The PRU design and start-up procedures were developed to insure that explosive gas mixtures did not form at any time in the process vessels or in the plant area. All electrical connections and devices in the plant, including lighting, were explosion proof. The computer control system was programmed to automatically shut down the system if an unsafe condition was detected.

Start-up procedures, described in the next chapter, required purging of the unit with nitrogen before introduction of hydrogen. All gases bled from the process during operation were vented to a flare. Also, combustible gas monitors continuously analyzed air in the PRU area. If high levels of a combustible gas developed, these monitors would alarm. If no action was taken to reduce combustible gas levels or if the level increased at too high a rate, the gas monitors triggered an automatic emergency shutdown.

High temperature piping and vessels were insulated to insure personnel protection. All mechanical equipment was equipped with appropriate guards to protect operating personnel. Furthermore, plant operating personnel underwent 
training to insure that work in the PRU area would always be conducted in a safe manner.

\section{Materials of Construction}

A list of materials used in PRU piping and vessel construction is shown in Table 3, along with the service for which each material was selected. The $250 \mathrm{X}$ specification piping (Incoloy $800 \mathrm{HT}$ ) was used for the carbon reactor glow bar muffles and certain high temperature nozzles.

\section{Table 3. Materials of Construction Used in the PRU}

Piping

Specification

$15 A$

$15 B$

$30 \mathrm{~A}$

$30 \mathrm{~B}$

$60 \mathrm{X}$

$250 S$

$250 X$
Material

Carbon Steel 150 ib Flange, Schedule 40

Carbon Steel 150 lb Flange, Schedule 40

Carbon Steel $300 \mathrm{lb}$ Flange, Schedule 40

Carbon Steel $300 \mathrm{lb}$ Flange, Schedule 40

316L Stainless $600 \mathrm{lb}$ Flange Schedule 80

$316 \mathrm{H}$ Stainless 2,500 lb

Flange, Schedule 160

Incoloy $800 \mathrm{HT} 2,500 \mathrm{lb}$ Flange, Schedule 160

\section{$\underline{\text { Service }}$}

Hydrocarbon Process and Utility, Screwed and Butt Weld Connections

Hydrocarbon Process and Utility, Socket Weld Connections

Hydrocarbon Process and Utility, Screwed and Butt Weld Connections

Hydrocarbon Process and Utility, Socket Weld Connections

General Process, Corrosive Service, Temperatures Less Than $1,000^{\circ} \mathrm{F}$

General Process, Corrosive Service, Temperatures Between 1,000 and $1,400^{\circ} \mathrm{F}$

General Process, Corrosive Service, High Temperatures Less Than $2,000^{\circ} \mathrm{F}$ 


\section{PROCESS RESEARCH UNIT OPERATING PROCEDURES}

Operating procedures involved preparing the unit to run, starting the unit, and operating to c'stain the desired test conditions and data. Ideally, the unit would then be shut down in a controlled manner. In some cases, runs were terminated by equipment failure or an emergency condition rather than by controlled shutdown. To insure consistent adherence to a standard set of procedures, operating check lists were developed and followed during start-up, operation, and shutdown. These detailed check lists are presented in Appendix A.

A list if maintenance items was performed on the day before a scheduled start-up. Our experience has shown that completion of these maintenance items increases the probability of obtaining a trouble free run. After completion of the pre-run mai tenance, a number of checks were made immediately before start-up.

After completion of all pre-run maintenance and pre-start-up activities, the PRU was ready to be started. Development of start-up procedures was one important objective of this development progiem, and by the end of the program, smooth start-ups were routinely obtained. Start-up procedures varied slightly, depending upon whether the entire integrated system was being operated or if only one of the reactors was being operated. A general start-up procedure for the integrated sysiem is described in detail in Appendix A and in general terms here.

The PRU was completely computer controlled, as described in the preceding chapter. The control computer also logged data. The first step in start-up was to start the computer. Next, the system was purged with nitrogen to remove air, and heating of the unit was initiated by starting the electric circulation heaters and glow bars. After purging oxygen from the system, nitrogen was then purged using hydrogen at moderate pressure. At this point, the system was ready for pressurization with hydrogen.

Steady state operating procedures varied considerably during the course of the development program. As modifications were made to the various unit operations, procedures were also modified to match equipment changes. Details of these operating procedures will be given in the descriptions of the various runs, which may be found in the next chapter. In general, we attempted to find stable operating points at which high quality data could be obtained.

In an emergency, the unit can be shutdown by simply pressing the emergency shutdown button on the 1/O rack or in the PRU area. It is also possible to take a controlled shutdown, which minimizes the maintenance and cleanup that must be performed before another run is attempted. A procedure for this is listed in Appendix $A$. 


\section{PROCESS RESEARCH UNIT OPERATION RESULTS}

During one year of PRU operation (July 19.90 to July 1991), 6 shakedown runs, 11 integrated PRU runs, 10 methanation unit runs, and 8 carbon formation unit runs were completed, for a total of about 800 hours of operation. After each run, modifications were made to equipment or operating procedures to improve the operability and performance of the process. In conjunction with the PRU studies, support studies were carried out in the laboratory. These included cold flow fluidization tests and analysis of samples from the PRU. To put this work in perspective, the PRU runs will first be presented in chronological order. A detailed analysis of selected runs and support studies will then be presented.

\section{CHRONOLOGY OF PRU TESTS AND UNIT MODIFICATIONS}

Each PRU run was given a designation which consisted of a letter followed by a number. The letter refers to the type of run and the number denotes which run of the given series was being conducted. The letter designations refer to four types of runs:

- S-series: Shakedown runs.

- I-series: Integrated runs where both reactors were operated.

- M-series: Runs where only the methanation reactor was operated.

- C-series: Runs where only the carbon reactor was operated.

All initial attempts before September 21, 1990, are designated as shakedown runs. For the next several months, attempts were made to operate the plant in integrated mode. It became apparent that more information could be gained in a more efficient manner by operating the primary unit operations separately, so this approach was pursued during the spring of 1991. After obtaining experience with the individual reactors, the integrated process was again operated in the summer of 1991. What follows is a description of all of the work performed in the PRU during the course of this project.

\section{Run S-1}

Attempt was made to heat the methane reactor. Shutdown was due to fire on the methanation reactor feed gas preheater discharge.

\section{Run S-2}

After several shutdowns, a temperature of $1,590^{\circ} \mathrm{F}$ was achieved in the methane reactor. A fire at the preheater discharge caused run termination. A determination was made that flange bolts at the heater outlet were expanding at the high temperatures encountered in this part of the process. Bolts suitable for higher temperatures were installed to prevent the leakage and fire problem. 


\section{Run S-3}

The methane reactor was heated and char feeding was attempted. Techniques for controlling flows through the membrane during start-up were developed. Lock hopper valves leaked, preventing reliable feeding. The lock hopper valves were inspected, but no problems were found.

\section{Run S-4}

It was determined that heat losses from the methane reactor were much higher than design, so design temperatures were difficult to achieve. To compensate for this, a method of oxygen injection into the reactor was developed. Initial operation with oxygen injection to the methane reactor was attempted in this run, achieving a maximum temperature $1,491^{\circ} \mathrm{F}$. This initiated the methanation reaction and resulted in about 40 percent $\mathrm{CH}_{4}$ in the gas separation membrane feed gas. Some plugging of the char feeding system was observed at the top of the inlet lock hopper valve. Start-up procedures continued to evolve, leading to more rapid, smoother start-up.

\section{Run S-5}

An attempt was made to run the plant in integrated mode using lampblack as seed carbon in the carbon formation reactor fluid bed. This material was too fine and much of it was entrained from the reactor, causing plugging which resulted in run termination.

\section{Run S-6}

In this run, the gas flow rate into the carbon reactor was reduced in an attempt to avoid lampblack entrainment. This was not successful and plugging forced a shutdown. After this run, most unit operations in the system were performing well, and the shakedown phase of the project was considered complete. Fluidization calculations indicated that increased flow rate in the carbon reactor would allow a higher heat transfer coefficient and higher temperatures to be obtained. However, with the lampblack seed material, entrainment would be too high. Therefore, mild gasification char was substituted as the seed material.

\section{Run I-1}

The next phase of the project was to develop detailed start-up and operating procedures. During this run, we developed improved start-up procedures with respect to obtaining stable flows. Improved methods of controlling flows at steady state were also implemented. Mild gasification char was used as the seed carbon in the carbon reactor. Difficulties in operating the spent char discharge J-valve were encountered. Also, some of the turbine flowmeters were not functioning reliably. 
Shutdown was caused by a leak and fire at the methane reactor preheater discharge. The problem was corrected by installing a new gasket at the discharge flange.

\section{Run 1-2}

The goal of this run was to continue development of the start-up procedures. During start-up, the emergency vent solenoid plugged with char or lampblack and finally burned out, forcing shutdown. To prevent further problems, the system was blown out with high pressure air after this run. Also, mild gasification char was removed from the carbon reactor and a new seed carbon material was loaded. The new material was a desulfurized petroleum coke called "Desulco". Desulco is produced from petroleum coke by processing at high temperature in a plasma arc. This high temperature processing removes metals, sulfur, and volatiles, producing a high purity carbon product.

\section{Run 1-3}

The system was successfully started and oxygen injection was successfully tested, providing a temperature of $1,340^{\circ} \mathrm{F}$. Char feeding appeared to be hindered by $a$ plug in the bottom lock hopper valve or char feed pipe. Design membrane performance was achieved and definitive methods for controlling flows through the membrane were developed. A temperature of $1,100^{\circ} \mathrm{F}$ was obtained in the carbon reactor.

\section{Run $1-4$}

The methane compressor (CP-102) was slowed by 10 percent to reduce entrainment from the carbon reactor. A temperature of $1,400^{\circ} \mathrm{F}$ was achieved in the carbon reactor, and a controlled shutdown was taken at the end of the run. The temperature in the carbon reactor decreased for several hours during this run, suggesting that seed material was being entrained out of the unit or that the heat transfer surfaces were becoming fouled. A comparison of compressor performance curves with the flow rates obtained using the turbine meters did not yield good agreement. Turbine meters were recalibrated and cleaned to correct this problem.

\section{Run 1-5}

The methane compressor (CP-102) flow rate was increased which led to attainment of $1,500^{\circ} \mathrm{F}$ in the carkon reactor with glow bars at $1,890^{\circ} \mathrm{F}$. The methanation reactor spent char discharge J-valve was operated manually several times, but the solenoid did not function properly. Some char was entrained through the grid of the methanation reactor during a process upset. This char entered the preheater, HT-101, and caused burnout of several resistance heating elements. 


\section{Run C-1}

Because of the burned-out heating elements on the methanation reactor feed gas preheater, it was decided to run the carbon reactor on bottled methane without heating the methane reactor. The methanation side of the plant was pressurized to a convenient level and hydrogen was circulated through this side of the plant. We heated the carbon reactor to $1,400^{\circ} \mathrm{F}$ with uniform temperature. Above this level, temperatures became non-uniform, with the bottom thermocouple at $1,620^{\circ} \mathrm{F}$ and the others near $1,500^{\circ} \mathrm{F}$. The glow bars were near $2,000^{\circ} \mathrm{F}$. The feed gas flow rate was limited by pressure drop in the carbon reactor sparge tubes and through the carbon reactor back pressure regulator.

Following this run, a variable speed drive was installed on CP-102 to facilitate start-up and flow rate adjustment. Maintenance of PRU systems was also performed.

\section{Run 1-6}

This run was curtailed because of an overload condition on CP-102. After consultation with the manufacturer, it was determined that a service/maintenance call was required. The manufacturer's service personnel installed new suction/discharge valves on $\mathrm{CP}-102$.

While the PRU was down for this maintenance, a full scale cold flow J-valve to model the methanation reactor discharge J-valve was fabricated. This cold flow unit was constructed from plexiglas. Studies in this system involved testing of several design modifications. One of the modifications was successful and appeared to have resolved J-valve operating problems. We also designed, fabricated, and installed a check valve in the methane reactor feed line to prevent entrainment of char into the preheater during process upsets. This was done to prevent recurrence of preheater heating element burnout. Also, bolts were replaced at a number of process flanges to insure safe operation at high temperatures.

\section{Run 1-7}

Prior to this run, a new J-valve based on the cold flow study results was installed. HT-101 was operated at partial capacity, that is with only a few heating elements operational. The methane reactor was heated to design temperature by oxygen injection. Feeding and discharging of char went well until the lock hopper vents plugged, preventing depressuring of the lock hoppers. The carbon reactor glow bars were at $2,000^{\circ} \mathrm{F}$ and 50 percent power before methane production began in the methanation unit. Upon methane production, the glow bars cooled and power was turned up to 100 percent. Apparently some fine product carbon was entrained to the filters. This run was hampered by a high pressure drop on the carbon side, probably in the carbon reactor sparge tubes and back pressure 
regulator. Operation was also hampered by continued poor reliability of flowmeters. This run lasted 36 hours and was the first run of more than 24-hours duration.

\section{Run I-8}

The carbon reactor heat transfer surfaces were inspected before this run, and it was noted that pyrolytic carbon had formed on the glow bar tubes. The run was aborted because the remaining elements in HT-101 burned out and CP-102 was not functioning properly. After this run, new heating elements were installed in HT-101. The poor performance of CP-102 was found to be caused by a plug of fine carbon at the suction valve which was removed.

\section{Run $1-9$}

The methane reactor was operated at design temperature and pressure in this run, but great difficulty was encountered in controlling the bed level. We continued to have problems with CP-102 and with high pressure drsp on the carbon reactor side of the plant.

Following the run, CP-102 was again repaired and filters were installed upstream of this compressor to prevent solids plugging. We also installed filters on the lock hopper vent lines to prevent these from plugging. A DP cell was installed on the methane reactor for bed level control, and the control software was updated for this service. Cold flow studies were conducted to determine an approximate relationship between bed level and pressure drop at various flow rates. This empirical relationship was incorporated into the computer control system for bed level control. Based on the difficulties encountered with entrainment of fine seed carbon particles from the carbon reactor, it was decided to install a baghouse to collect these fines and discharge them through a lock hopper. The baghouse was designed and ordered.

\section{Run $1-10$}

Fluidization calculations indicated that the carbon reactor was just barely fluidized and suggested that higher heat transfer coefficients could be obtained at the same gas flow rates by using smaller seed carbon particles (but still much larger than the original lampblack). We reduced the particle size of the seed carbon (Desulco) by grinding and tested a new start-up strategy to more rapidly heat this reactor. The carbon reactor was heated to $1,464^{\circ} \mathrm{F}$ with an average bed temperature of $1,259^{\circ} \mathrm{F}$. Glow bars were operated at 100 percent power for the entire run and the reactor was still heating. We initiated methane production by oxygen injection. Shutdown occurred because of overheating of the methane reactor wall which was caused by impingement of the oxygen jet/flame on the refractory lining. 
Following this run, it was determined that failure of the oxygen injection lance caused shutdown of the run, and we replaced the lance with an improved design. We also replaced the refractory in the lower part of the methane reactor. Inspection of the cyclone dip legs after completion of the runs had indicated that plugs were forming. In an attempt to prevent this plugging and improve cyclone performance, heaters and vibrators were installed on the cyclone dip legs.

\section{Run $M-1$}

This run was aborted because of a plugged $\mathrm{J}$-valve and a fire at the methane reactor feed pipe caused by the use of the wrong bolts on a flange.

\section{Run M-2}

Operation of the methanation reactor at design conditions for 7 hours was achieved with oxygen injection. Difficulty was experienced in feeding char because of plugging of the feed valve, but char was fed successfully many times. Discharge systems worked fairly well.

\section{Run M-3}

The unit was started up and heated to design conditions by oxygen injection. Attempts at feeding were not successful until we opened the lock hopper vent valve while filling the lock hopper. Apparently this allowed gas to escape and be displaced by solids. A soft shutdown was initiated to implement this change in the computer control logic. Soft shutdown caused a vent valve to open, leading to entrainment of solids into the methane reactor check valve and excessive pressure drop which terminated the run. After this run, the control system was altered so that control software could be updated or modified without shutting the system down.

\section{Run $M-4$}

A smooth start-up and heat-up to design conditions was achieved in this run. As char was fed and discharged, the lock hopper valves began to allow severe leakage from the reactor into the lock hoppers. The leakage through the discharge lock hopper was so severe that the plant was shut down because of safety concerns. It appeared that the Everlasting lock hopper valves originally installed were unsuitable for this application. These valves were sent back to the factory for modification and a search for improved valves was initiated.

\section{Run C-2}

The carbon reactor was operated on compressed natural gas and start-up was smooth. Before this run, pyrolytic carbon had been removed from the heat 
transfer surfaces and the sparge tube gas injection holes had been drilled out to increase their diameter and reduce pressure drop in this side of the system. The carbon reactor was heated to $1,450^{\circ} \mathrm{F}$ and then methane addition was initiated. Reactor temperature began to fall and no methane was consumed.

We had observed in several runs that the carbon reactor feed gas temperature was substantially lower than design, probably because heat losses were higher than design. To overcome this problem, it was decided to install an electric circulation heater as a preheater on the carbon reactor feed gas. This trim heater was installed on the carbon reactor inlet. Also, methanation cold flow tests were conducted which suggested that we should reduce bed inventory. In particular, in this expanded top bed, a "standing slug" formed at the bottom of the expanded section, leading to extremely poor mixing of solids in the fluid bed.

\section{Run C-3}

The carbon reactor was heated to $1,650^{\circ} \mathrm{F}$ with the trim heater installed, at which time methane injection was initiated. It appeared that some of the methane cracked based on gas analysis, but reactor temperature could not be maintained. The actual flow rate into the unit was not known very accurately because of problems with the turbine flowmeters. The reactor was operated for 34 hours.

Based on the results from several carbon formation and integrated runs, it was decided to replace the heat transfer tubes and install a gas distribution grid. The horizontal heat transfer tubes would be replaced with finned, vertical tubes leading to a large increase in heat transfer surface area. A scale drawing of this modified carbon formation reactor is shown in Figure 14. Replacement of the sparge tubes with a gas distribution grid was expected to improved gas distribution, reduce bubble size, and increase heat transfer from surface to bed and from gas to solids. This major modification of the carbon reactor also required replacement of some of the refractory lining.

During the month of March, the carbon reactor was modified and the baghouse was installed. A cold flow model of the carbon reactor was also constructed.

\section{Run M-5}

Modified Everlasting valves were received from the manufacturer. These valves were installed and tested in this run. Start-up was trouble free. Upon feeding of char, excessive gas leakage through the new valves occurred. The spent char discharge system was modified to accommodate severe gas leakage by insuring that the leakage was vented to a safe area. 


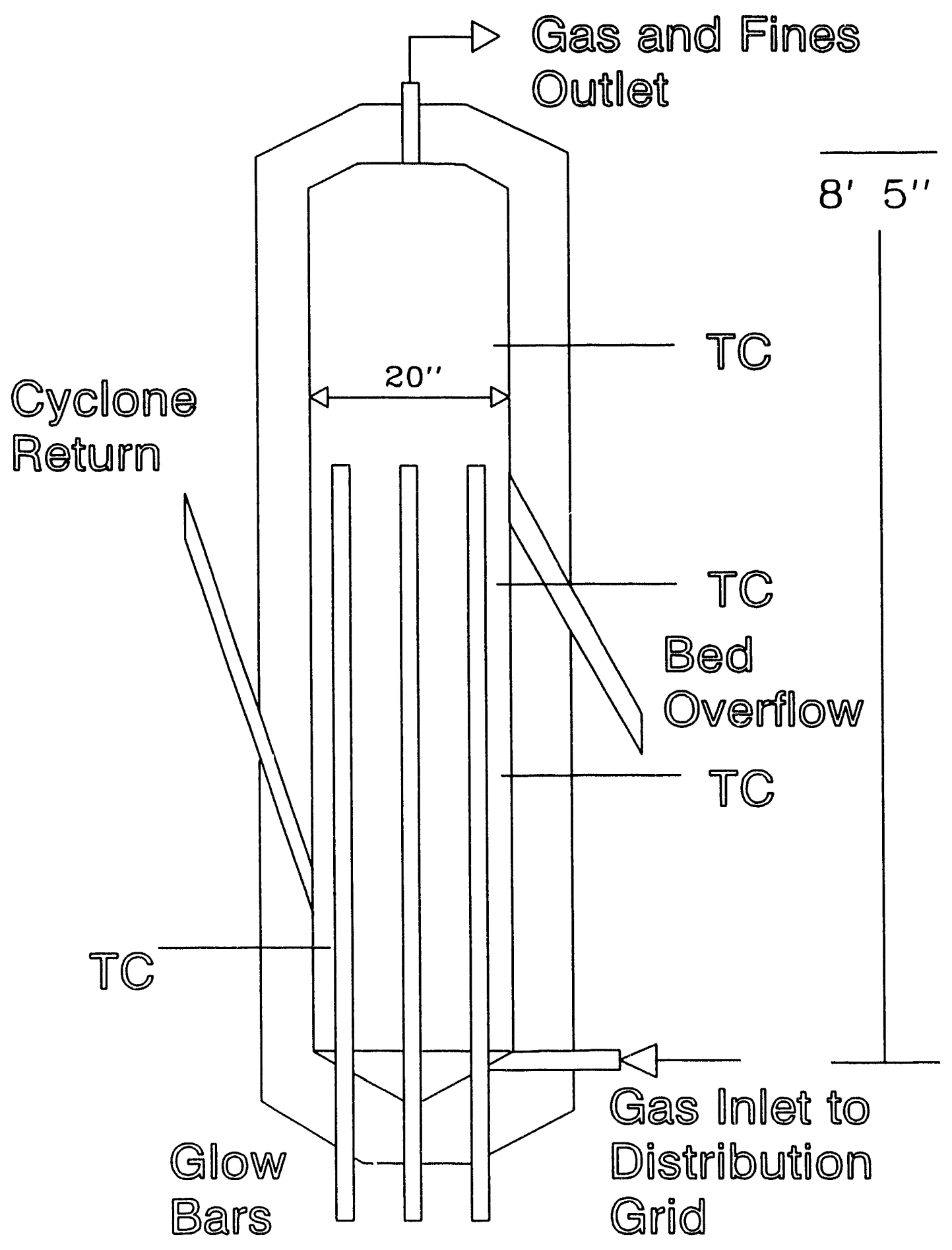

Figure 14. Scale drawing of modified carbon reactor. 


\section{Run M-6}

Before this run, the char feed pipe was extended to within 4 inches of the bottom of the methanation reactor. Cold flow studies had indicated that this modification might reduce char bypassing and improve reactor efficiency. The feed system did not function well because of excessive leakage. Discharge system operation was trouble free in this run because leaking gas could be vented to the flare. The run was terminated because of a small hydrogen explosion which occurred above the feed system. This explosion resulted in minimal damage to equipment and no injuries. A decision was made to try a Dezurik eccentric plug valve in the lock hopper application. This valve has an extremely low leakage rate relative to other valves on the market.

\section{Bun C-4}

All modifications to the carbon side of the plant were completed before this run. During the run, the methane reactor was pressurized, but not heated, to allow testing of the Dezurik valve. The run was terminated because of shorting of a glow bar. It was apparent that the Dezurik valve was experiencing severe leakage. A decision was made to go to a pressurized feed hopper which would feed char into the reactor through a lock hopper. By using this approach, leakage of the lock hopper valves would not be a problem.

\section{Run C-5}

The carbon reactor was heated to $1,550^{\circ} \mathrm{F}$ with one thermocouple reading $1,650^{\circ} \mathrm{F}$. The carbon reactor trim heater provided only minimal heating because its shell was oversized, leading to reduced gas velocity and heat transfer coefficient. A great deal of water was removed from the system, indicating that the new refractory was curing. Methane was added but none was consumed. From a mechanical standpoint, this run was problem free.

\section{Run C-6}

The carbon reactor was again heated to $1,550^{\circ} \mathrm{F}$. The refractory appeared to have been cured because very little water was removed from the system. Methane was added to the system. Some methane was decomposed, and methane concentration dropped from 60 to 55 volume percent upon passing through the carbon reactor. A carbon balance indicated that only a small amount of carbon production had occurred. Operation was trouble free.

\section{Bun C-7}

Cold flow tests indicated that 150 pounds of additional seed carbon were required in the carbon reactor to completely cover the heat transfer surfaces. The 
carbon reactor feed gas trim heater was also modified to have the correct shell diameter. The carbon reactor was heated to $1,660^{\circ} \mathrm{F}$ with the trim heater increasing the gas temperature by $150^{\circ} \mathrm{F}$. Methane addition was initiated and between 60 and 70 volume percent methane was in the feed gas. The exit gas contained 50 to 60 volume percent methane. The baghouse was discharged numerous times, and we collected a mixture of Desulco and carbon product. Later inspection of the reactor indicated that significant carbon deposition as pyrolytic carbon had also occurred inside the reactor both on the heat transfer surfaces and throughout the reactor volume.

\section{Run C-8}

The glow bars were rewired before this run to improve power output and several new thermocouples were installed. The reactor was again heated to about $1,660^{\circ} \mathrm{F}$ and methane addition was initiated. Some methane was consumed. The unit was eventually shut down because of a high pressure drop through the filters and condensers. Later inspection of these indicated that they had become plugged with a pale yellow organic material which was later identified as naphthalene. Naphthalene has been discussed as an important intermediate in methane decomposition in several fundamental studies. ${ }^{7}$

The carbon reactor was opened after this run, and it was observed that several different types of pyrolytic carbon had deposited on the heat transfer surfaces. Also, it was apparent that the heat transfer surfaces were beginning to corrode or carburize. Analysis of the seed material taken from the bed after this run indicated that growth of the seed carbon particles was occurring.

\section{Run $\mathrm{M}-7$}

A pressurized feed system was installed on the rivethanation reactor. Reliable operation of the new feed system was established over 65 hours of operation. The run was hampered by high pressure drops and plugging thought to be caused by naphthalene and char volatiles condensation.

\section{Run $M-8$}

Reliable feeding and discharging of the system was again demonstrated. Flow upsets were caused when the J-valve was fluidized with process gas or bottled gas. These upsets resulted in severe temperature fluctuations in the reactor. To eliminate this problem, it was decided to remove the J-valve, and a simple lock hopper system was installed. Bed level was to be controlled by a bed overflow located at the original solids discharge leg. This modification resulted in some reduction in unit capacity (reactor volume). 


\section{Run I-11}

The methane reactor was fed continuously during this 42-hour run except when filling the char feed reservoir. Refilling of the reservoir resulted in serious process upsets and flow instability caused by the need to stop feeding during refilling. Carbon reactor feed gas ran between 40 and 50 percent $\mathrm{CH}_{4}$. About 770 pounds of char was fed and 400 pounds discharged, suggesting roughly 40 percent carbon conversion assuming all hydrogen and oxygen are converted (about 10 percent of the starting char). Oxygen was not added to the methane reactor during this run. The carbon reactor was operated at design conditions early in the run, but the temperatures declined in the last 12 to 24 hours, indicating bed displacement from the reactor. Maximum reactor temperatures were 1,600 to $1,700^{\circ} \mathrm{F}$. Methane concentration dropped about 5 percent across the reactor, indicating carbon formation, but no carbon was collected in the baghouse discharge lock hopper. It is suspected that all product carbon formed on the seed particles or as pyrolytic carbon on the hot surfaces in the bed.

\section{Run 1-12}

The PRU was operated for 48 hours and shut down after run objectives had been met. The methane reactor was fed and discharged successfully, although refilling the feed reservoir took 30 to 40 minutes, resulting in plant upsets. About 920 pounds of char was added and about 575 pounds of spent char removed, suggesting roughly 30 percent carbon conversion. Reactor exit gas ranged from 9 to 18 percent $\mathrm{CH}_{4}$. Methane reactor conditions ranged between 25 and 30 pounds/hour char feed rate, 1,400 to $1,450^{\circ} \mathrm{F}, 300 \mathrm{psi}, 0.5 \mathrm{cfm}$ oxygen assist, and $60 \mathrm{scfm}$ hydrogen. Carbon reactor glow bars were operated at $1,950^{\circ} \mathrm{F}$, but reactor bed temperatures never exceeded $1,550^{\circ} \mathrm{F}$. The reactor was either not fluidizing or the heat transfer surfaces were coated with carbon reducing heat flux. Methane concentration across the reactor dropped by about 3 to 5 percent. The membrane filters plugged with tar and were replaced by larger filter media. The hydrogen compressor ran hot due to a high pressure drop between the compressor and methane reactor probably caused by 3 to 5 percent methane in the compressur discharge. This relatively high methane content was caused by high (60 to 70 percent) methane content in the membrane feed. Char feed and discharge systems periodically plugged but were cleared by overpressuring the reservoirs.

After this run, the PRU was disassembled and cleaned. The carbon reactor was opened and the heating manifold removed. About 125 pounds of carbon-like material was deposited around the heating tubes. A photograph of these heavily scaled heat transfer tubes is shown in Figure 15. The material was carbon product, probably formed during the last two runs. The glow bar sheaths were subsequently inspected. The stainless tube fins had melted at some locations especially on the center tube. There were indications that the tubes had been reduced in cross section from carburization by the packed carbon at elevated temperatures. The 
carburization compromised sheath integrity such that they could no longer be used. About 400 pounds of carbon was removed from the reactor, baghouse, and piping. This compares with 245 pounds added to the reactor before the two runs.

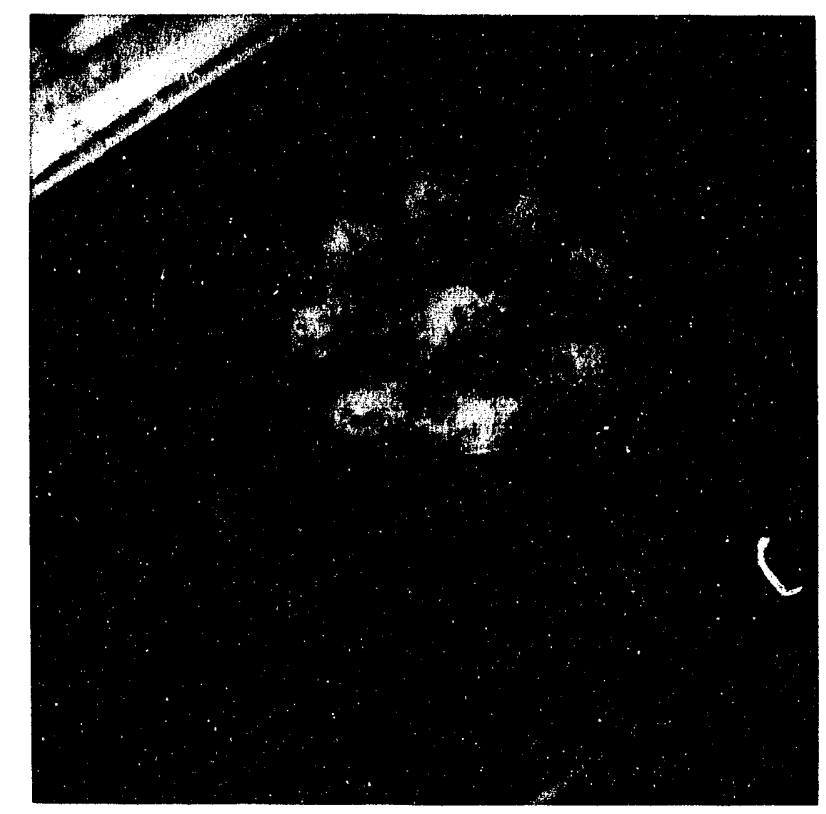

Figure 15. Photograph showing large carbon deposit on carbon formation reactor heat transfer surfaces after Run $1-12$.

The methane reactor and associated piping was cleaned out. The oxygen lance was deformed on the tip where apparently a hole had burned through during the last two runs. A new tip was installed. The dip leg, cyclone, and heat exchanger were cleaned out. A tar-like plug was removed from the heat exchanger by flushing with acetone. Modifications were made to the methane char feed system to expedite filling the feed reservoir.

\section{Run M-9}

After various attempts to operate the methane reactor without oxygen, conditions were set at $1,400^{\circ} \mathrm{F}, 300 \mathrm{psi}, 20$ pounds/hour char, $50 \mathrm{scfm} \mathrm{H}_{2}$, and 0.75 scfm $\mathrm{O}_{2}$. The run was continued for 32 hours. The methane compressor began vibrating and had to be shut down when the head came apart. Circuit operation continued, but excess methane and hydrogen had to be vented from the membrane rather than recycled. Throughout the run, the mass spectrometer appeared to be plugged and gas sample readings were incorrect. After the compressor failure, the circuit never stabilized and the plant was shut down. 


\section{Run $M-10$}

During this final run, the methane reactor was operated at five sets of operating conditions over a 48-hour period. The circuit ran well and no significant problems were encountered. The conditions and period of time they were in use are listed in Table 4. Oxygen was used for each test with less required for the higher hydrogen flows. Feeding and discharging of the reactor proceeded smoothly. There were no reported problems such as plugging or leakage which interrupted the tests. Test conditions were very stable, reflecting excellent computer control response. The only reported problem was with the mass spectrometer plugging from reaction products. After the final test period, char feeding was stopped and the char in the reactor was allowed to react for over 1 hour. This char sample will provide an indication of maximum attainable char conversion at these conditions.

Table 4. Operating Conditions for PRU Test $\mathrm{M}-10$

\begin{tabular}{|c|c|c|c|c|c|}
\hline $\begin{array}{l}\text { Test } \\
\text { No. }\end{array}$ & Date & $\begin{array}{l}\text { Start/Stop } \\
\text { Time } \\
\end{array}$ & $\begin{array}{l}\text { Temperature, } \\
{ }^{\circ} \mathrm{F} \\
\end{array}$ & $\begin{array}{c}\mathrm{H}_{2} \\
\text { SCFM }\end{array}$ & $\begin{array}{l}\text { Char, } \\
\text { lb/hr }\end{array}$ \\
\hline 1 & $7 / 31$ & $07: 00-13: 00$ & 1,450 & 43 & 20 \\
\hline 2 & $7 / 31$ & $14: 00-22: 00$ & 1,425 & 65 & 20 \\
\hline 3 & $8 / 1$ & $00: 00-06: 00$ & 1,400 & 70 & 39 \\
\hline 4 & $8 / 1$ & $06: 00-12: 00$ & 1,420 & 43 & 39 \\
\hline 5 & $8 / 1$ & $13: 00-16: 00$ & 1,410 & 40 & 60 \\
\hline
\end{tabular}

\section{COLD FLOW TEST RESULTS}

During the course of this development project, several opportunities for conducting cold flow studies of fluidization and solids transport were identified. As noted in the previous section, problems with the spent char discharge J-valve were eliminated by conducting full scale cold flow tests of the original and several alternative designs. These tests identified a configuration in which solids discharging could be performed with high reliability. Ultimately, however, the J-valve was removed from the system because its operation contributed to flow instability.

We also conducted cold flow tests in full scale models of the methanation and carbon formation reactors. These models were fabricated from plexiglass, and the fluidizing gas used was air. A comparison of the properties of ambient air and process gases is shown in Table 5. For gases which simulate the methanation reactor $\left(\mathrm{H}_{2}\right.$ and 98 percent $\left.\mathrm{H}_{2}\right)$, the viscosity of ambient air is quite close to the viscosity of the process gas. The process gas density is approximately half of the density of ambient air. Given these properties, the ambient air cold flow model 
should simulate the actual reactor fairly well in a qualitative sense. Both the viscosity and density of gas in the carbon reactor are significantly different than the values for ambient air. Again it seems likely that cold flow tests with ambient air will qualitatively model the carbon reactor, but quantitative results cannot be expected.

Table 5. Comparison of the Properties of Ambient Air and Process Gases.

\begin{tabular}{|c|c|c|c|c|}
\hline & $\underline{\text { Air }}$ & $\underline{\mathrm{H}}_{2}$ & $\underline{98 \% \mathrm{H}_{2}} / \mathrm{CH}_{4}$ & $\underline{40 \% \mathrm{H}_{2}} / \mathrm{CH}_{4}$ \\
\hline Temperature, ${ }^{\circ} \mathrm{F}$ & 77 & 1,200 & 1,382 & 1,652 \\
\hline Pressure, psia & 12 & 200 & 300 & 100 \\
\hline Density, $\mathrm{lb} / \mathrm{ft}^{3}$ & 0.0740 & l.0340 & 0.0349 & 0.0460 \\
\hline Viscosity, lb/tt-hr & 0.04356 & 0.04250 & 0.04403 & 0.07129 \\
\hline
\end{tabular}

In general, minimum fluidization velocity declines with both increasing gas density and increasing gas viscosity. As the gas becomes more dense or viscous, momentum transport to the particles can occur at lower gas velocities. For the methanation cold flow model, the viscosity is modeled fairly closely, while the cold density is too high. This suggests that fluidization velocities measured in the cold flow unit will be low, possibly by as much as $\mathbf{5 0}$ percent. For the carbon formation cold flow model, density is again high, while viscosity is low. It may be that these effects cancel each other out. In any case, the cold flow results should be treated with some caution because of these differences in gas properties. We employed empirical correlations for determination of minimum fluidization velocity ${ }^{19}$ at process conditions and used cold flow models to provide information on mixing and residence time distributions.

\section{Methanation Reactor Simulation}

While the PRU was undergoing modifications in March, a number of tests were conducted in a full scale methanation cold flow model. A photograph of the cold flow model is shown in Figure 16. These tests indicated that at the design gas velocity and bed inventory, large square slugs formed in the lower, small diameter section of the unit (see Figure 5). These slugs were so severe that solids mixing between the upper and lower sections was prevented, and frequently, most of the solids were blown into the stagnant upper section for extended periods of time. It also appeared that bypassing of unreacted char was occurring.

The cold flow tests suggested that bypassing can be mitigated by extending the char feed pipe into the lower section of the reactor, and this modification was tested in the cold flow unit. However, solids mixing between the upper and lower sections was still poor. By varying the bed level, it was determined that by reducing the unit capacity by 15 weight percent, solids mixing can be improved. 
Results also indicated that increasing gas velocity by 15 to 20 percent improved solids mixing.

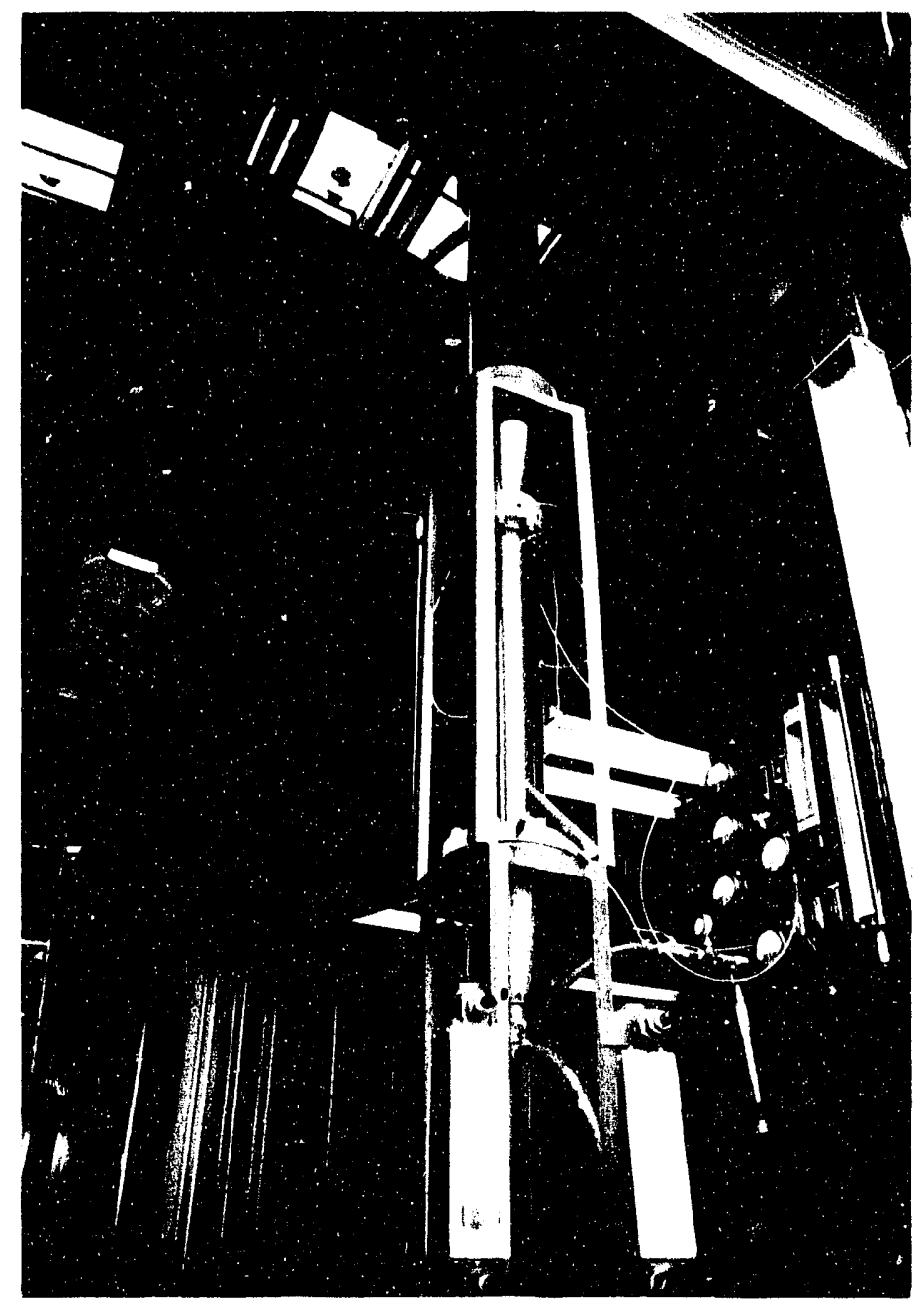

Figure 16. Photograph of methanation unit cold flow model.

To further quantify these results, we undertook the measurement of solids residence time distribution (RTD) by tracer studies. Measurement of RTD allows a more quantitative evaluation of the effect of bed level and gas velocity on solids mixing and bypassing.

RTD was measured by conducting a tracer study. The reactor was filled with char that had been tagged by impregnation with molybdenum. The reactor was then fluidized, and untagged char was fed and discharged as in actual operation. The discharged char was analyzed for molybdenum, yielding a so-called "wash out" function from which the RTD can be derived. ${ }^{20}$ 
Results of the RTD studies using the original feed and discharge design are shown in Figures 17 and 18 for mean residence times of 40 and 30 minutes, respectively. Both tests employed a feed rate of 48 pounds/hour, but bed inventory (bed level) was different in the two tests. At these levels of bed inventory, both the upper and lower sections of the reactor were filled with char. The gas flow rate in these tests was 9.7 acfm. Based on bed inventory and feed rate, a mean residence time was computed, assuming perfect mixing. Theoretical wash out functions based on these overall mean residence times are also shown in the figures.

The experimental curves fell below the theoretical curves for both residence times. The experimental data were fitted to the perfect mixing equation to yield an experimental mean residence time. These curves and the fitted values are also reported in Figures 17 and 18. Residence times were reduced by 13 and 26 percent, respectively, in these tests. Because the experimental curves were closely fitted by a perfect mixing model, it seemed possible that good mixing was actually occurring. If this was true, the cold flow data indicated that the effective reactor volume was smaller than the total volume. This made sense because the presence of slugs or bubbles reduced the volume available for solids. However, the reduced residence times relative to theoretical could also be caused by bypassing of char.

To reduce the possibility of bypassing, we modified the actual PRU methanation unit so that the solids feed tube extended to within 4 inches of the gas distribution grid at the bottom of the 5-inch diameter zone. These modifications were tested in run M-6 in late March and the results were described in the previous section.

Based on the cold flow results, the discharge system was changed from a Jvalve to a bed overflow which controls the bed at a level significantly lower than the original design. Cold flow studies indicated that the bed overflow would control bed level over a wide range of gas and solid feed rates. The inventory of the system was reduced approximately 40 percent by this modification.

An RTD study was conducted with the modified cold flow unit. The results of this study are shown in Figure 19. The mean residence time was 28 minutes, feed rate was 30 pounds/hour, and bed inventory was 14 pounds. The gas flow rate was 9.7 acfm. Bypassing or effective volume reduction appeared to be even more severe in this test, as demonstrated by the nearly 42 percent reduction in actual mean residence time relative to the overall value. Again, the data were adequately fitted with a perfect mixing model, and this suggested that effective reactor volume for solids was reduced by 42 percent. In this test, it was observed that solids discharging (overflowing) was highly reliable. Bed level was also nearly constant in this test. Because of the good level control, this modification was implemented in the PRU during early June. The most successful methanation unit runs, $M-9$ and $M-$ 10 , were made with this modification. 


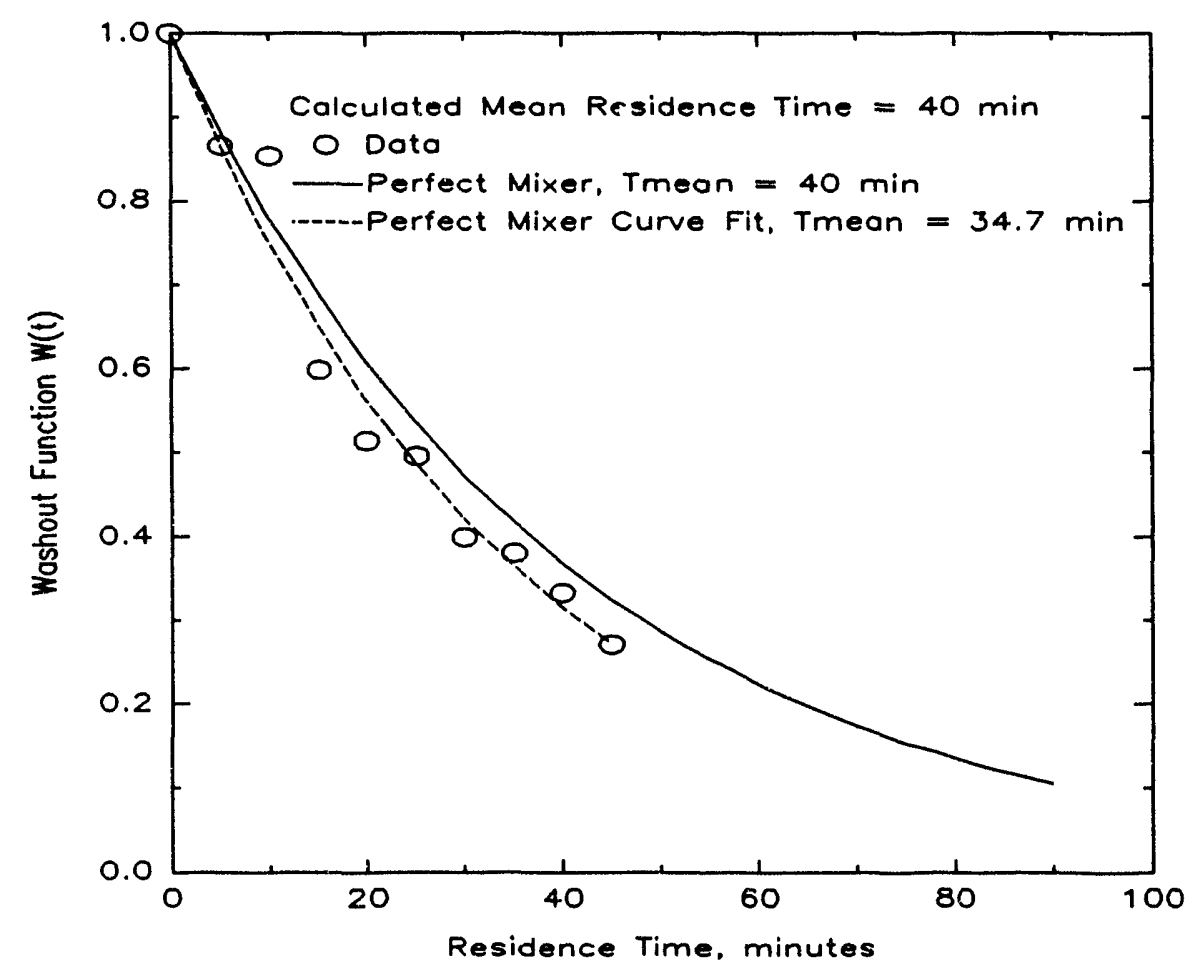

Figure 17. Results of methanation reactor cold flow tracer study (32-pound bed inventory and mean residence time of $\mathbf{4 0}$ minutes).

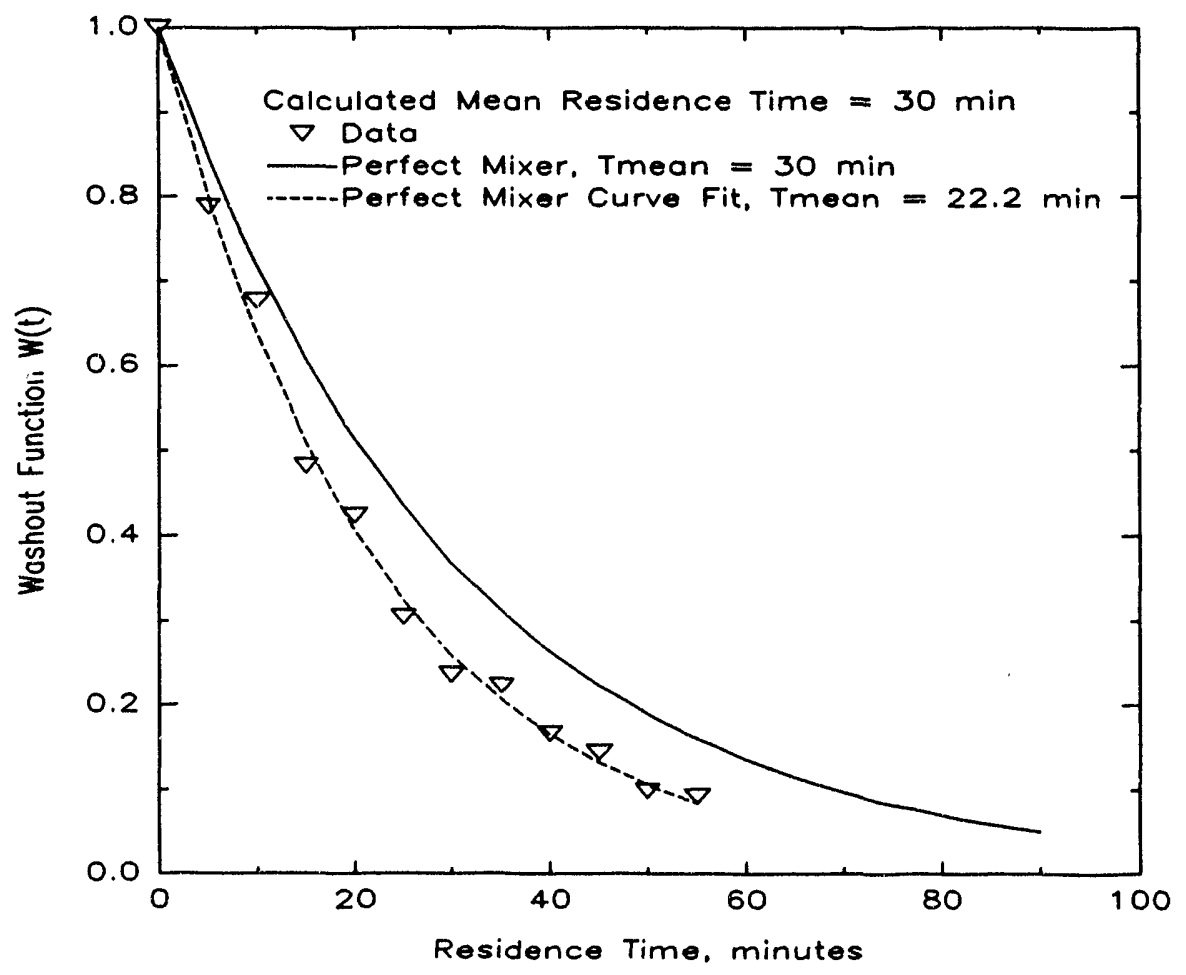

Figure 18. Results of methanation reactor cold flow tracer study (24-pound bed inventory and mean residence time of $\mathbf{3 0}$ minutes). 


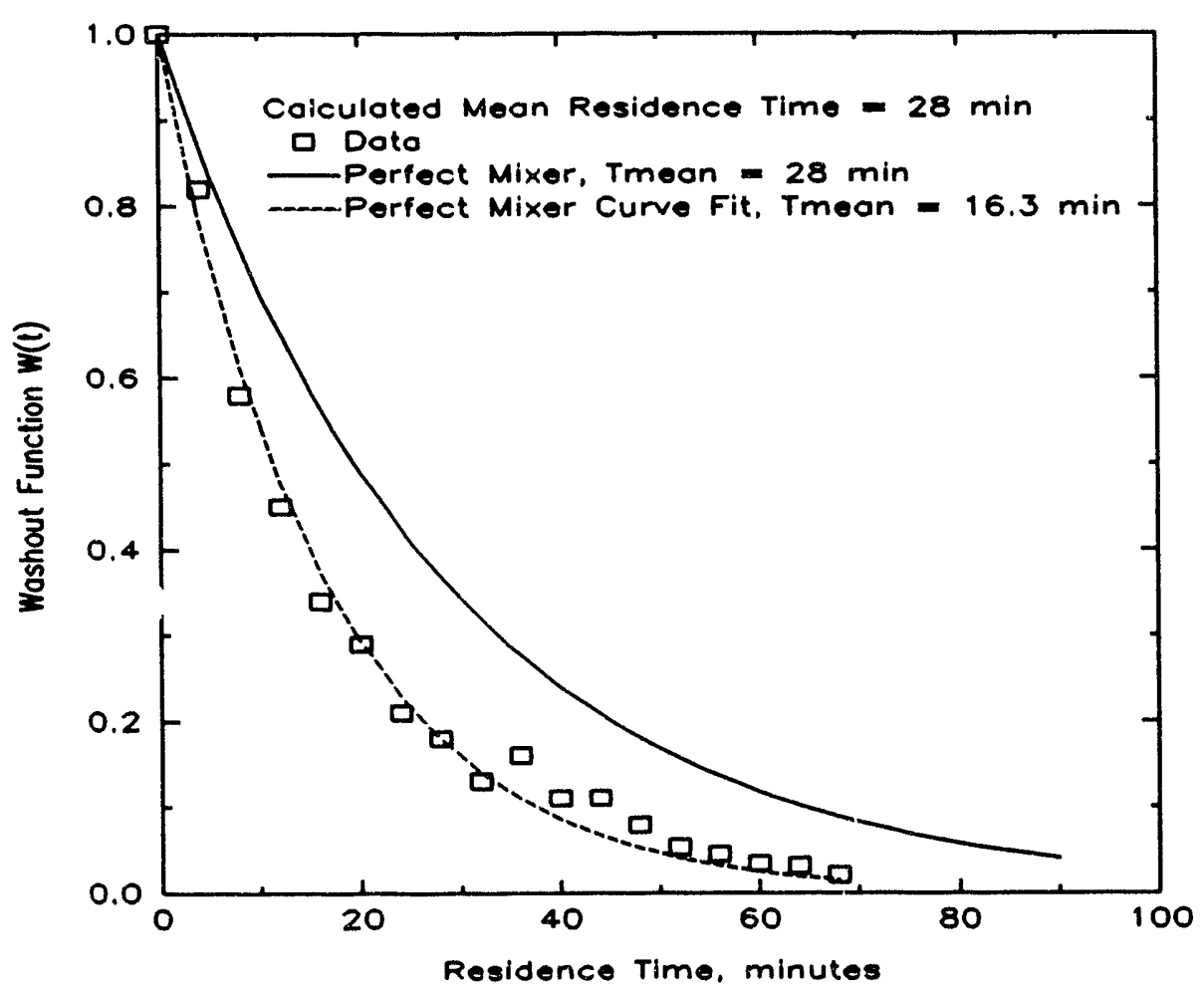

Figure 19. Results of methanation reactor cold flow tracer study (14-pound bed inventory and mean residence time of 28 minutes).

\section{Carbon Formation Reactor Simulation}

Fabrication and calibration of the carbon reactor cold flow model was completed early in May. A photograph of this cold flow unit is shown in Figure 20. This cold flow simulation was not of the original design but of the modified design with the gas distribution grid and vertical, finned heat transfer tubes, as shown in Figure 14. Cold flow tests indicated that bed expansion was much less in the full scale test model than in the 4-inch diameter tube utilized during the design studies. Therefore, the inventory of seed carbon was increased to insure that the heat transfer tubes were completely covered. This change was implemented in run C-7. The cold flow work confirmed that the bed was well fluidized and exhibited a classical solids mixing pattern. That is, solids were pulled up by bubbles in the center of the bed and then moved down at the reactor wall. Solids motion did not appear to be hindered by the presence of the finned heat transfer tubes. 


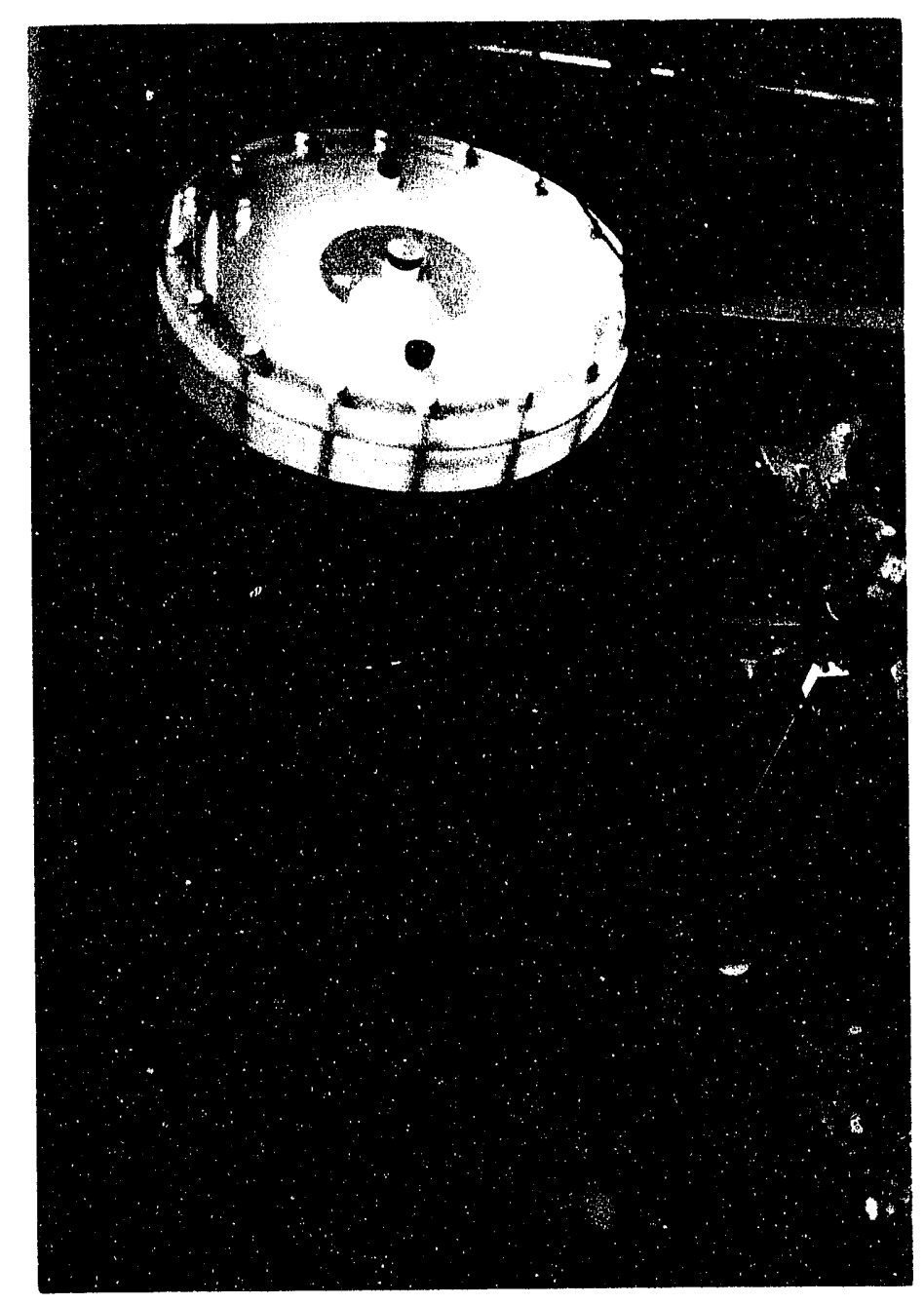

Figure 20. Photograph of carbon formation unit cold flow model.

\section{DETAILED TEST DATA FOR SELECTED RUNS}

Considerable modification and development of the process unit operations occurred during the first 8 months of PRU operation. Consequently, steady state operating data were only obtained during the later runs. In this chapter, several runs are reviewed in detail. These runs were selected based on a review of operating results. The criteria for selection included the attainment of steady state at useful operating conditions for a reasonable length of time, at least 1 to 2 hours for example.

\section{Run C-2 Results}

In this run, the carbon reactor was operated on bottled natural gas for a period of about 20 hours. The carbon reactor used was of the original design with 
horizontal muffle tubes for the glow bars. Glow bar temperatures and bed temperatures are shown in Figure 21, parts a) and b) respectively. Only two of the 12 glow bar temperatures were measured in this original configuration. Methane addition was initiated at about 4:00 and resulted in a decline in both glow bar and bed temperatures. Feed gas temperature increased, however. After this initial decline, the power input was increased and temperatures began to rise until the end of the run (at 8:30).

Gas analytical results indicated that little or no methane was consumed in this run. Figure 22 shows the feed gas flow rate for the run and indicates that the flow rate was fairly stable. Utilizing an average glow bar temperature and the top and bottom bed temperatures, a mean overall heat transfer coefficient was calculated. This parameter is plotted in Figure 23. The heat transfer coefficient increased at a fairly constant rate until methane was injected, at which point $U$ increased markedly. A value near $12 \mathrm{Btu} / \mathrm{hr}-\mathrm{ft}^{2}-\mathrm{F}$ was maintained for the entire time period of methane injection. This value was substantially below the value of around $\mathbf{3 0}$ assumed in the reactor design.

\section{Run C-6 Results}

This run was made with the modified carbon reactor configuration as shown in Figure 14 using bottled natural gas. The new refractory had been cured in two previous runs, so very little water was produced in Run C-6. The reactor was heated to above $1,500^{\circ} \mathrm{F}$, and methane addition was started at 2:00. Glow bar temperatures and bed temperatures are shown in Figure 24, parts a) and b) respectively. The addition of methane resulted in a slight increase in feed temperature and in the temperature of the center glow bar. The temperature of the hottest glow bars began to fall, leveling out at about $1,575^{\circ} \mathrm{F}$. Both glow bar and bed temperatures were fairly stable. Methane addition was curtailed at about 11:00, and both bed and glow bar temperatures increased to a different steady state value.

There was a slight decline in methane concentration upon passing through the reactor, but conversion and carbon yield were very low. Figure 25 shows the feed gas flow rate for this run. The figure indicates that flows were stable until around 9:00 at which time increasing pressure drop through the compressor filters led to a reduction in the flow rate. Overall heat transfer coefficients were calculated for each glow bar and averaged. Some of these numbers, including the average value, are plotted in Figure 26 . The average value was around 3 , which is much less than design and about 25 percent of the value observed for the horizontal tubes.

\section{Run C-7 Results}

In this run the carbon reactor was operated independently of the rest of the plant on bottled natural gas. The run lasted about 24 hours and methane addition 
a)

PRU Run C-2, Carbon Reactor Glow Bar Temperatures

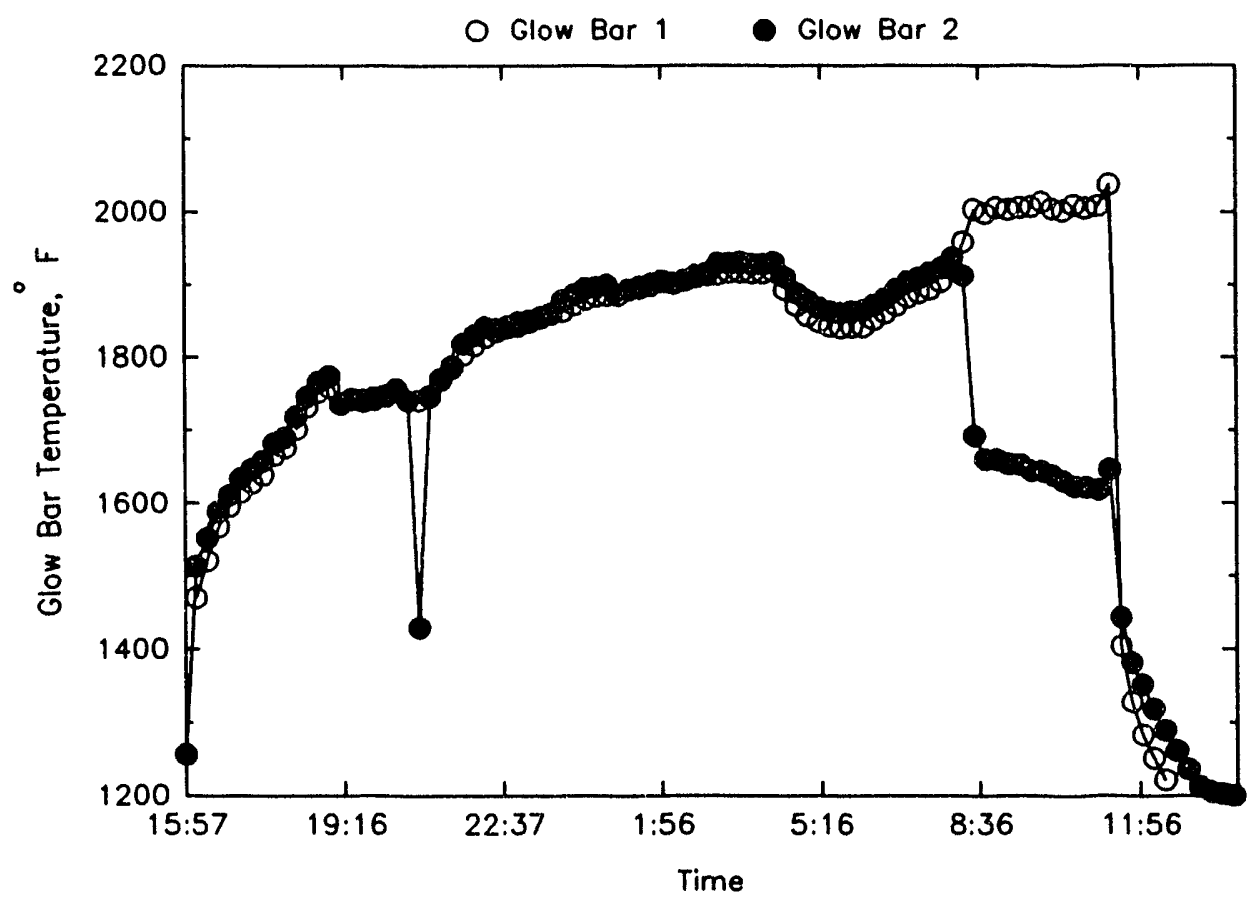

b)

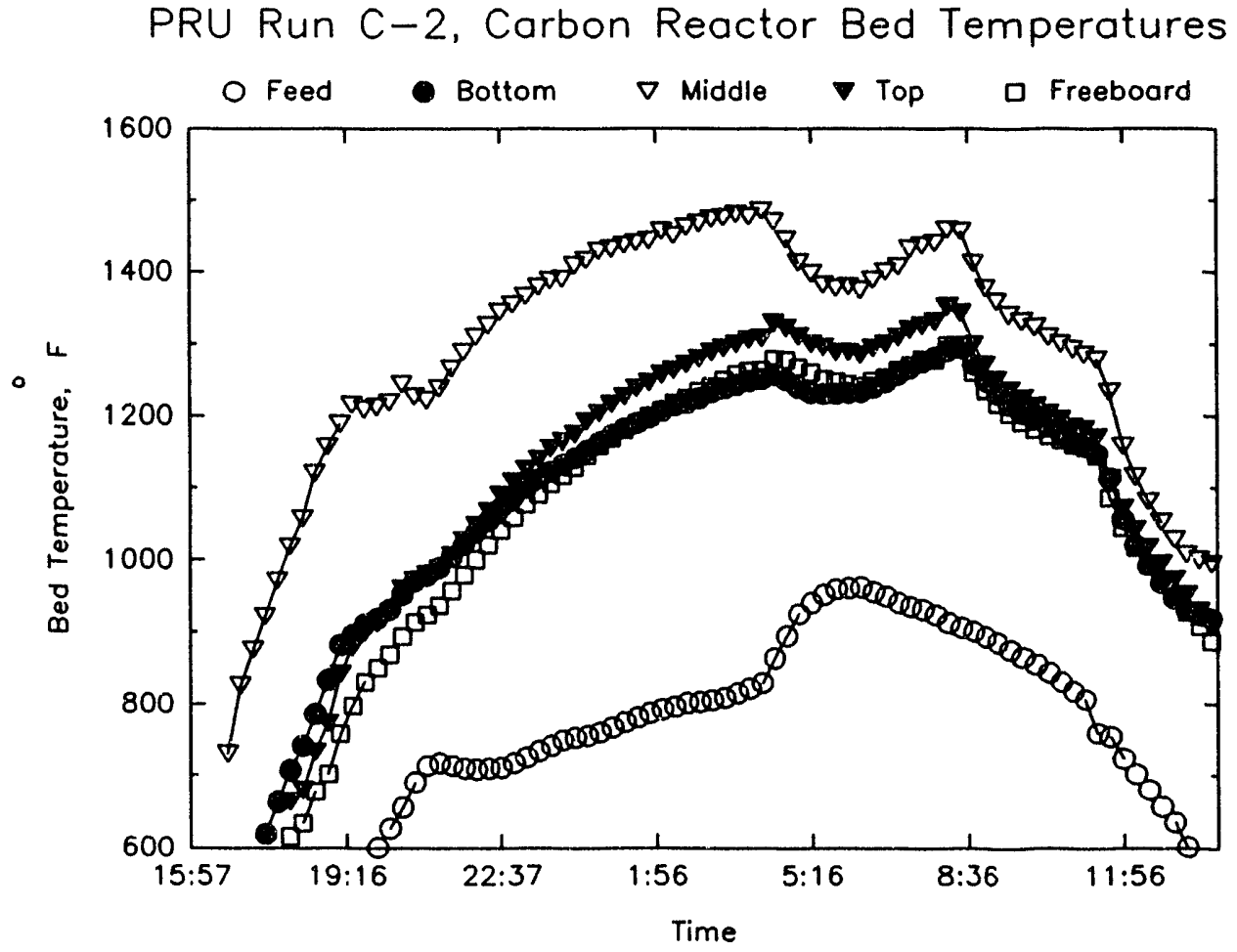

Figure 21. a) Glow bar temperatures and b) carbon reactor bed temperatures for Run C-2. 
PRU Run $\mathrm{C}-2$, Carbon Reactor Feed Gas Flow Rate

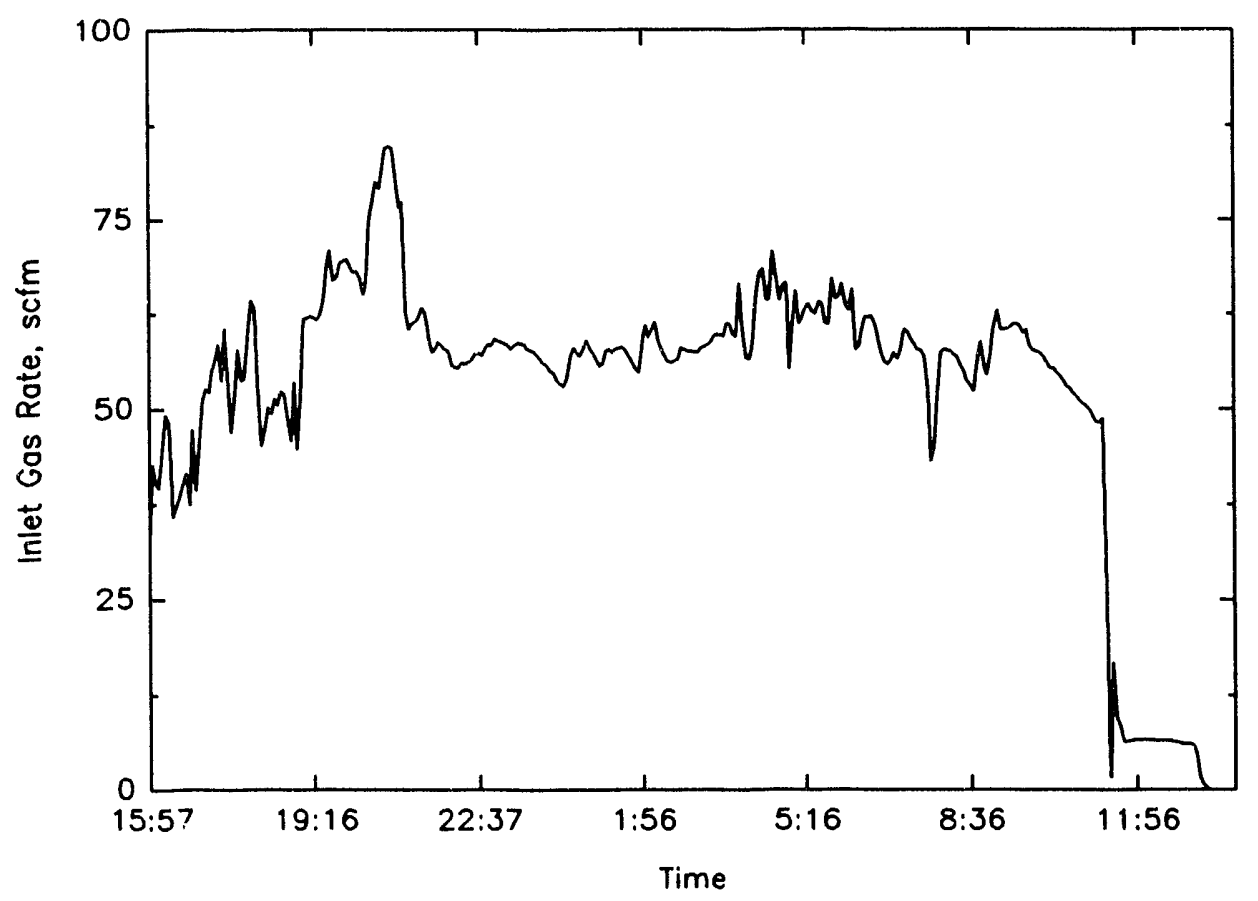

Figure 22. Carbon reactor feed gas flow rate for Run C-2.

PRU Run C-2, Carbon Reactor Heat Transfer Coefficient

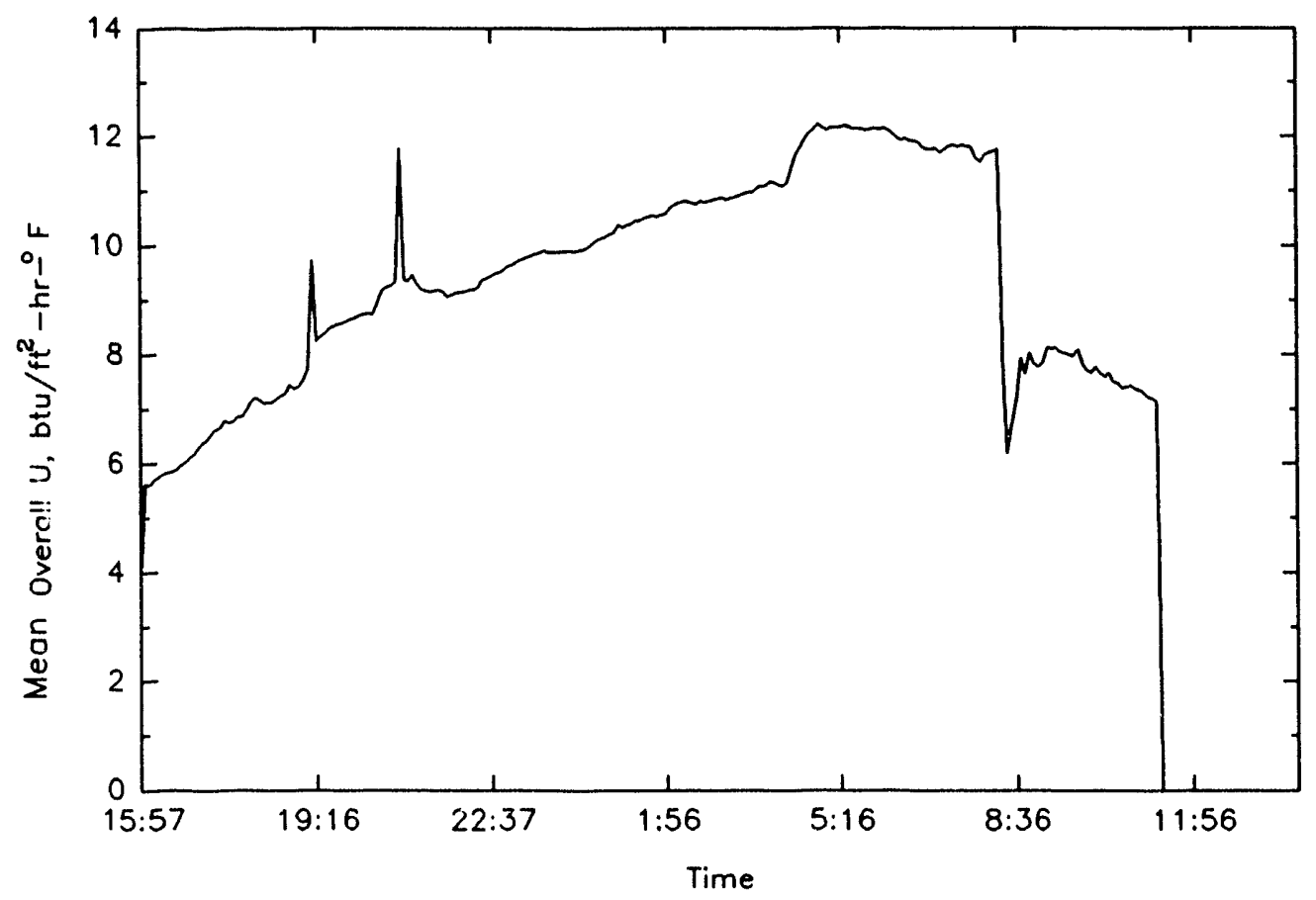

Figure 23. Mean carbon reactor heat transfer coefficient for Run C-2. 
a)

PRU Run C-6, Carbon Reactor Glow Bar Temperatures

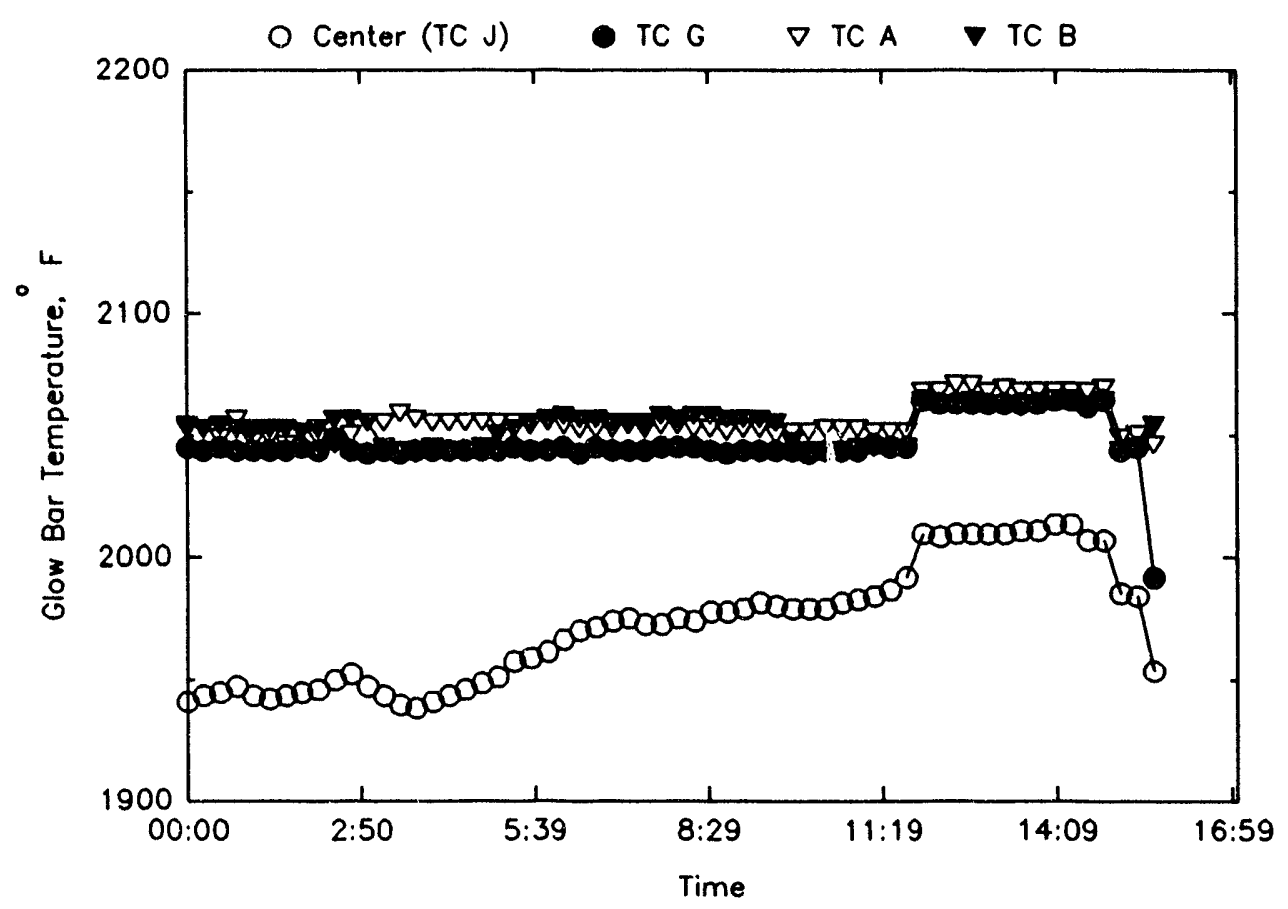

b)

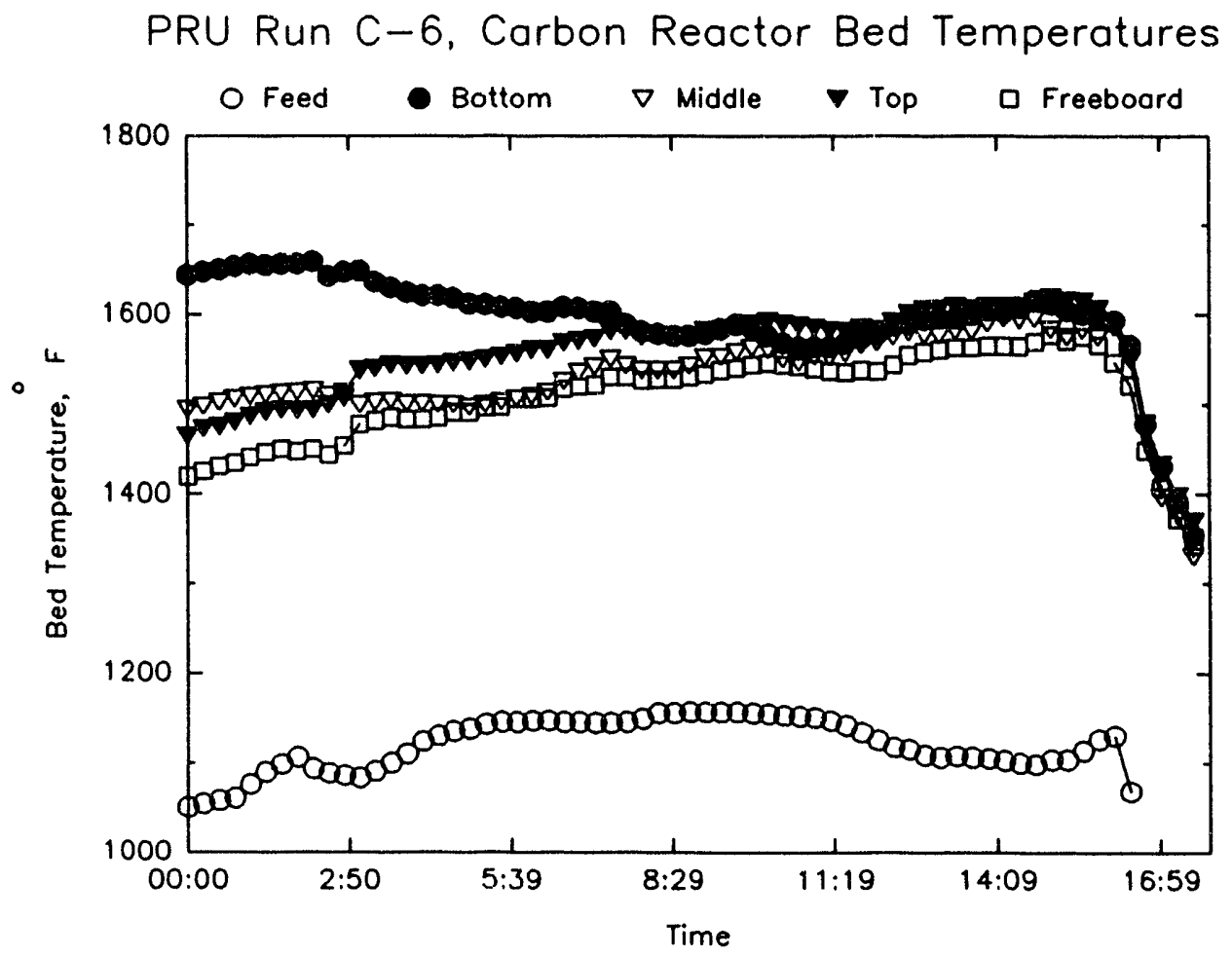

Figure 24. a) Glow bar temperatures and b) carbon reactor bed temperatures for Run C-6. 
PRU Run C-6, Carbon Reactor Feed Gas Flow Rate

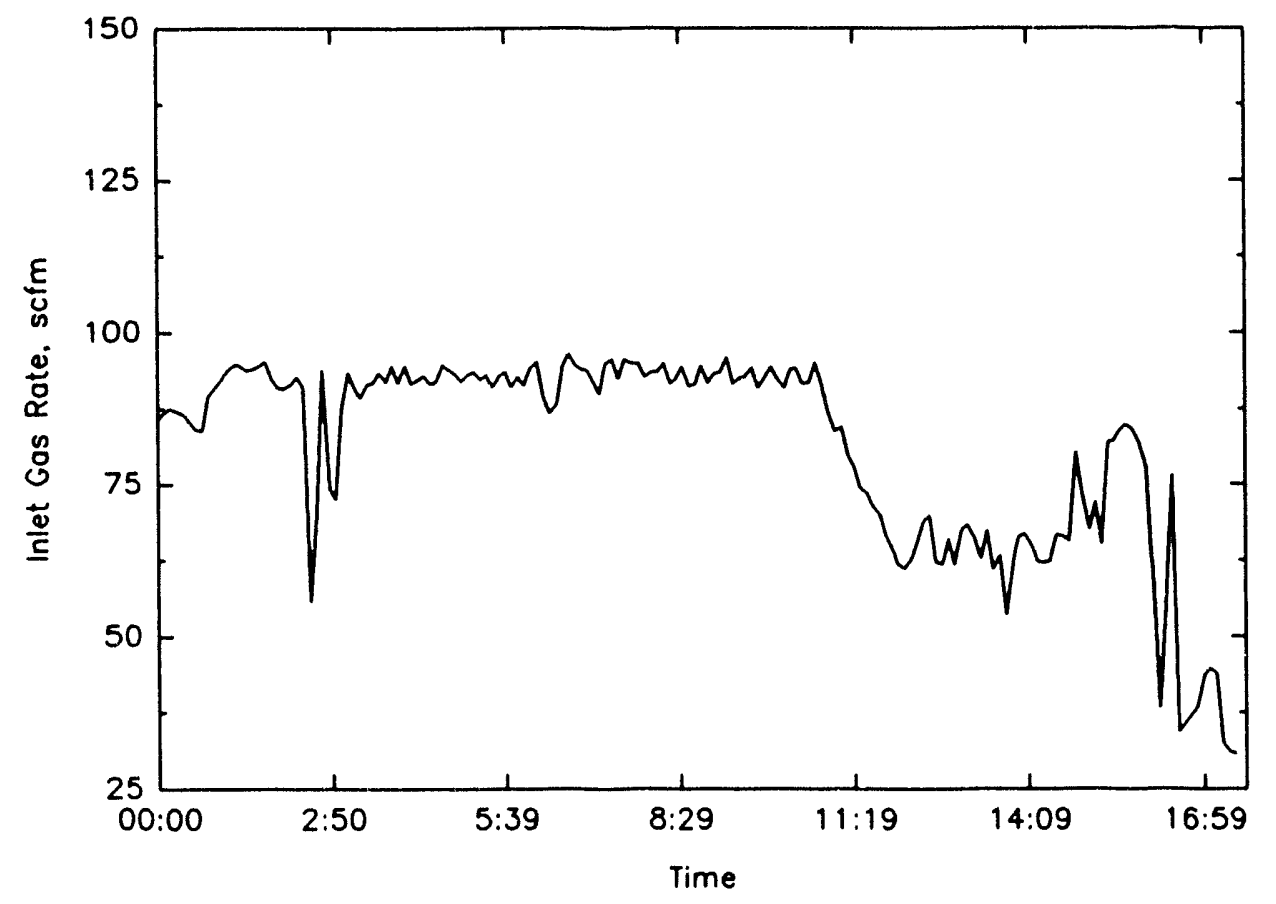

Figure 25. Carbon reactor feed gas flow rate for Run C-6.

PRU Run C-6, Carbon Reactor Heat Transfer Coefficients

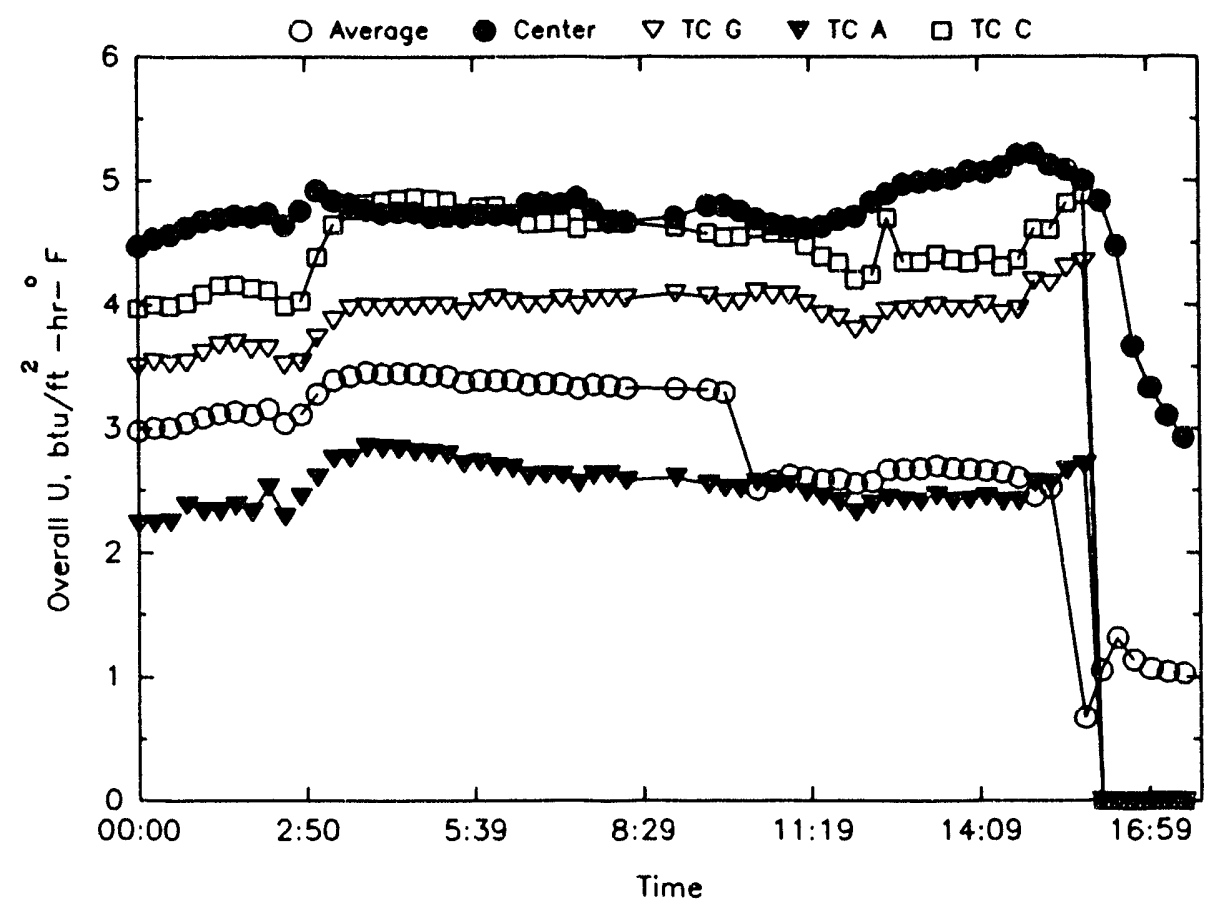

Figure 26. Overall carbon reactor heat transfer coefficients for Run C-6. 
was performed twice for periods of about 3 hours. A mixture of product carbon and Desulco was discharged from the baghouse several times during the run.

Glow bar temperatures and bed temperat'-ures are shown in Figure 27, parts a) and b) respectively. These data showed that after start-up, both glow bar and bed temperatures remained relatively constant. A slight decrease in bed temperature with time could be noted, however. It was also apparent that the center glow bar was 75 to $100^{\circ} \mathrm{F}$ cooler than the other glow bars whose temperatures were plotted. This was presumably because of the higher heat transfer coefficient for the center glow bar.

Figure 28 shows the feed gas flow rate as a function of time for this run. Feed gas flow was relatively stable until around 10:00 at which time instability developed. Figure 29 a) shows inlet and outlet gas compositions for this run. This figure shows that the instability coincides with the end of the first period of methane injection. Flow stability was never fully recovered, but the second period of methane injection occurred at a substantially lower flow rate than the first. This figure and Figure $29 \mathrm{~b}$ ) indicate that the difference in flows had only a minimal effect on methane conversion, however.

An interesting aspect of Figure $29 \mathrm{~b}$ ) is that the highest methane conversion was obtaiced immediately after the start of methane injection. Given that a great deal of scale was found to have formed on the heat transfer surfaces during this run, this large initial loss of conversion was probably caused by scale formation and loss of heat transfer capability.

In order to address this question more fully, heat transfer coefficients were calculated for individual glow bars and averaged to produce a single value for the entire reactor. The average and several individual values are reported in Figure 30. Here it can be seen that overall coefficients were relatively constant. There was a very weak trend towards decreasing heat transfer coefficient with time on stream but no dramatic decline coinciding with the initiation of methane injection.

\section{Run 1-11 Results}

In this run the system was operated in an integrated mode for approximately 30 hours after the completion of start-up. In the integrated mode, all unit operations in the plant were utilized. The results will be presented in three parts: membrane performance results, carbon reactor results, and methane reactor results.

Performance of the gas separation membrane can be evaluated from the data shown in Figure 31. Part a) of this figure shows the methane concentration in the feed, reject, and permeate gas streams for thie complete duration of the run. The permeate stream always contained less than 4 volume percent methane. There was great variability in the feed gas and reject gas methane contents because of difficulty in maintaining constant flow rates and the intermittent nature of char feeding. This point is discussed more below. 
a)

PRU Run C-7, Carbon Reactor Glow Bar Temperatures

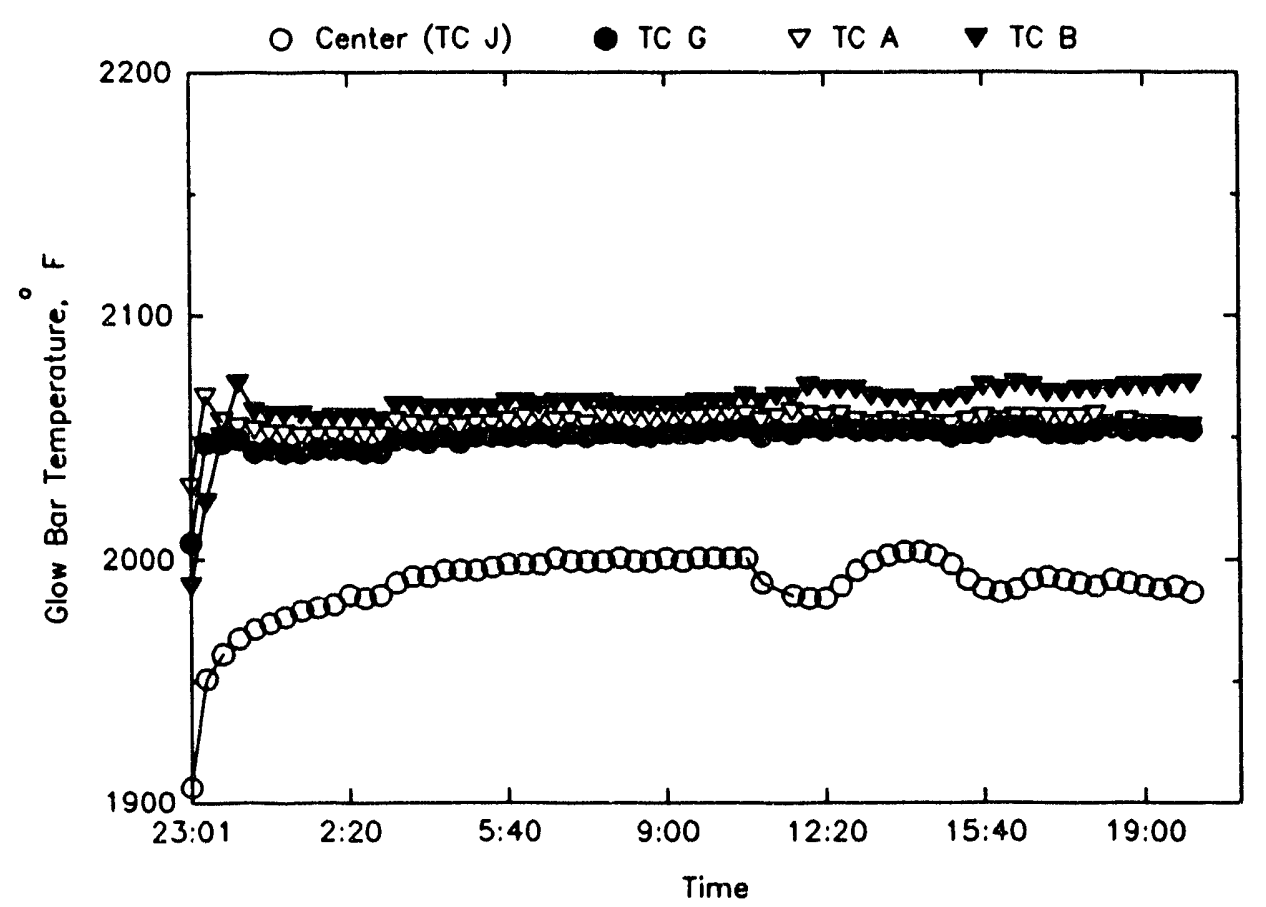

b)

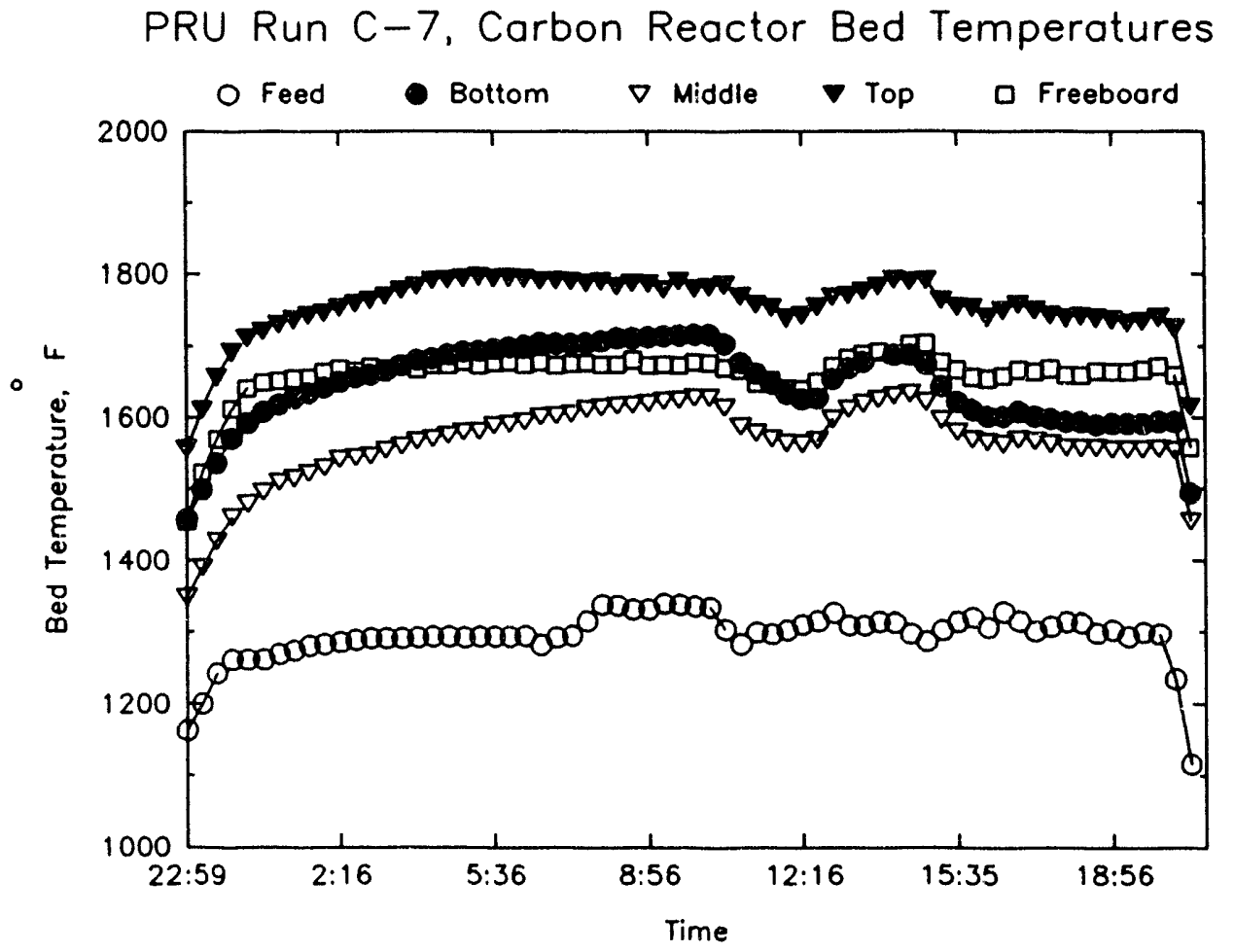

Figure 27. a) Glow bar temperatures and b) carbon reactor bed temperatures for Run C.7. 


\section{PRU Run C -7 , Carbon Reactor Feed Gas Flow Rate}

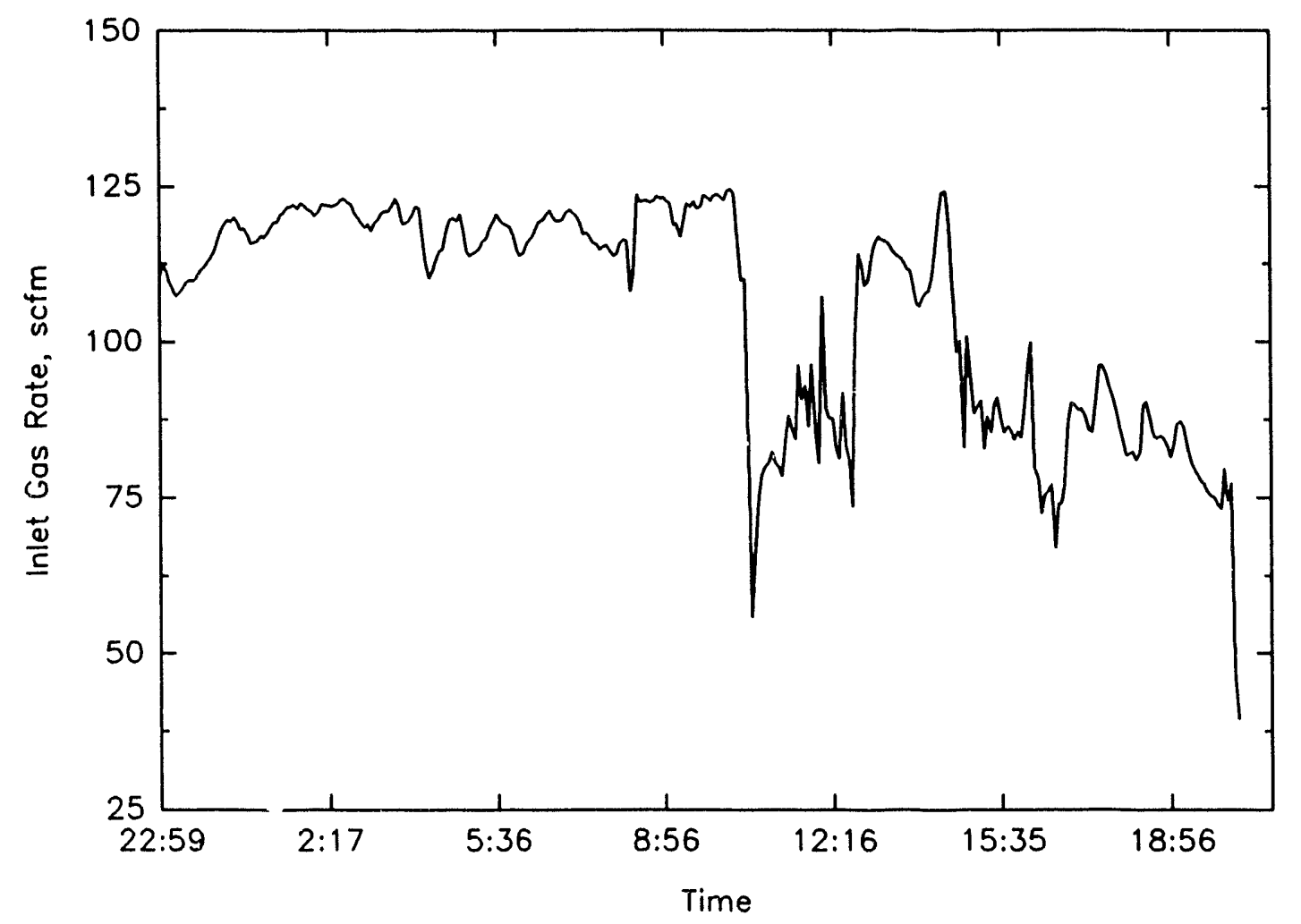

Figure 28. Carbon reactor feed gas flow rate for Run C-7. 
a)

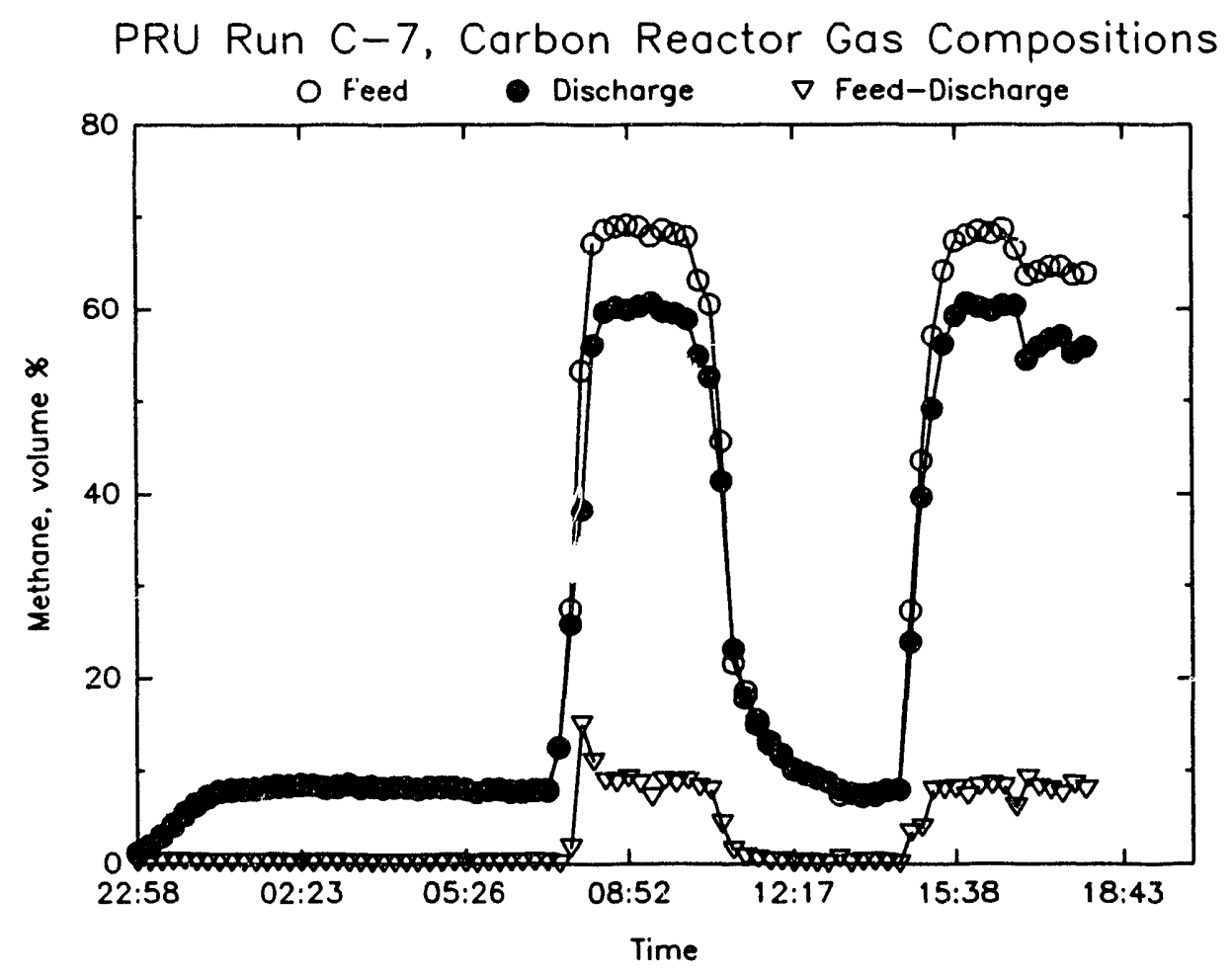

b)

PRU Run C-7, Carbon Reactor Methane Conversion

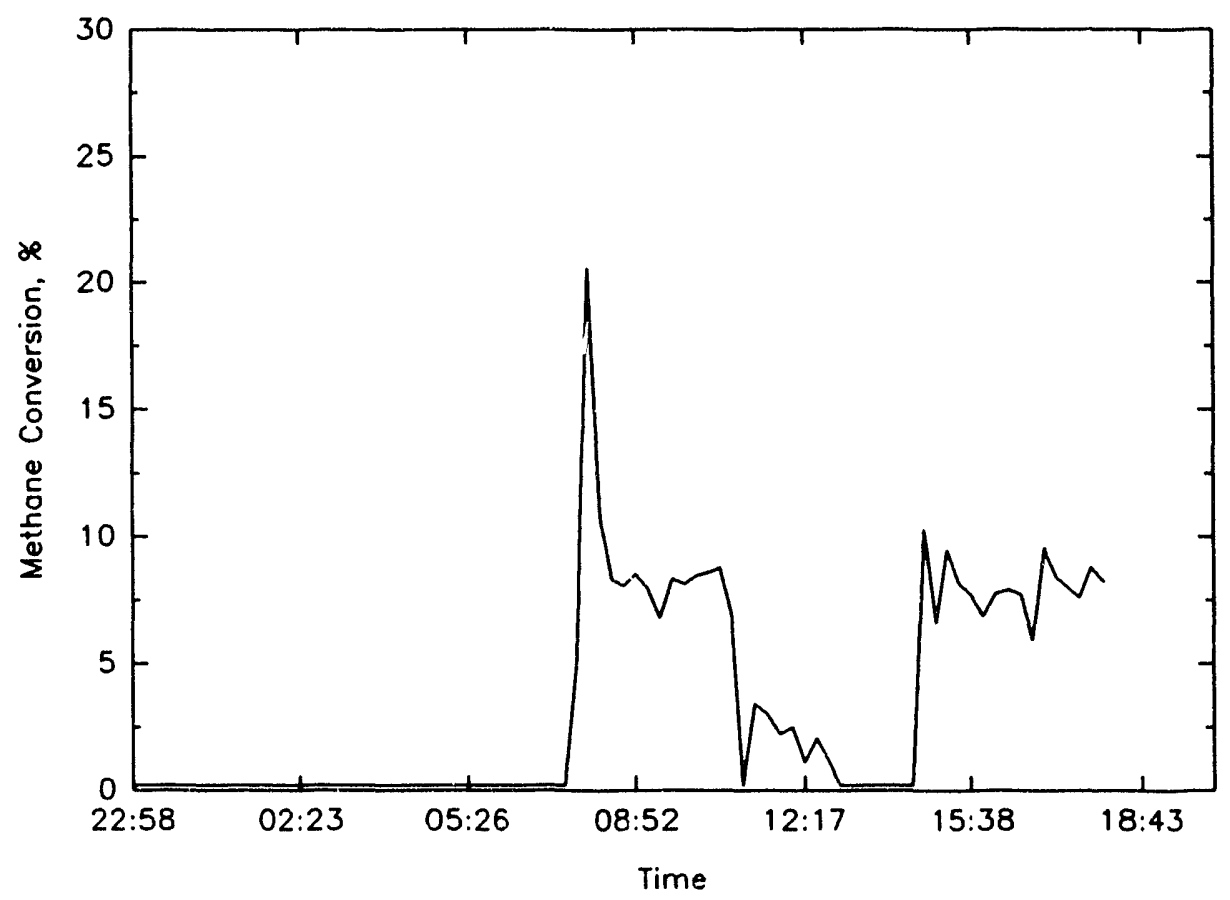

Figure 29. a) Carbon reactor gas compositions and b) carbon reactor methane conversion for Run C-7. 
PRU Run C-7, Carlon Reactor Heat Transfer Coefficients

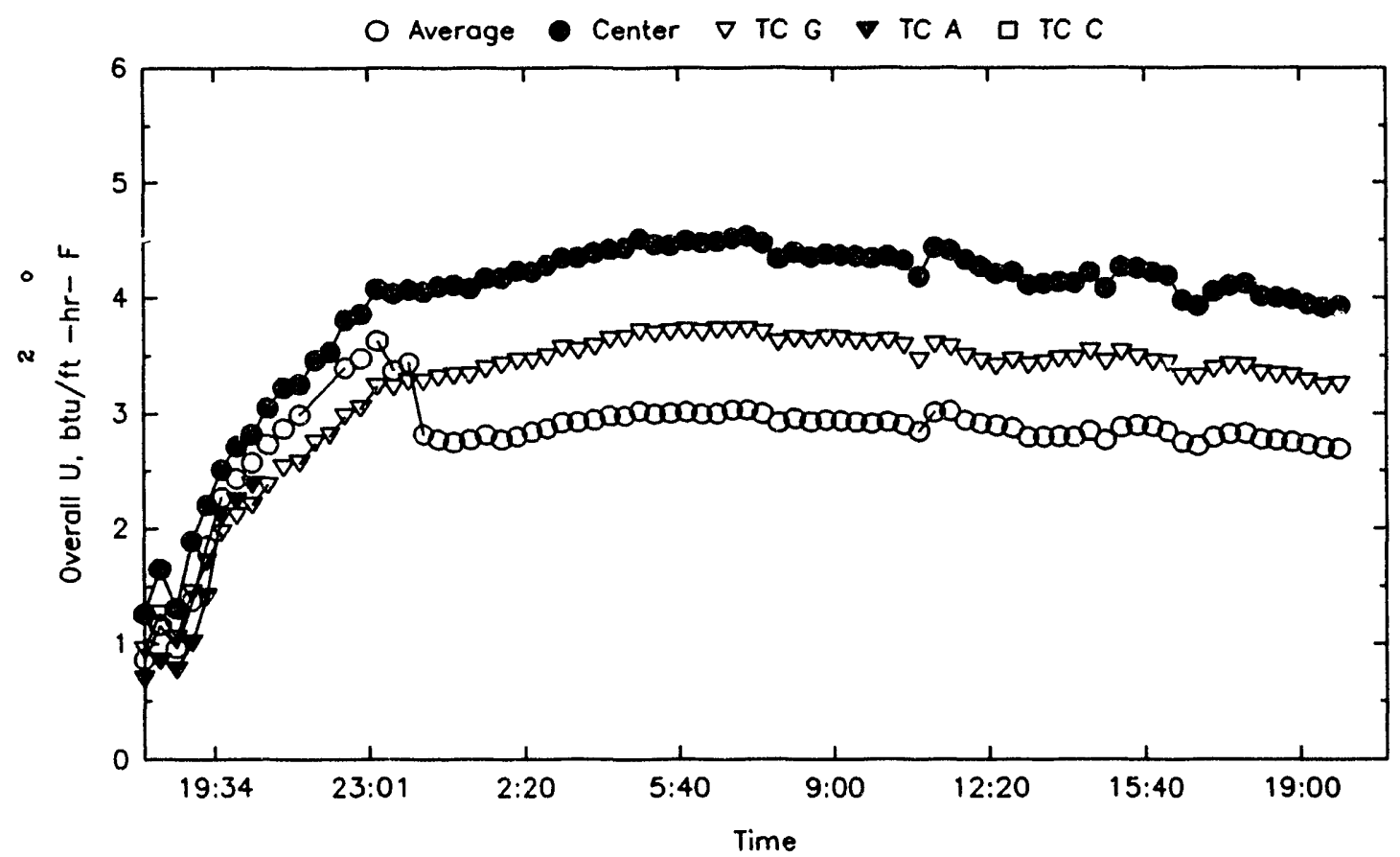

Figure 30. Overall carbon reactor heat transfer coefficients for Run C-7. 
a)

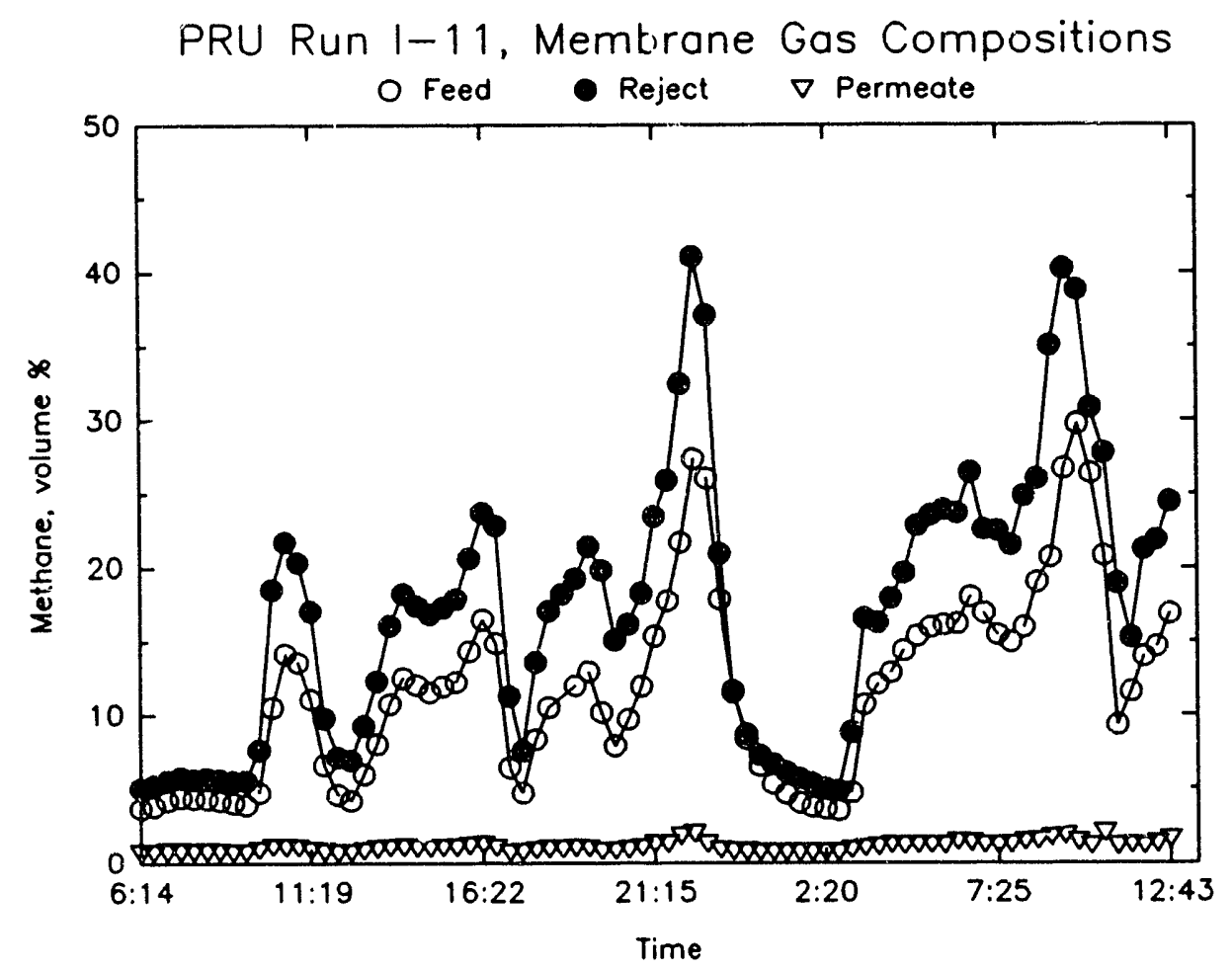

b)

PRU Run 1-11, Membrane Efficiency

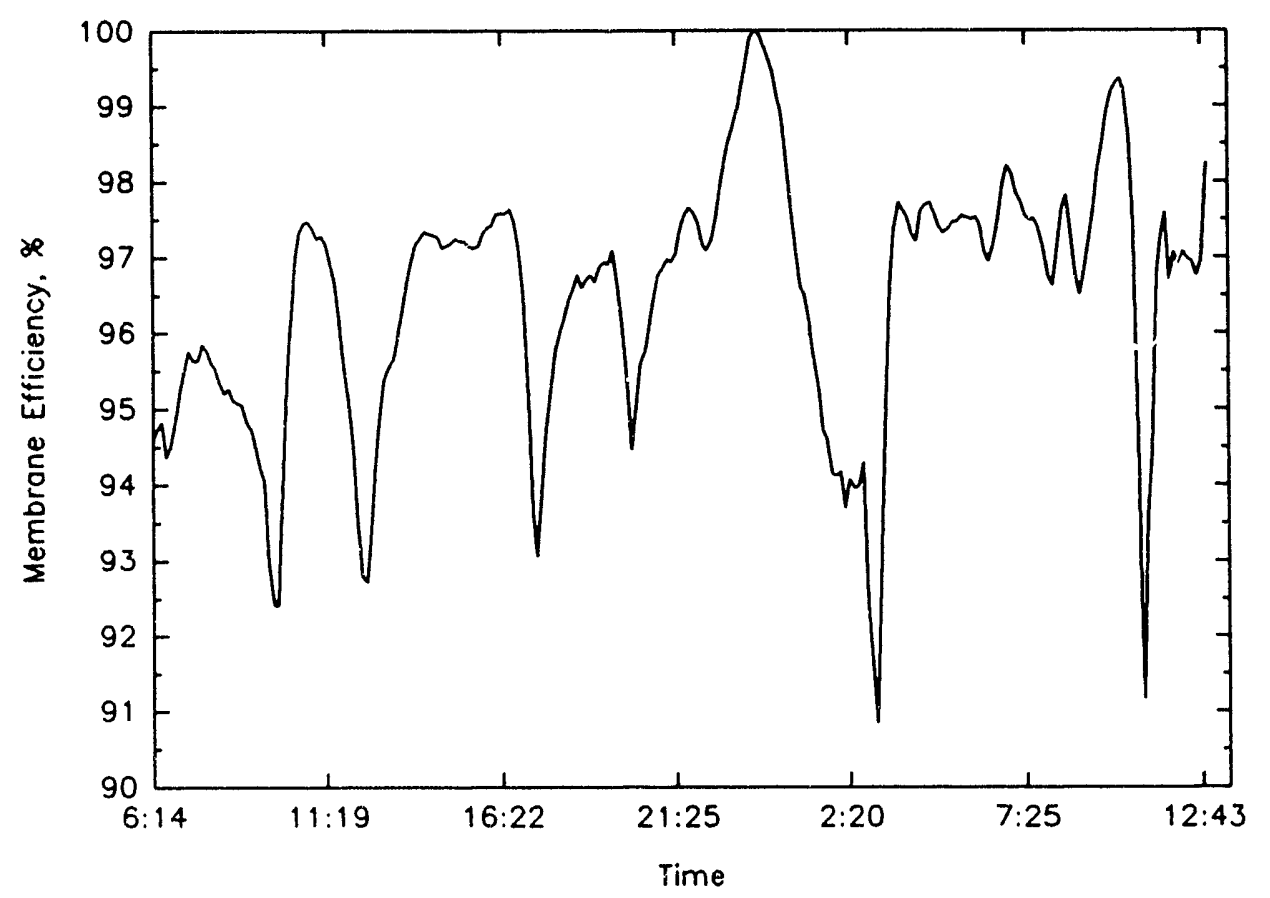

Figure 31. a) Membrane gas compositions and b) membrane efficiency for Run I11. 
We defined a membrane efficiency for methane recovery as:

$$
\text { Efficiency }=100\left(\frac{C_{F}-C_{\mathrm{P}}}{C_{\mathrm{R}}-C_{\mathrm{P}}}\right)\left(\frac{C_{\mathrm{P}}}{C_{\mathrm{F}}}\right)
$$

Where: $C_{p}=$ Methane concentration in permeate.

$\mathrm{C}_{\mathrm{F}}=$ Methane concentration in feed.

$\mathrm{C}_{\mathrm{R}}=$ Methane concentration in reject.

This efficiency is plotted as a function of time in Figure 31, part b). Comparison of the two parts of Figure 31 indicates that the highest efficiencies are obtained at the highest inlet methane concentrations. This observation was expected based on the manufacturers specifications. In general, membrane separation efficiency was very high for any reasonable operating coridition during this run.

Figure 32 shows methane reactor bed temperatures as a function of time. Thermocouple locations refer to the small diameter ( 5 inch) and large diameter (10 inch) zones, as shown in Figure 9. Results for this run indicated that a design temperature of $1,380^{\circ} \mathrm{F}$ was never achieved and that temperatures fluctuated greatly. The difference in temperature between the top and bottom of the 5 inch diameter zone suggested that mixing in the reactor was not good. Oxygen injection was not performed, which may account for failure to achieve design temperature.

The feed gas flow rate for this run is shown in Figure 33. These data indicated great variability in feed gas flow. Much of this variability was caused by the intermittent nature of char feeding and the need to stop feeding to refill the char reservoir. More rapid procedures for filling this reservoir were implemented in later runs.

Comparison of feed gas flow rates with bed temperatures suggested that the higher bed temperatures were obtained at the higher gas flow rates. Feed gas temperature was relatively constant between 1,150 and $1,200^{\circ} \mathrm{F}$. Increasing the flow rate did not appear to improve temperature uniformity in the smaller diameter zone, however.

Inlet and outlet methane concentrations for this run are shown in Figure 34. Inlet concentrations were from direct measurement. In this run, outlet methane concentration was not directly measured but was calculated from a material balance. This material balance involved several assumptions. Thus, the absolute values for outlet methane concentration reported in Figure 34 may not be totally correct. 


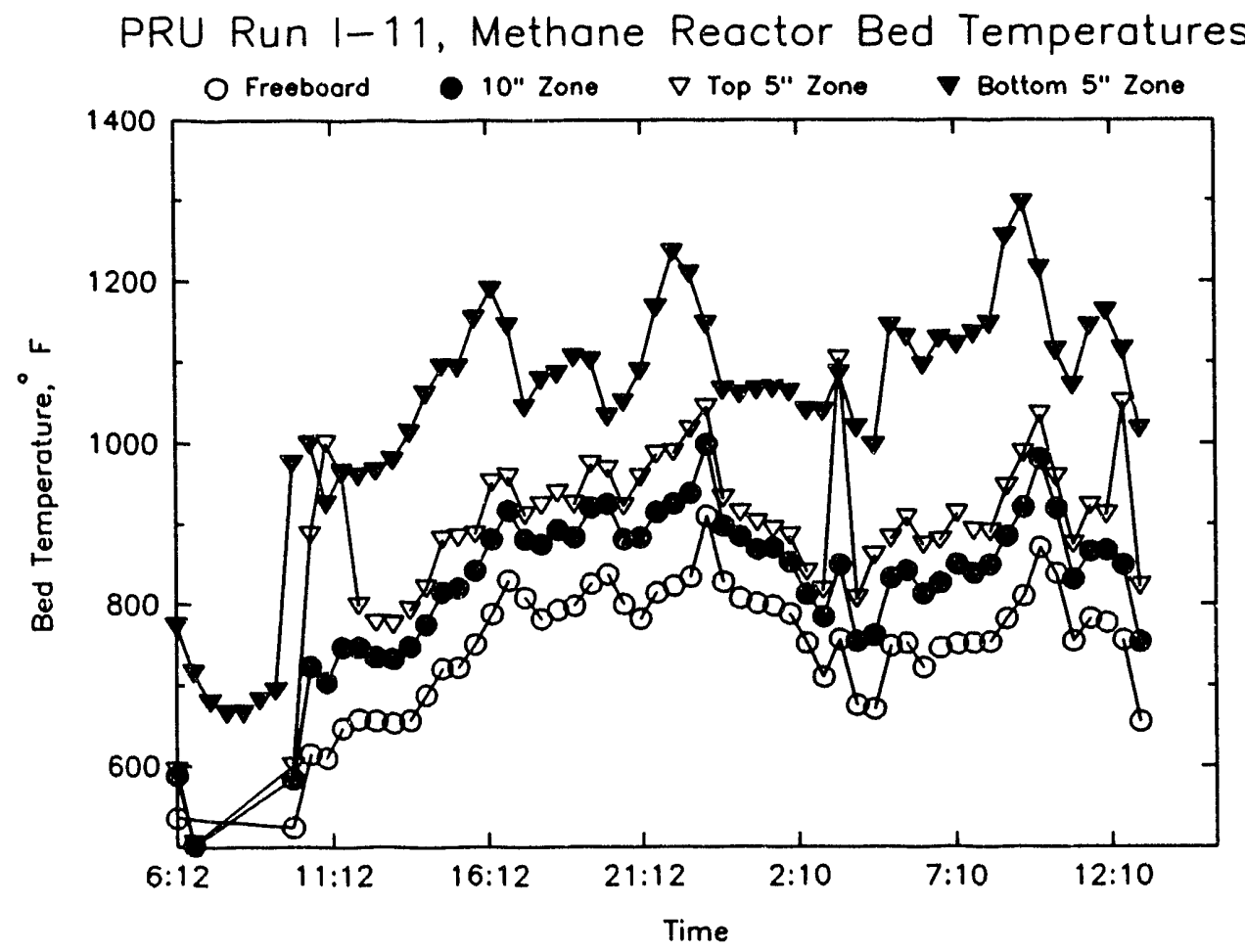

Figure 32. Methane reactor bed temperature for Run I-11.

PRU Run 1-11, Methane Reactor Feed Gas Flow Rate

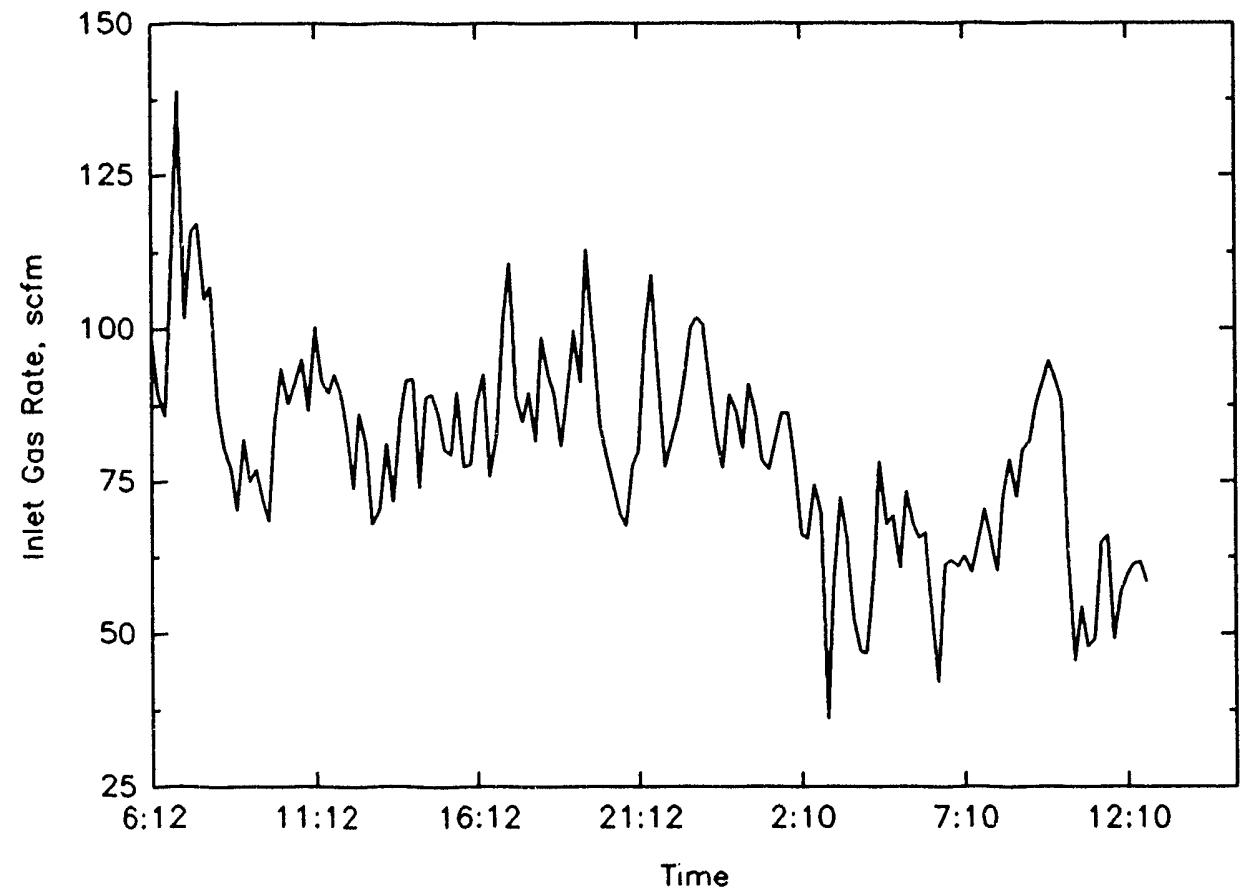

Figure 33. Methane reactor feed gas flow rate for Run $1-11$. 
However, we believe that any trend to higher or lower concentrations with conditions is real. In particular, comparison of the outlet compositions with bed temperature data (Figure 32) revealed an excellent correspondence between temperature at the bottom of the 5-inch zone and product methane concentration. All of these methane concentrations were believed to be well below the thermodynamic equilibrium level at the conditions of this run. Therefore, the reactor was operating in a reaction kinetic regime where it was not surprising that increasing temperature leads to increased rates of methane generation.

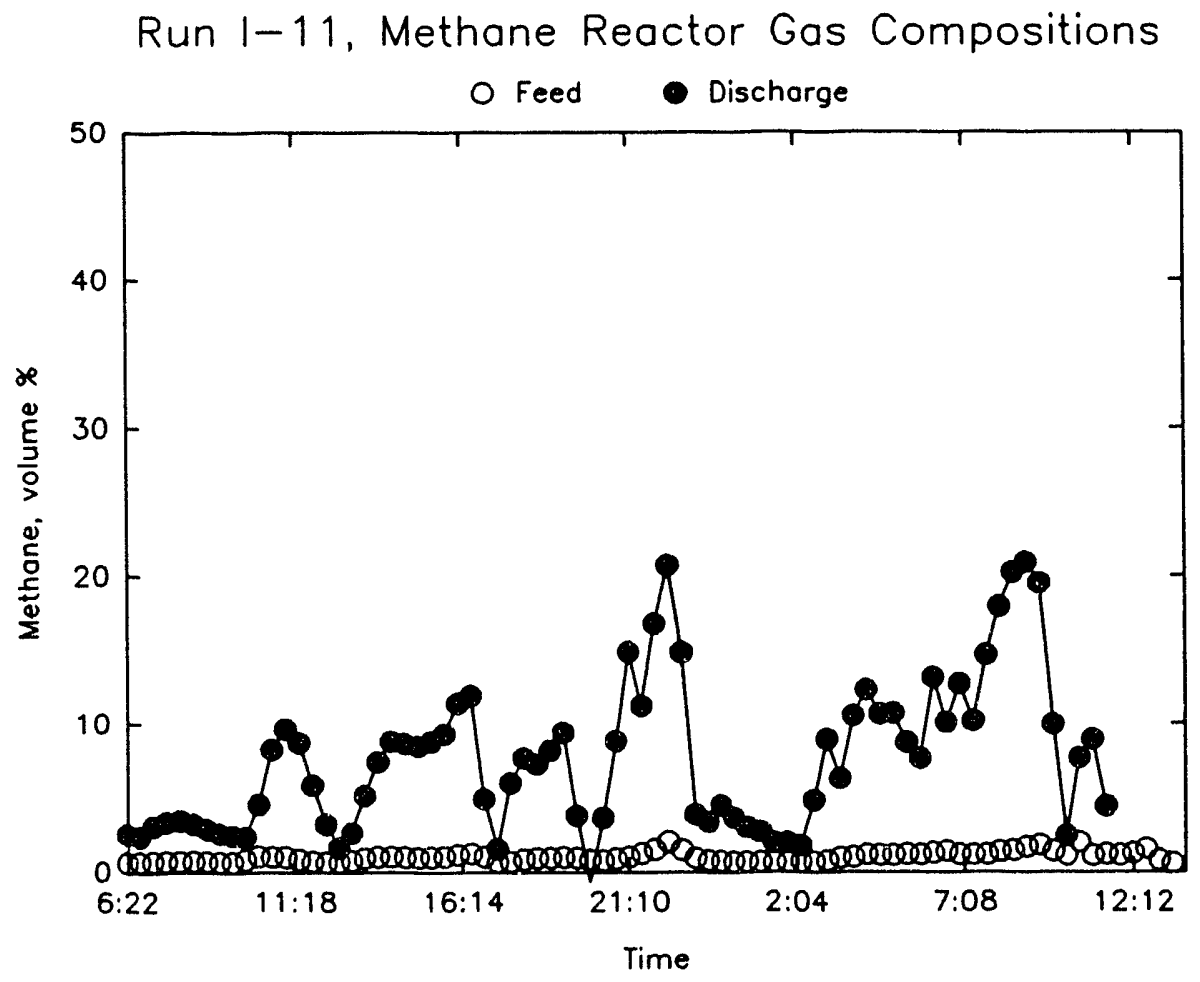

Figure 34. Methane reactor gas compositions for Run I-11.

Temperatures of some of the carbon reactor glow bars are shown in Figure 35 a). Here it can be seen that the center glow bar was not hotter than the others and, in fact, was actually cooler than one of the outer glow bars for most of the run. For the glow bars shown, and indeed for roughly half of the glow bars in the system, the maximum temperature of $2,050^{\circ} \mathrm{F}$ was not obtained.

Figure $35 \mathrm{~b}$ ) shows carbon reactor bed temperatures which are relatively stable. The temperature in the top of the bed was easily maintained at the $1,900^{\circ} \mathrm{F}$ level. Freeboard temperature and the temperature at the bottom of the bed exhibited a slow decline with time on stream. In the middle of the bed, a slow 
a)

PRU Run 1-11, Carbon Reactor Glow Bar Temperatures

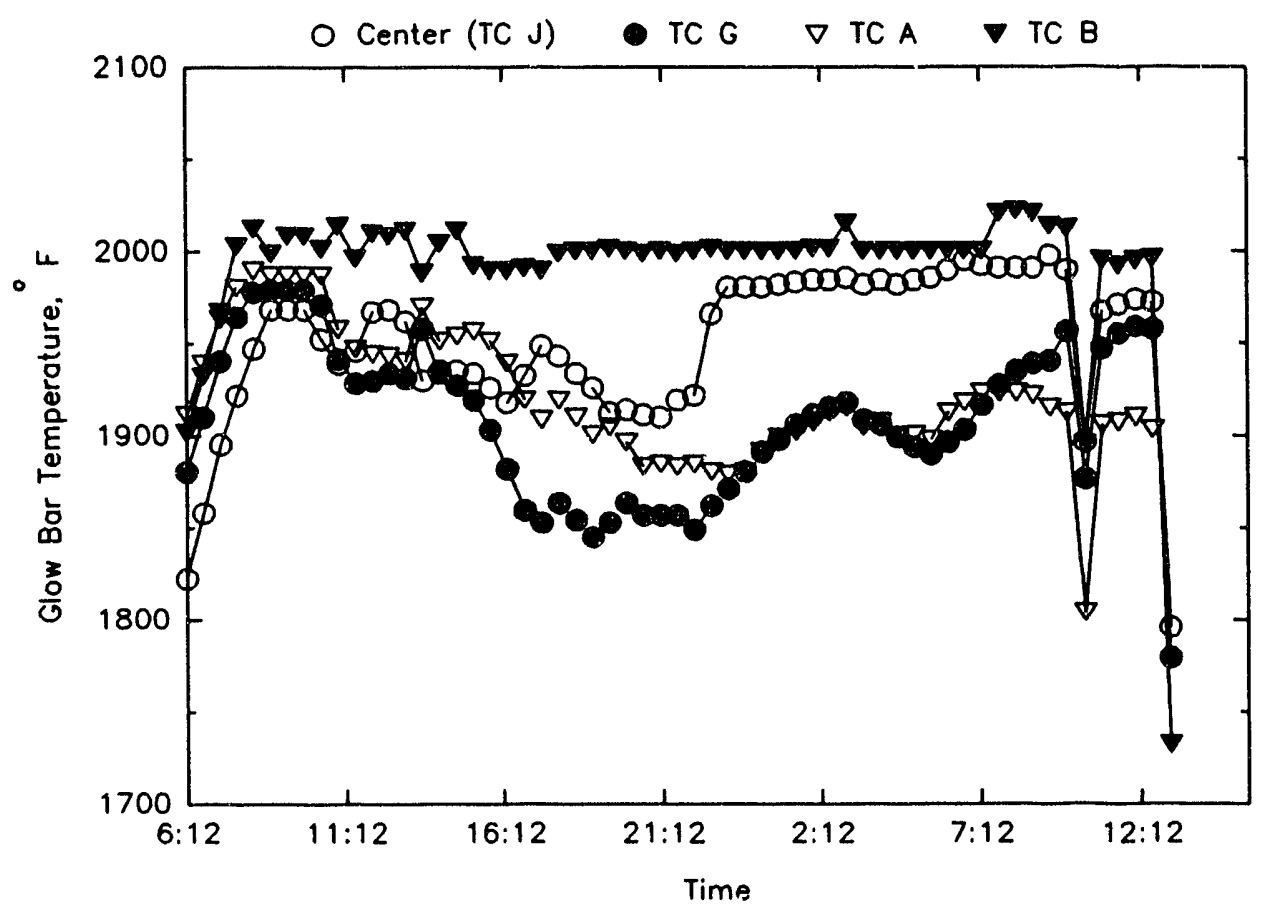

b)

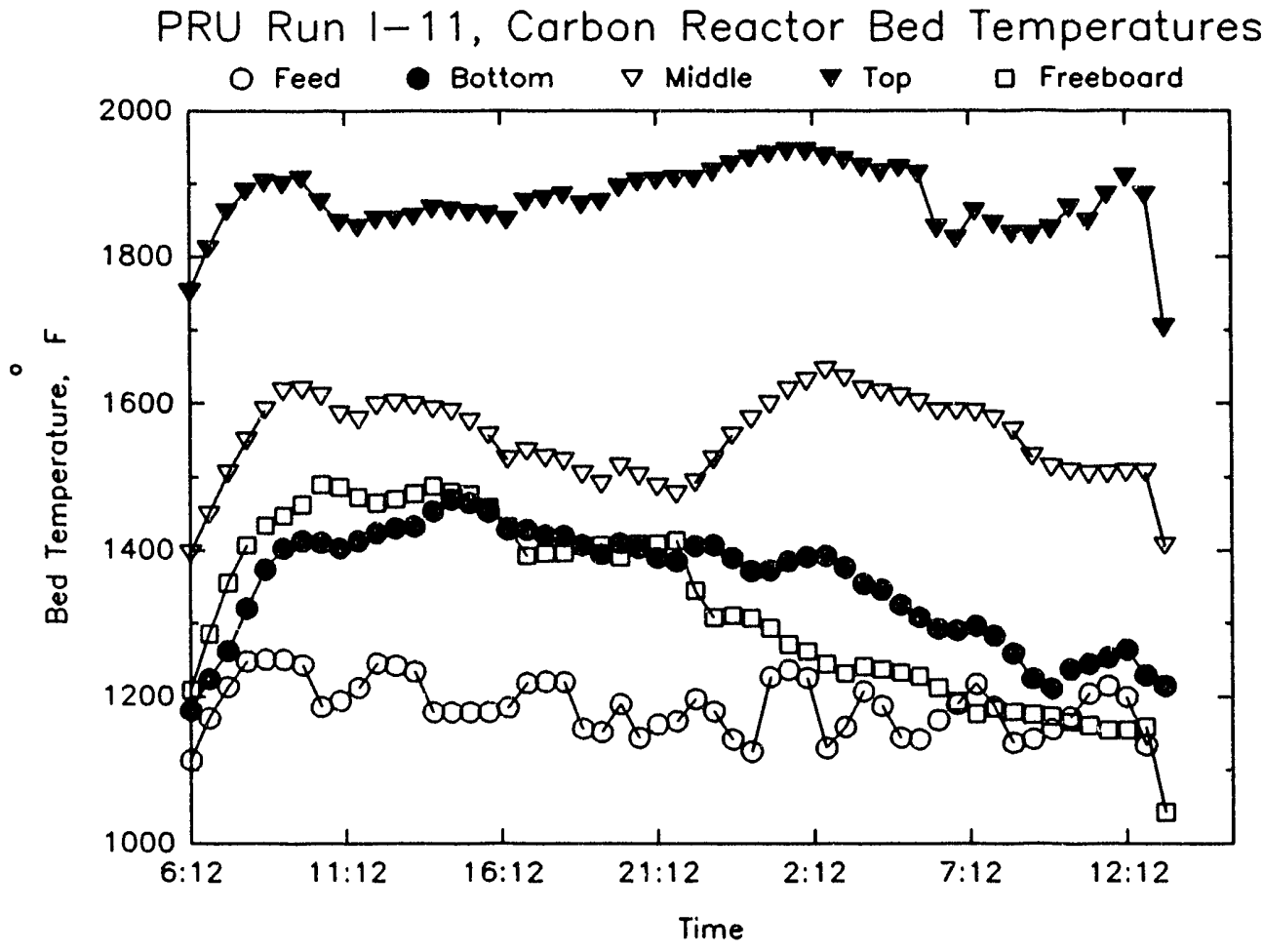

Figure 35. a) Glow bar temperatures and b) carbon reactor bed temperatures for Run I-11. 
decline started and was then reversed for several hours before beginning again. Only at the top of the bed were design temperatures achieved.

Carbon reactor flow rates for this run are shown in Figure 36. Inlet gas flow rates fluctuated considerably during this run. Comparison of flow rate data and temperatures indicated that a period of very high flow rate immediately preceded the increase in temperature noted for the middle bed thermocouple. Carbon reactor gas compositions, shown in Figure 37, also experienced considerable fluctuation. A comparison of inlet methane concentration with that leaving the methane reactor (Figure 34) revealed a reasonable correspondence. There also appeared to be some correspondence between feed gas methane content and feed gas flow rate. This suggested that most of the instability in conditions observed during this run could be traced to the methane reactor.

Inspection of the carbon reactor gas compositions also revealed some interesting results about methane conversion. Figure 37 shows the difference between the feed and discharge methane content. For this run, we took this as a crude indication of methane conversion. This change in methane content was the greatest at the highest methane contents, as might be expected. In all cases, little or no methane conversion occurred until the feed gas composition was above 20 volume percent. In our design calculations, we estimated that the equilibrium methane content under these conditions would be around 20 volume percent, so this was as expected. However, even at feed gas compositions near 40 volume percent, conversion was still quite low. This could probably be attributed to the lack of temperature uniformity in the bed of seed carbon, leading to short residence time at the desired temperature. It appeared that only a small part of the bed was hot enough to actually crack methane at an appreciable rate.

Glow bar and bed temperature data were utilized to calculate heat transfer coefficients for the carbon reactor in this run. These results are shown in Figure 38. On the average, the overall heat transfer coefficient was about $5 \mathrm{Btu} / \mathrm{ft}^{2}-\mathrm{hr}-\mathrm{F}$, similar to what was observed in previous runs. However, some of the individual glow bars had $U$ factors closer to 10 in this run. Near the end of the run (about 5:00), all heat transfer coefficients began to decline, probably because of scale formation on the heat transfer tubes and elutriation of the seed carbon material out of the bed.

Based on the plots shown above, statements can be made about overall system performance in this run. The most obvious feature of the data was the instability of flows, compositions, and temperatures. This instability was caused in part by the cyclic nature of char feeding and the need to stop feeding when refilling the pressurized feed bin. Similar instabilities were observed in the carbon reactor side of the process which was expected to be somewhat shielded from these effects. 
PRU Run 1-11, Carbon Reactor Feed Gas Flow Rate

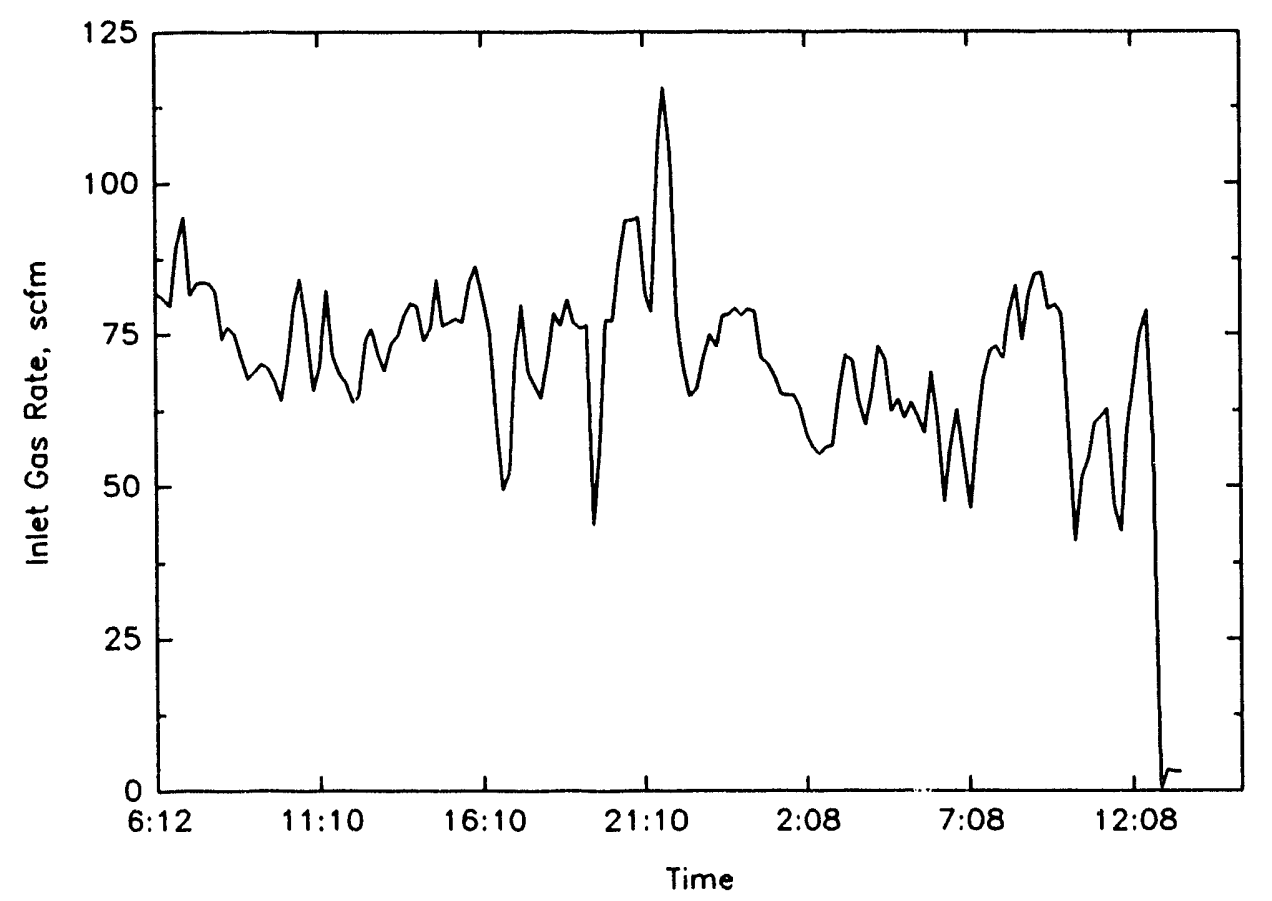

Figure 36. Carbon reactor feed gas flow rate for Run $1-11$.

PRU Run 1-11, Carbon Reactor Gas Compositions

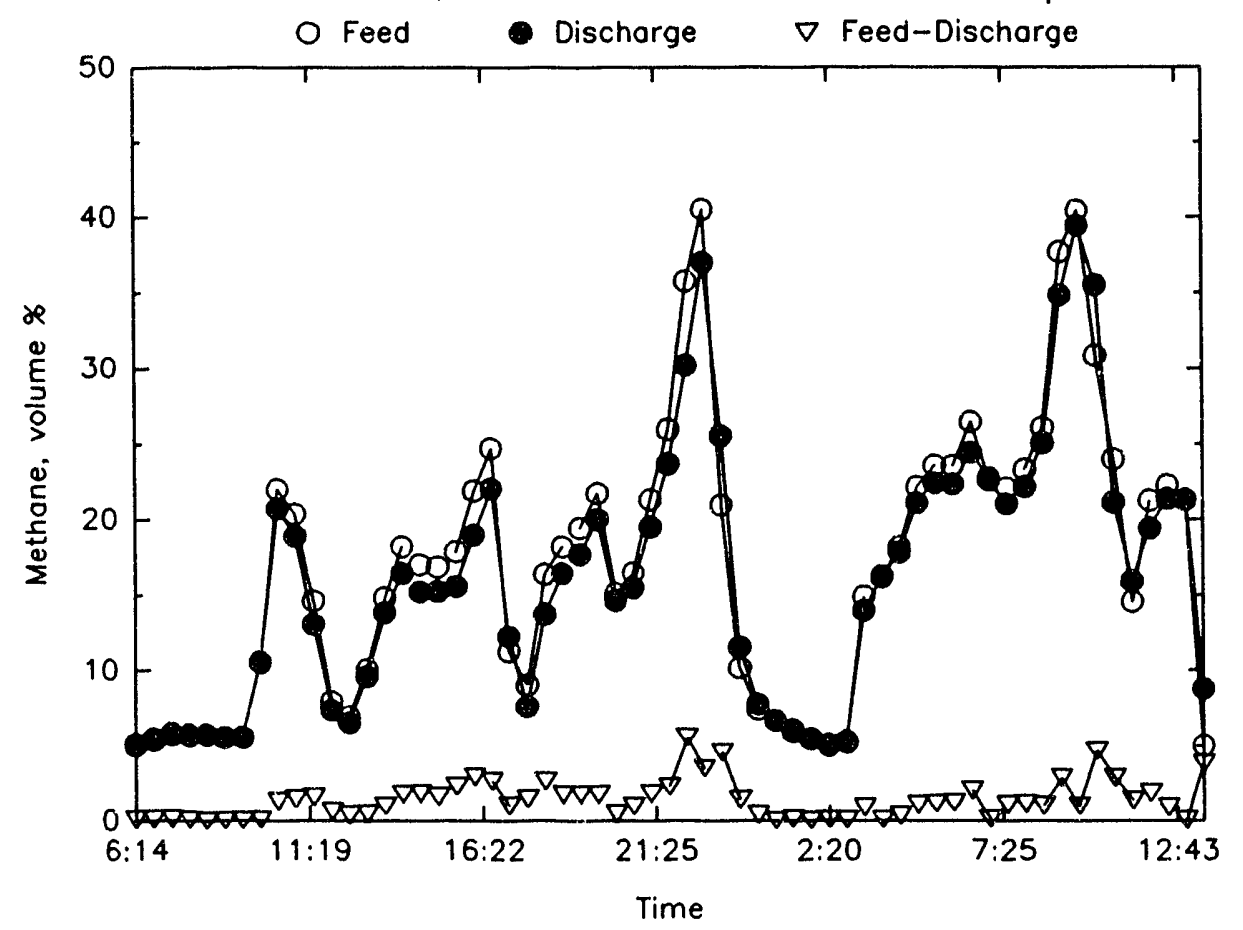

Figure 37. Carbon reactor gas compositions for Run I-11. 


\section{PRU Run 1-11, Carbon Reactor Heat Transfer Coefficients}

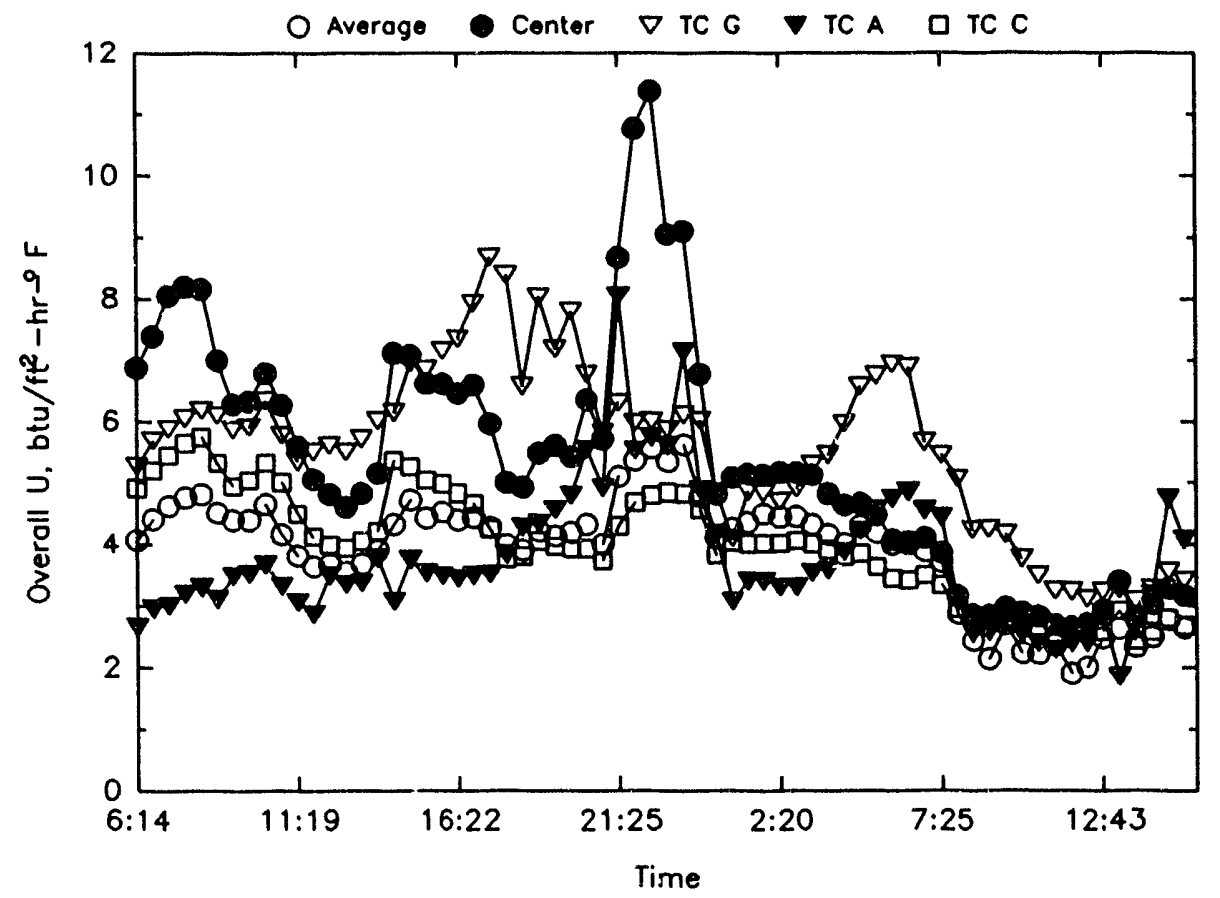

Figure 38. Overall carbon reactor heat transfer coefficients for Run I-11.

\section{Run M-10 Results}

In this run, the methanation reactor was run independently using bottled hydrogen and recycled hydrogen recovered with the membrane. Conditions were varied systematically to obtain valuable data on system performance. The test conditions employed were shown in Table 4. In addition to these tests, char was left in the reactor at the final conditions for more than 1 hour at the end of the run. This final char was expected to provide an indication of the properties of highly converted char. The duration of this run was approximately 48 hours. The methanation unit feed system had been modified to allow more rapid refilling of the feed bin. Bed level was controlled by a bed overflow. This bed overflow controlled bed level at a point substantialiy below our original design, resulting in a reduction in bed volume. These changes resulted in improved flow stability, as will be shown.

Figure 39 shows data relevant to membrane performance in this run. Membrane gas compositions are shown in part a) and indicated that the permeate contained substantially higher levels of methane than in Run I-11 (compared with Figure 31). Membrane separation efficiency is plotted in Figure $39 \mathrm{~b}$ ). This figure indicated no degradation in membrane performance, suggesting that the higher 
a)

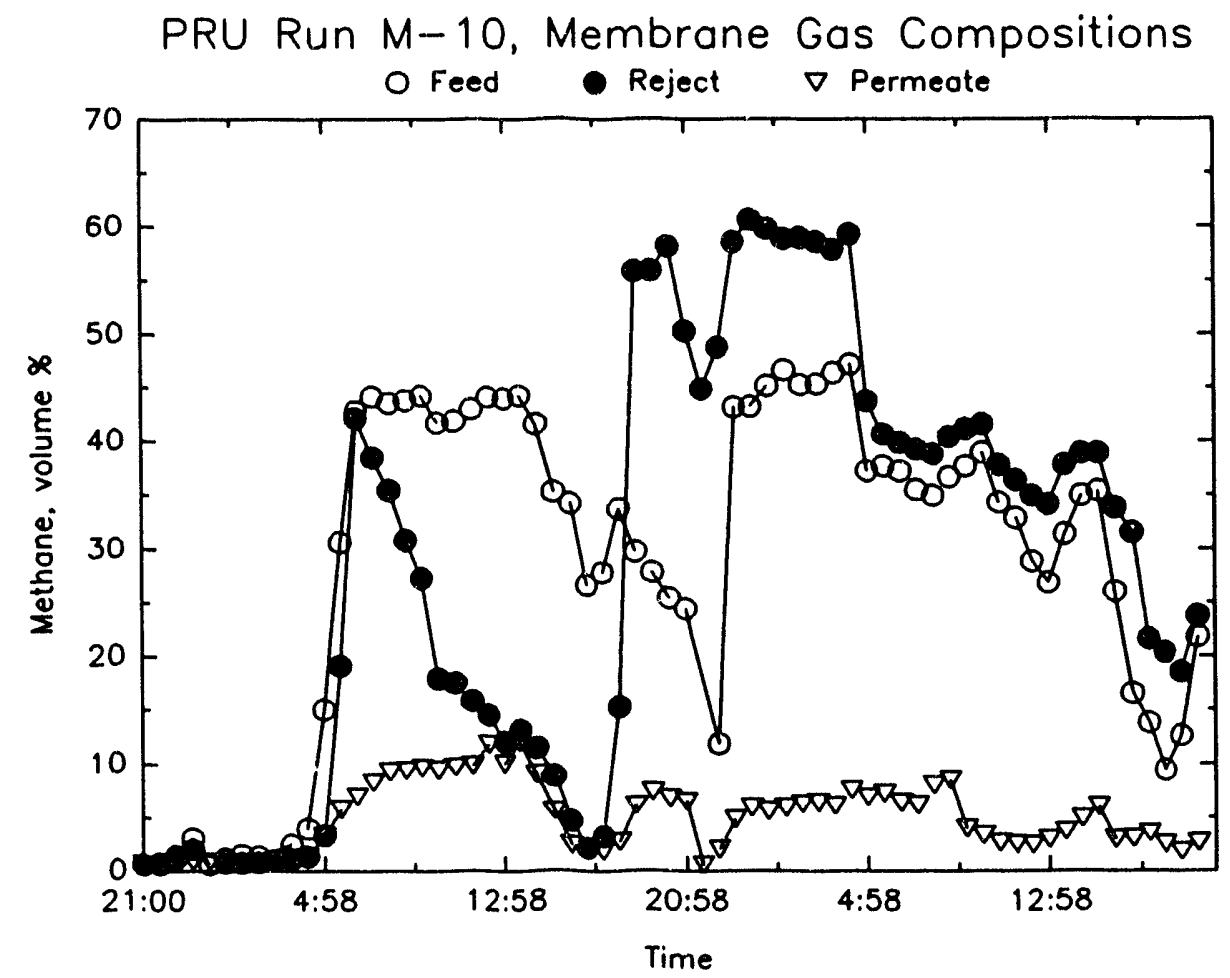

b)

PRU Run M-10, Membrane Efficiency

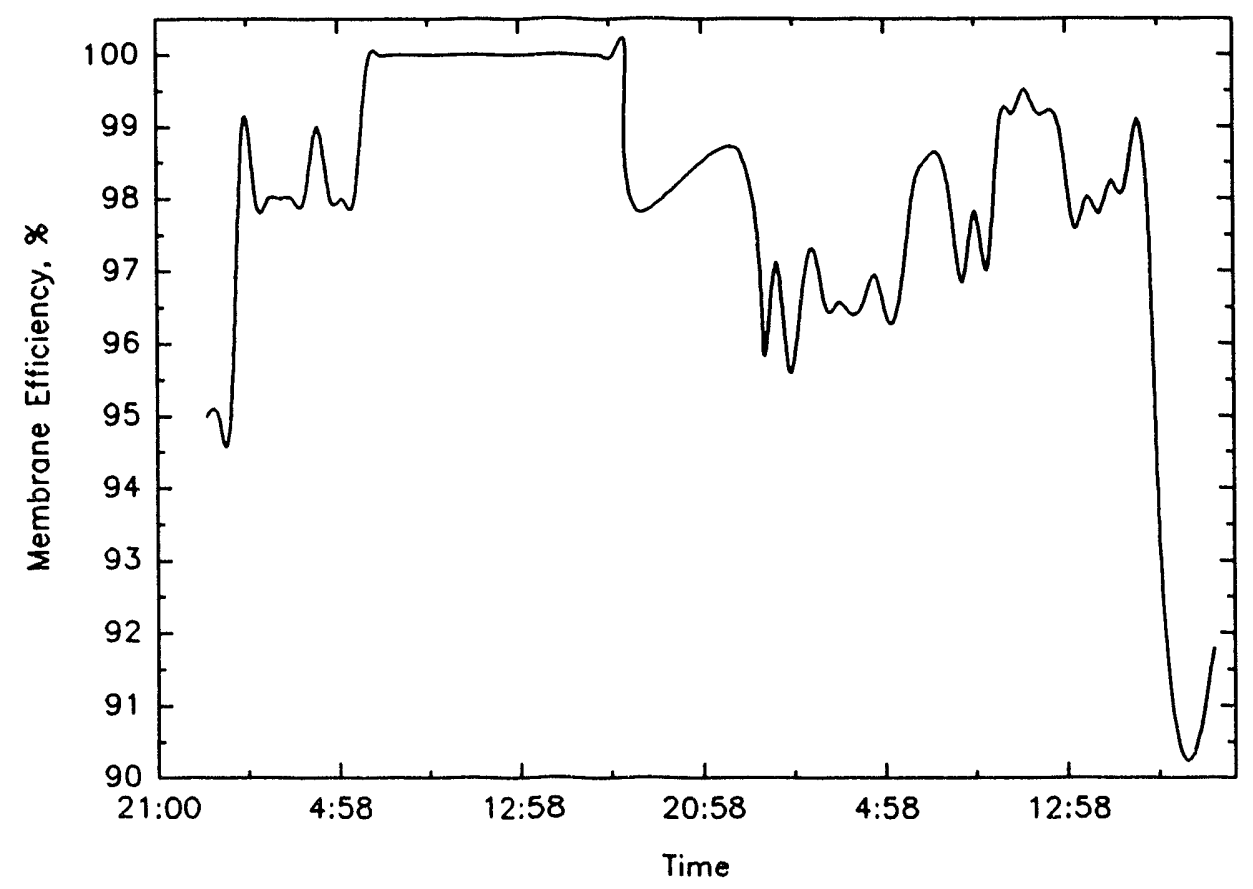

Figure 39. a) Membrane gas composition and b) membrane efficiency for Run M10. 
methane content of the permeate in Run $M-10$ was caused by the higher feed gas methane content relative to Run 1-11. In any case, membrane performance was completely adequate throughout the run.

The bed temperatures for this run are shown in Figure 40. Temperatures in the bottom of the bed rapidly increased to the desired level of around $1,400^{\circ} \mathrm{F}$ upon oxygen injection. Other temperatures increased much more slowly, and it seemed likely that the unit was not thermally lined out during test period No. 1. In any case, the distribution of temperature in the 5-inch zone suggested that fluidization was not particularly good so that cold feed char cooled the top of the bed, while hot inlet gas and oxygen injection heated the bottom of the bed.

Feed gas flow rate is shown in Figure 41. Comparison of this figure with Figure 33 from run $1-11$ showed that a substantial increase in flow stability was obtained by removing the J-valve and shortening the feed bin refilling time. Flows were relatively constant for test periods 1,2 , and 4 , with minor upsets occurring in periods 3 and 5 . Comparison of flow data and temperatures indicated that at the higher flows, temperatures in the top 5 -inch zone were higher, suggesting better mixing of the bed.

Figure 42 a) shows inlet and outlet gas methane content for this run. These values fluctuated considerably, and we believe that this was caused by the intermittent nature of char feeding. Inlet methane content was also higher than observed previously during run $1-11$. This figure also shows the inlet and outlet carbon monoxide concentrations. Carbon monoxide was formed by reaction of the char with oxygen injected to heat the reactor.

The gas flow rate and composition data was used to perform a material balance on the reactor and predict char carbon conversion. These values are shown in Figure 42 b). We saw great deal of fluctuation in these values which corresponded fairly well with the variation in outlet gas composition.

Spent char samples were collected at several times during each test period. Char analyses typical of each test period are shown in Table 6. Based on analyses of the feed and spent chars, a second value for carbon conversion was calculated. These values are also plotted in Figure 42 b). Agreement between the time averaged values from char analysis and the point values from gas analysis was not particularly good. To obtain more comparable numbers, average parameter values for each test period were computed and these are listed in Table 7. These values were then used to calculate a char carbon conversion using a carbon material balance equation which assumes no change in flow rate with gas conversion.

$$
X_{c}=Q_{\text {acfm }} C_{\text {total }}\left(y_{o}-y_{i}\right) \frac{12}{F_{\text {carbon }}}
$$


PRU Run M-10, Methane Reactor Bed Temperatures

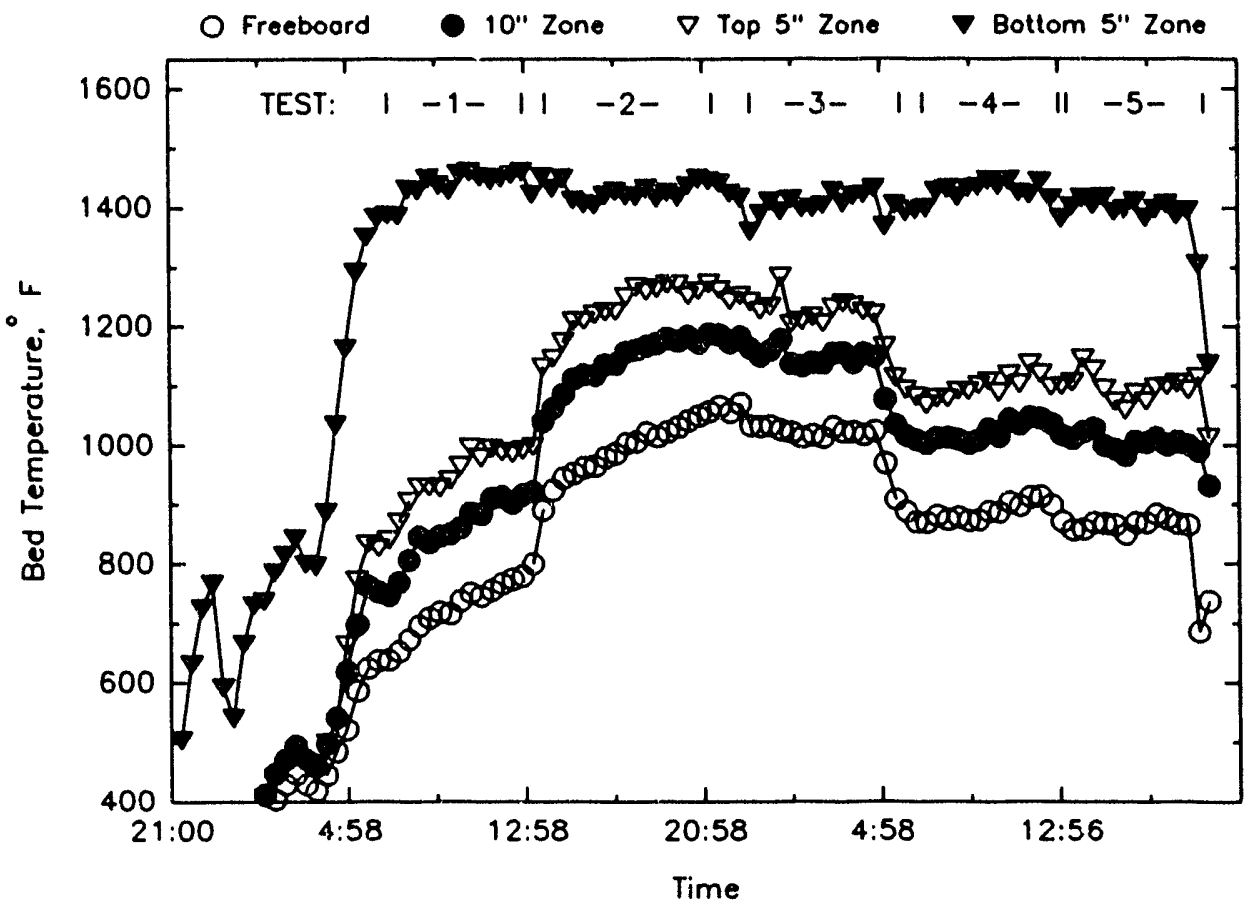

Figure 40. Methane reactor bed temperature for Run M-10.

PRU Run M-10, Methane Reactor Feed Gas Flow Rate

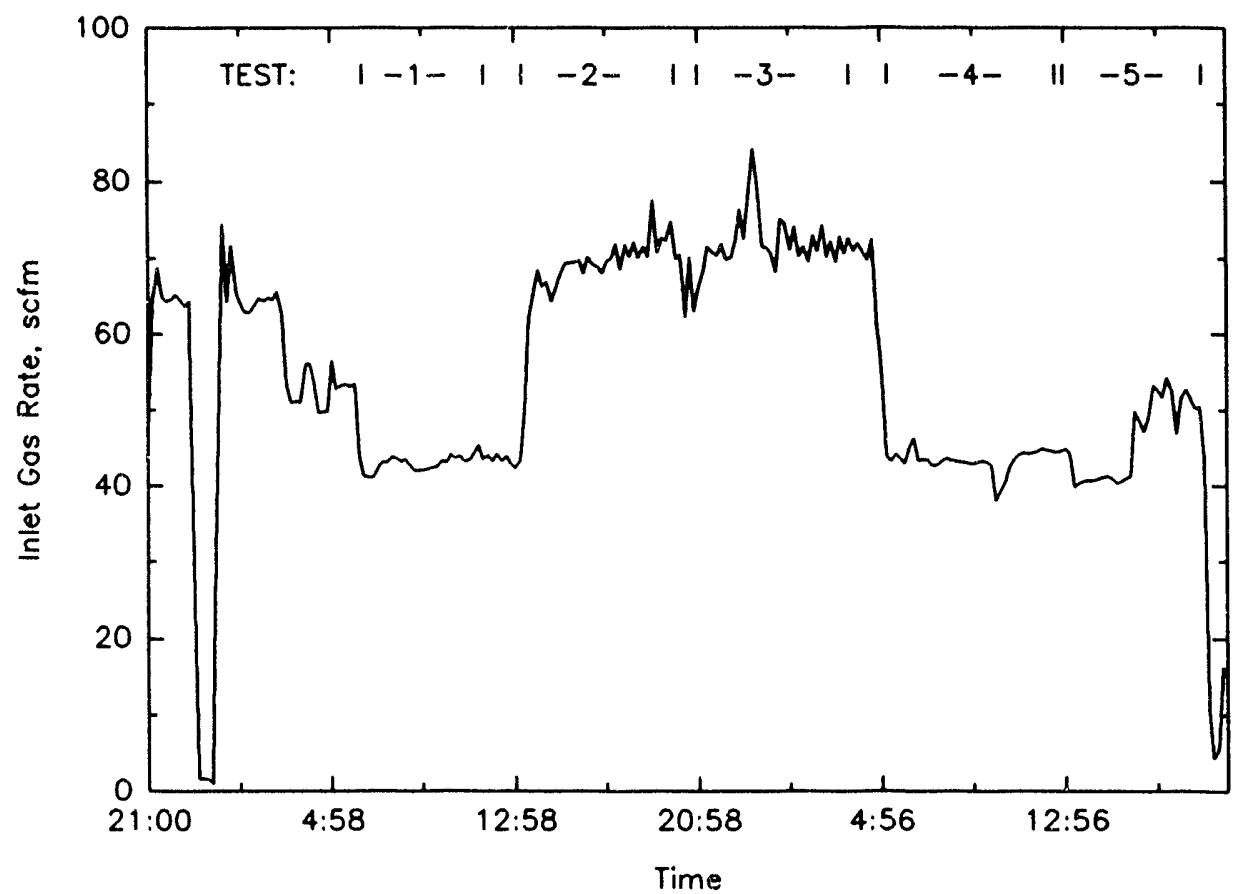

Figure 41. Methane reactor feed gas flow rate for Run M-10. 
a)

PRU Run $\mathrm{M}-10$, Methane Reactor Gas Compositions

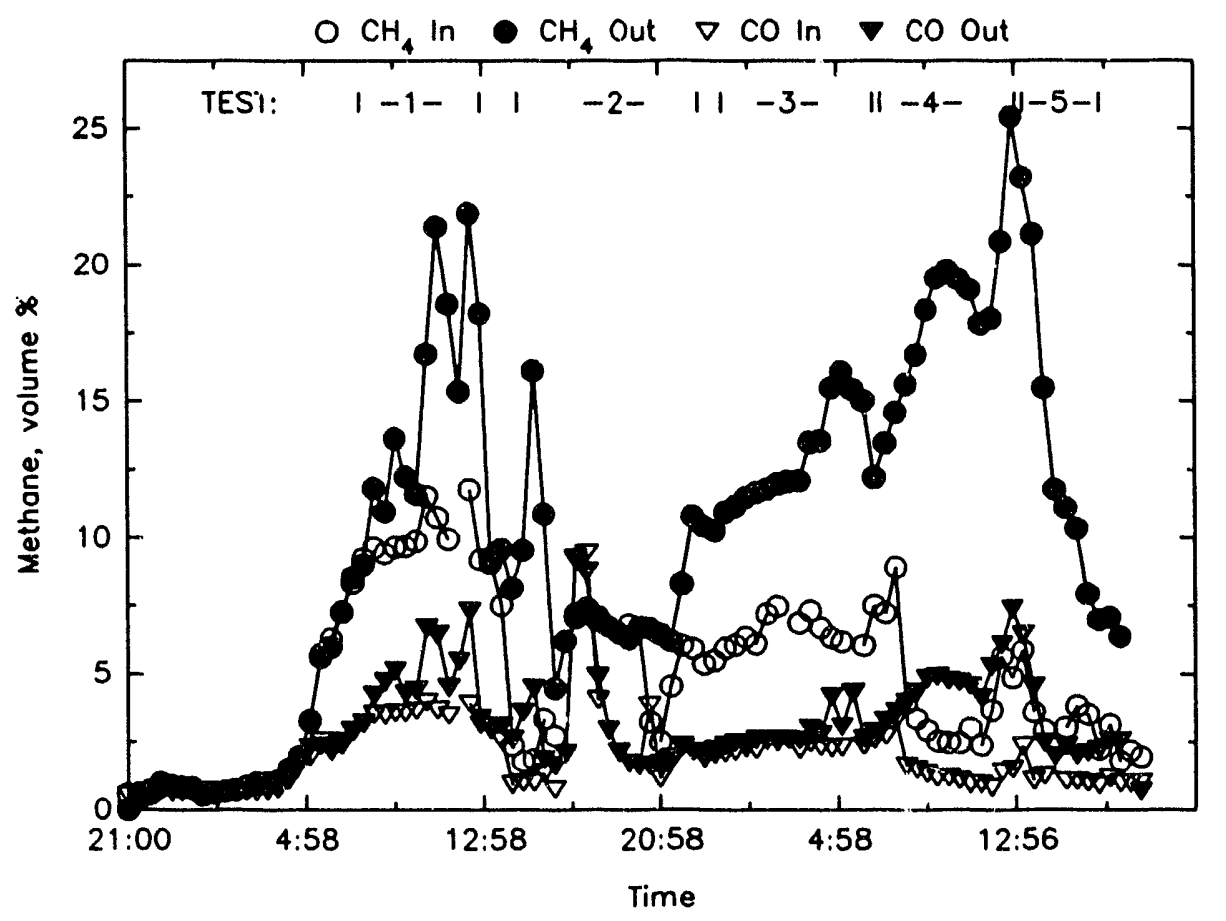

b)

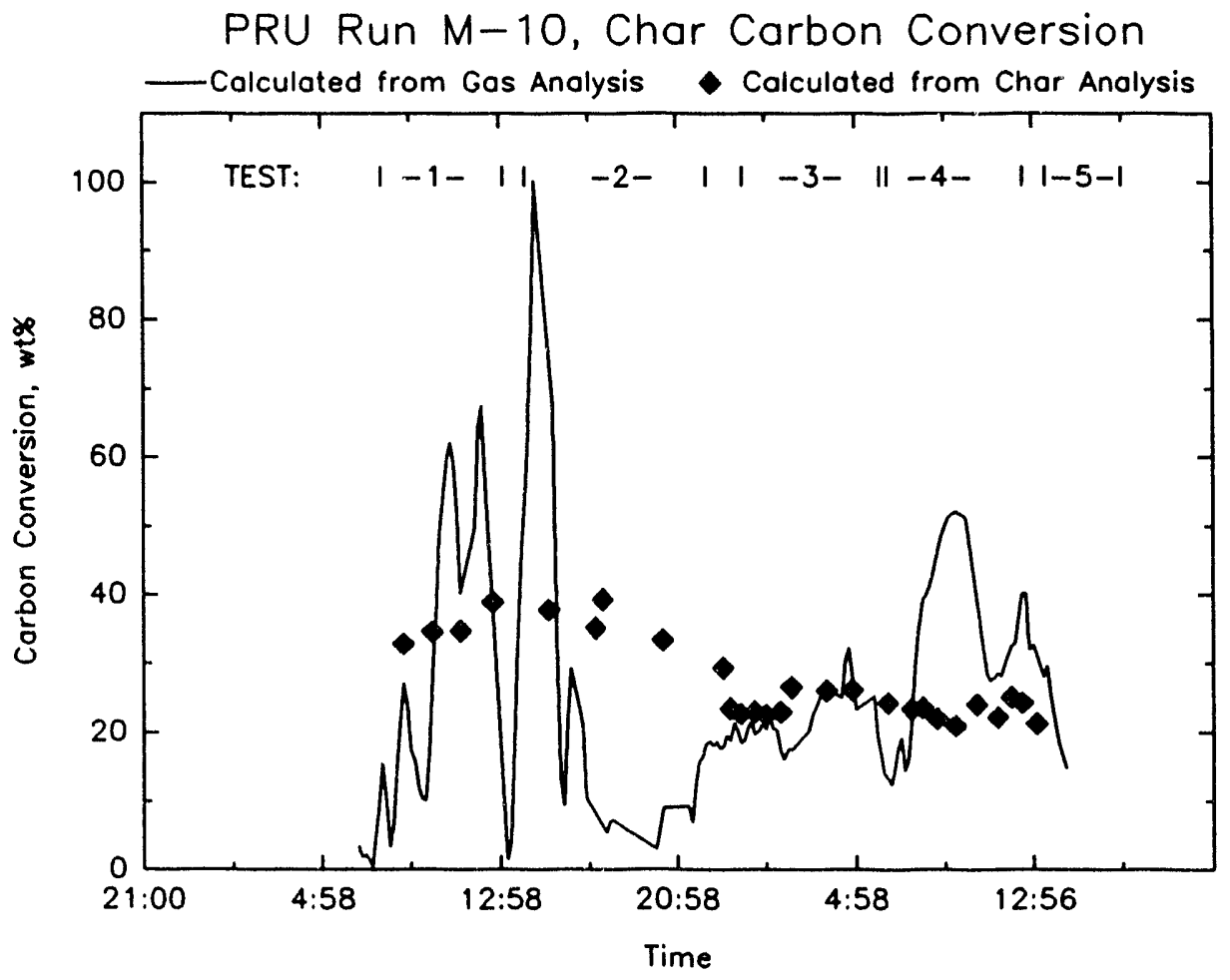

Figure $42 . \quad$ a) Methane reactor gas compositions and b) char carbon conversions for Run $\mathrm{M}-10$. 
Where: $X_{c}=$ Weight \% carbon conversion.

$\mathrm{Q}_{\mathrm{acfm}}=$ Volumetric gas flow rate at conditions.

$\mathrm{C}_{\text {total }}=$ Gas concentration ( $\left(\mathrm{b}\right.$ mole/ $/ \mathrm{ft}^{3}$ ).

$\mathrm{y}_{\mathrm{i}} \quad=$ Inlet methane mole fraction.

$y_{0}=$ Outlet methane mole fraction.

$\mathrm{F}_{\text {carbon }}=$ Carbon feed rate to reactor.

The average value of carbon conversion from char analysis is also listed in Table 7. Here agreement was improved but was still not good. For the first three test periods, conversion from char analysis was higher than conversion from material balance, while the reverse was true for the last two tests. There was no obvious change in test parameters that could account for this, and it seemed likely that this discrepancy could be traced to the intermittent nature of char feeding and failure to sample the spent char with great enough frequency. Also, we had no independent measurement of the char feed rate, so the char feed rates used in the material balance calculation were based on the original calibration of the feeder. While this calibration was thought to be fairly good, it may be that it was not accurate enough for inclusion in material balance calculations of this type.

The conversion of the final char sample is also seen to be low. This probably reflects the fact that the reactor contained dead zones which were at substantially lower temperature than the relatively well fluidized 5-inch zone. While portions of the char may have been highly converted, on average the conversion is low because of the cooler dead zones.

Table 6. Analytical Data for Spent Chars from Run M-10

\begin{tabular}{|c|c|c|c|c|c|c|}
\hline & & & Test & & & \\
\hline & 1 & 2 & 3 & 4 & 5 & Final \\
\hline Proximate, Weight 9 & & & & & & \\
\hline Moisture & 1.49 & 1.56 & 1.63 & 1.87 & 1.74 & $<0.1$ \\
\hline Volatile (Dry) & 6.42 & 5.28 & 7.71 & 5.69 & 7.09 & 4.50 \\
\hline Fixed Carbon (Dry) & 79.03 & 80.54 & 79.91 & 81.91 & 80.67 & 82.35 \\
\hline Ash (Dry) & 14.55 & 14.18 & 12.38 & $12 \% 0$ & 12.24 & 13.15 \\
\hline Ultimate, Weight \% & & & & & & \\
\hline Carbon & 97.03 & 96.53 & 96.64 & 96.87 & 96.59 & 96.55 \\
\hline Hydrogen & 0.82 & 0.94 & 1.29 & 1.06 & 1.24 & 1.25 \\
\hline Sulfur & 0.74 & 0.71 & 0.67 & 0.63 & 0.60 & 0.61 \\
\hline Nitrogen & 0.67 & 0.81 & 0.82 & 0.82 & 0.77 & 070 \\
\hline Oxygen & 0.76 & 1.01 & 0.89 & 0.64 & 0.79 & 0.90 \\
\hline
\end{tabular}


Table 7. Average Values of Carbon Conversion for Run M-10

\begin{tabular}{|c|c|c|c|c|c|c|c|c|}
\hline \multirow[b]{3}{*}{ Test } & \multirow{3}{*}{$\begin{array}{c}\text { Inlet Gas } \\
\text { Rate, } \\
\text { scfm } \\
\end{array}$} & \multirow{3}{*}{$\begin{array}{l}\text { Temperature } \\
\text { Mean, }{ }^{\circ} \mathrm{F}\end{array}$} & \multicolumn{4}{|c|}{ Mean Gas Analysis } & \multicolumn{2}{|c|}{ Carbon Conversion } \\
\hline & & & \multicolumn{2}{|c|}{$\%$ inlet } & \multicolumn{2}{|c|}{$\%$ Outlet } & \multirow{2}{*}{$\begin{array}{l}\text { Material } \\
\text { Balance }\end{array}$} & \multirow{2}{*}{$\begin{array}{c}\text { Char } \\
\text { Analysis }\end{array}$} \\
\hline & & & $\mathrm{CH}_{4}$ & $\underline{\mathrm{CO}}$ & $\underline{\mathrm{CH}}_{4}$ & $\underline{\mathrm{CO}}$ & & \\
\hline 1 & 43.3 & 1,443 & 10.0 & 3.5 & 14.0 & 4.7 & 25.4 & 35.3 \\
\hline 2 & 69.5 & 1,425 & 5.2 & 3.1 & 8.1 & 3.6 & 26.4 & 36.4 \\
\hline 3 & 66.3 & 1,403 & 6.3 & 2.2 & 11.1 & 2.4 & 18.8 & 24.0 \\
\hline 4 & 43.2 & 1,428 & 5.2 & 2.0 & 16.1 & 3.9 & 31.7 & 23.8 \\
\hline 5 & 41.4 & 1,402 & 4.1 & 1.4 & 19.8 & 5.0 & 29.4 & 23.2 \\
\hline Final & 41.4 & 1,402 & -- & -- & -- & -- & -- & 28.0 \\
\hline
\end{tabular}

\section{PRODUCT CHARACTERIZATION RESULTS}

This work was directed at analysis of seed carbon taken from the carbon reactor after run C-8 to determine if deposition of carbon onto the seed particles was occurring. Also, the carbon product produced in run C-7 was characterized. These results indicated that much of the material collected in the baghouse was Desulco mixed with fine carbon product which was contaminated by metal particles from erosion of the heat transfer surface. The properties of pyrolytic carbon which formed on the heat transfer surfaces in the carbon formation reactor are also described.

\section{Growth of Seed Carbon}

Particle size analysis results for both the original seed carbon and seed carbon withdrawn from the reactor are shown in Figure 43. It is apparent that the seed material is quite a bit larger than when it was put into the reactor. The material removed from the reactor contained virtiailly no particles smaller than 140 mesh. The particle size increase could be caused by elutriation of fines from the reactor, by particle growth, or both. Because very fine Desulco particles were always collected in the baghouse, it was certain that fines elutriation was occurring. Optical microscopy of the seed carbon particles was utilized to determine whether or not particle growth had occurred.

Photomicrographs of both original seed and seed removed from the reactor are shown in Figure 44. These low magnification images show that the used particles have changed dramatically. It is possible that carbon has deposited on the surface, causing particle growth and formation of a smooth, highly reflective surface. Another possibility is that abrasion in the fluid bed has resulted in the roundec, polished surfaces. To further resolve this question, the particles were cast in an epoxy resin, cut in half, and polished. The cross sections were then imaged in both optical and electron microscopes. Photomicrographs are shown in Figure 45. These pictures clearly show the formation of a coating on the seed carbon 
particle surface. X-ray mapping using the SEM/EDX system indicated that the coating was essentially pure carbon.

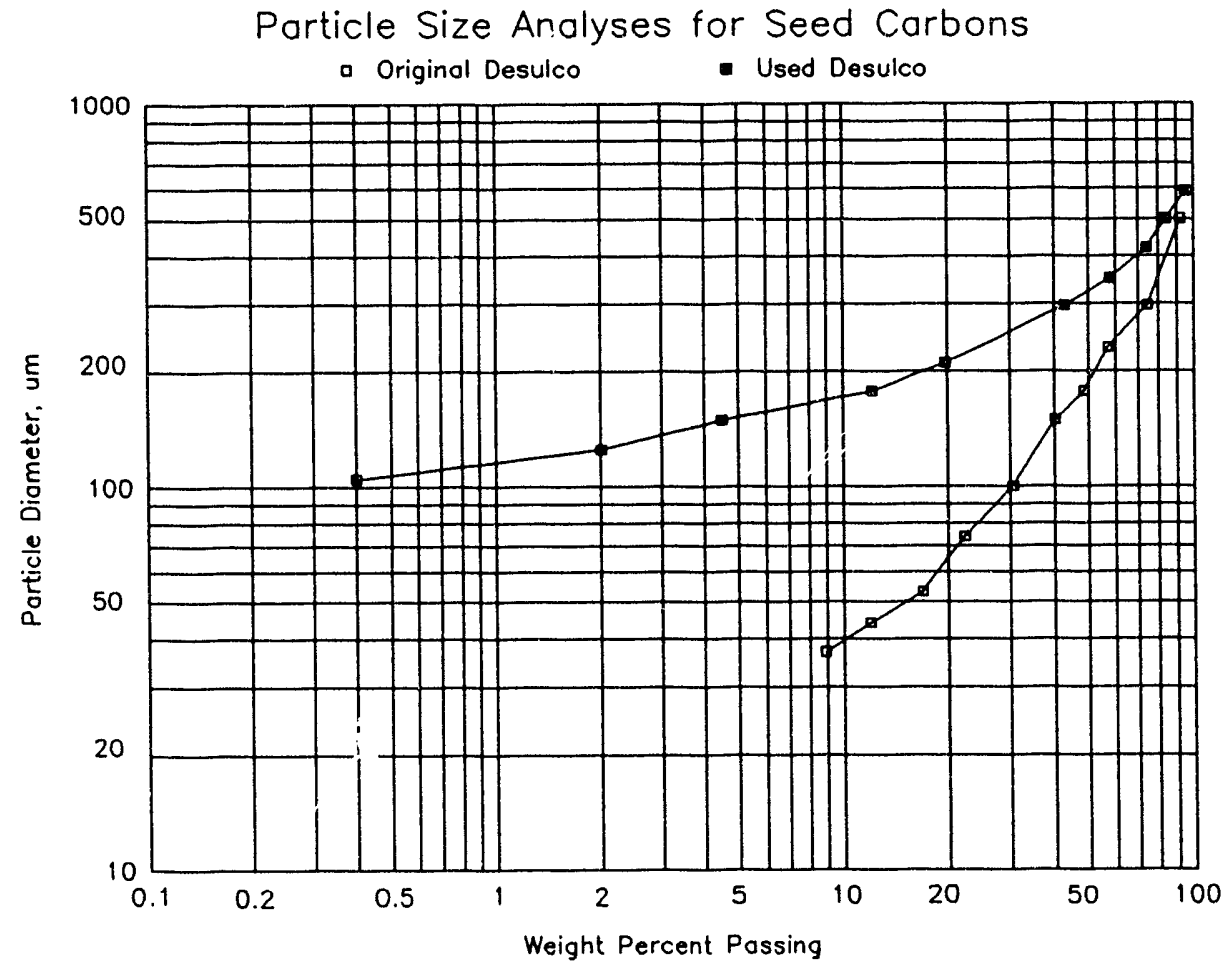

Figure 43. Particle size distributions for original seed carbon and seed carbon withdrawn from the reactor after run C-8.

Analysis of these materials is shown in Table 8. The seed carbon has been enriched in iron and nickel relative to the original material but depleted in vanadium. We suspect that individual metal particles containing iron and nickel were present rather than metal incorporation into the carbon matrix. Depletion of the vanadium content was consistent with the formation of a carbon coating on these particles. This was because the Desulco seed carbon had a relatively high vanadium content as received and would be diluted with the formation of a carbon coat.

Table 8. Analytical Data on Seed Carbons

$\begin{array}{cccccc}\text { Fe, } & \mathrm{Cr}, & \mathrm{Ni}, & \mathrm{Mn}, & \mathrm{Ti} & \mathrm{V}, \\ \text { ppm } & \mathrm{ppm} & \mathrm{ppm} & \mathrm{ppm} & \mathrm{ppm} & \mathrm{ppm}\end{array}$

$\begin{array}{lrrrrrr}\text { Desulco, As-Received } & 60 & -- & 40 & -- & -- & 865 \\ \text { Ussed Desuico }(\overline{6}-\overline{8}-\overline{9} i) & 300 & 90 & 120 & 20 & <\overline{0} .001 & 550\end{array}$


a)

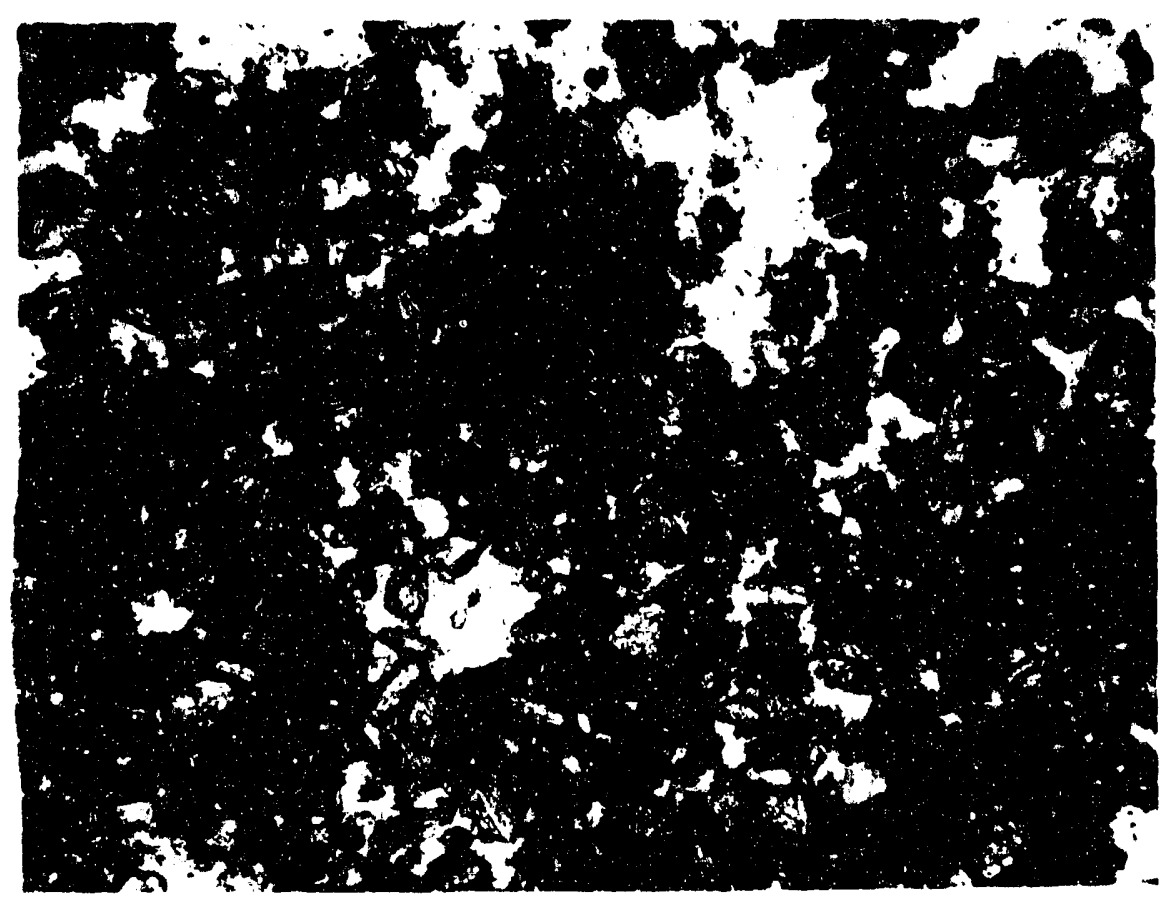

b)

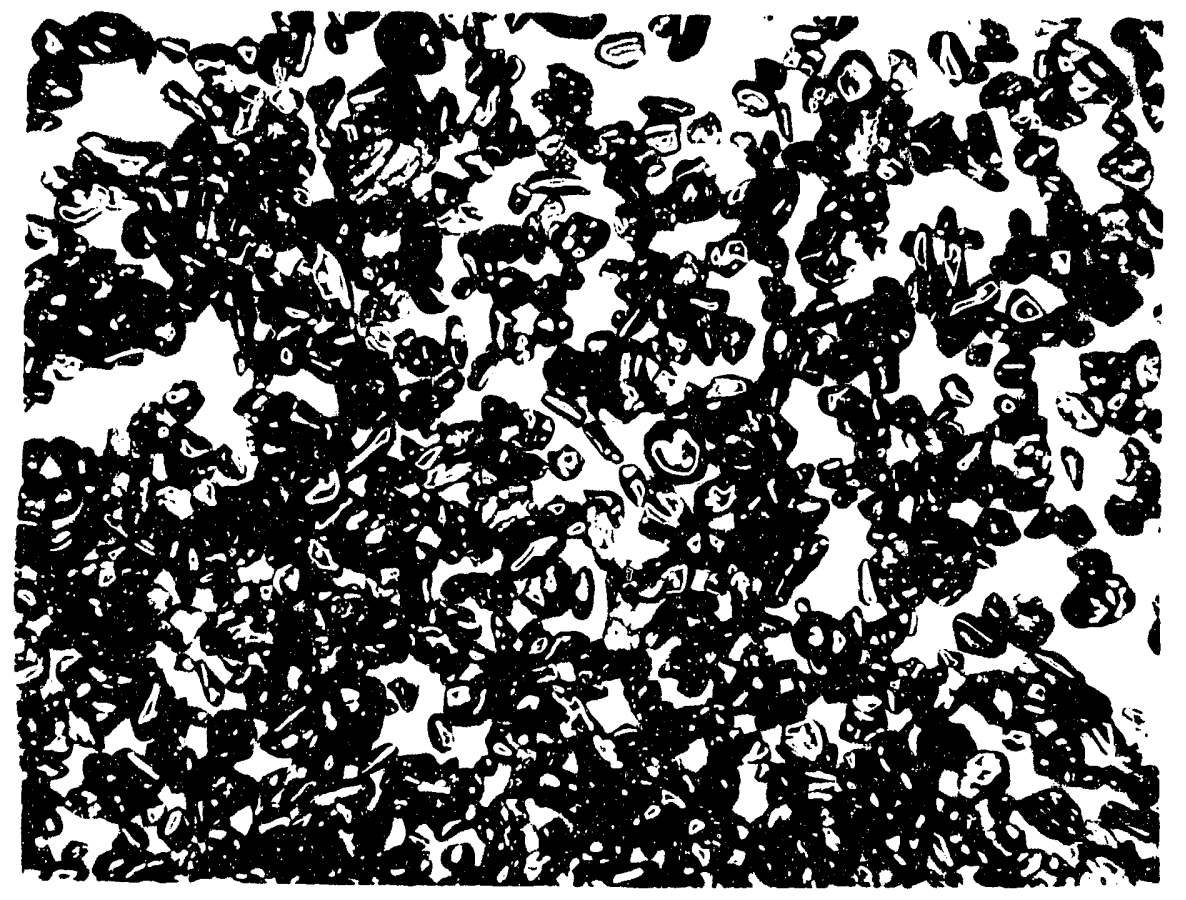

Figure 44. Photomicrographs of a) original seed carbon and b) seed carbon withdrawn from the reactor after Run C-8. 
a)

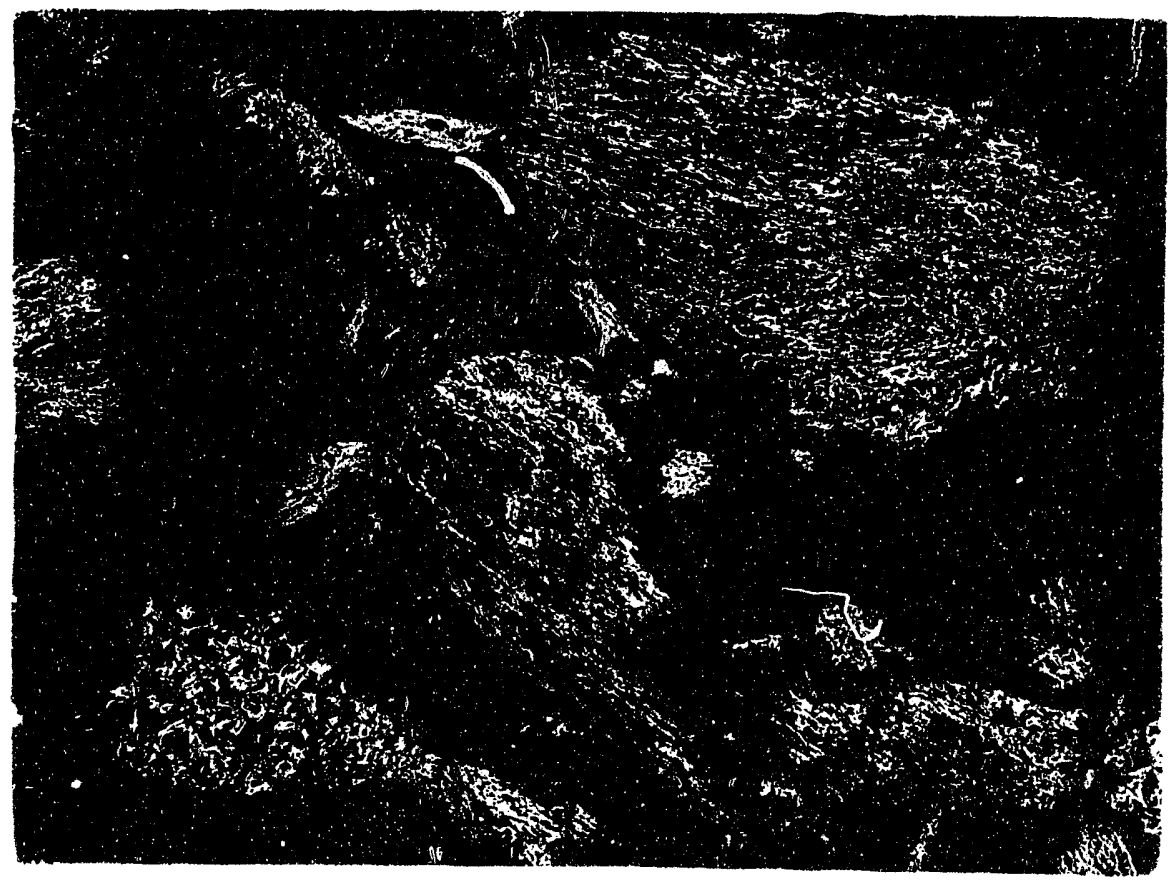

b)

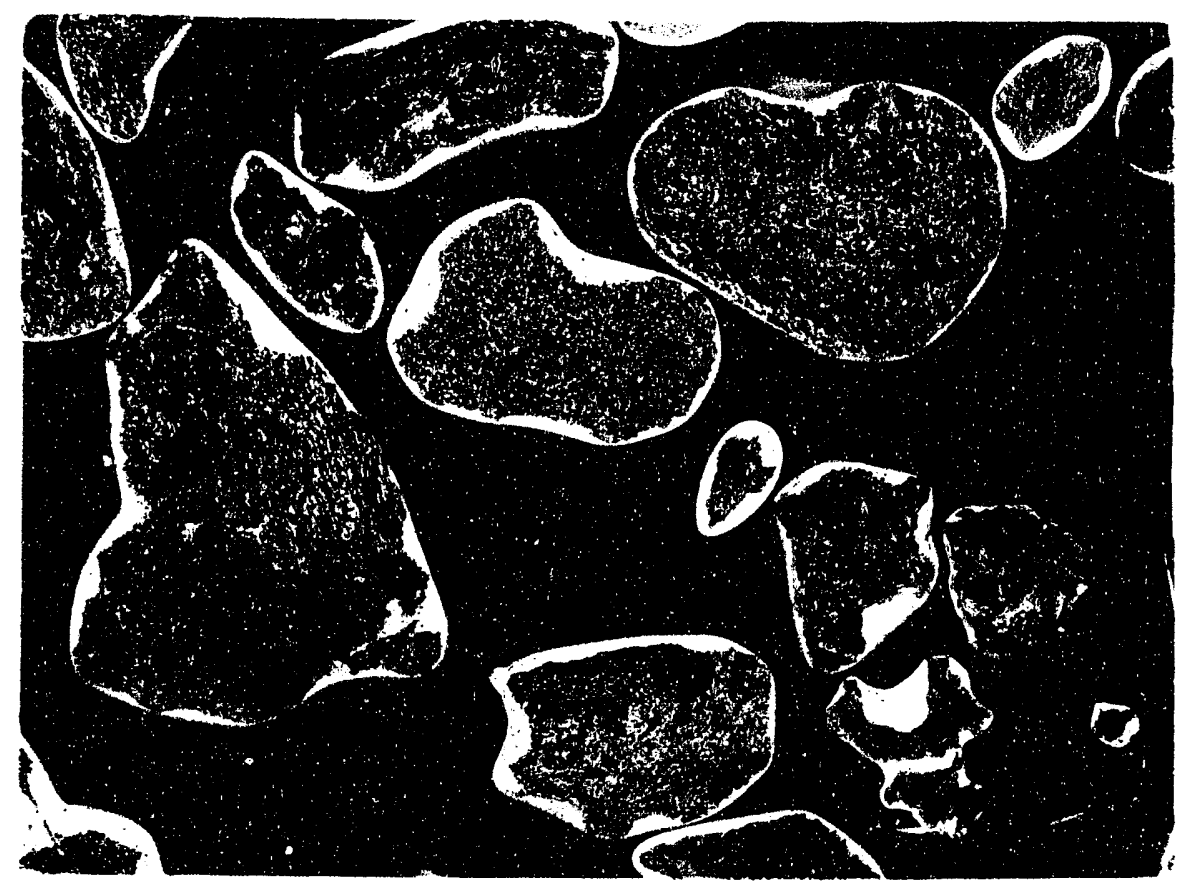

Figure 45. Photomicrographs of cross sections of a) original seed carbon and b) seed carbon withdrawn from the reactor after Run C-8. 


\section{Fine Carbon From Baghouse}

The carbon discharged from the baghouse during Run C-7 is quite different in appearance from the Desulco seed carbon. An analysis of this material was undertaken and results are shown in Table 9. These product lots are very heterogeneous and difficult to sample representatively. Consequently, ash analyses varied between about 13 and 24 weight percent for any given sample. The numbers which identify each sample are the times at which the sample was taken.

Table 9. Analysis of Fine Carbon Product from Run C-7

$\begin{array}{lccc} & \underline{13: 50} & \underline{16: 44} & \underline{18: 20} \\ \text { Carbon, Weight \% } & 84.9 & 88.8 & 87.3 \\ \text { Hydrogen, Weight \% } & 0.2 & 0.2 & 0.1 \\ \text { Nitrogen, Weight \% } & 0 & 0 & 0 \\ \text { Sulfur, Weight \% } & 0 & 0 & 0 \\ \text { Ash, Weight \% } & 21.0 & 14.7 & 13.9 \\ \text { Vanadium, ppm } & 848 & 681 & 521 \\ \text { True Density, g/cc } & -- & 1.7 & --\end{array}$

The most surprising aspect of the product analyses is the high ash content. Interestingly, the ash is black in color while coal derived ashes are usually tan or yellow. Analysis of the ash indicated that it is composed of the metals $\mathrm{Fe}, \mathrm{Cr}$, and $\mathrm{Ni}$. These metals must come from erosion of the steel or Incoloy heat transfer surfaces inside the reactor. The vanadium content of the 13:50 sample suggested that it is primarily Desulco fines. The reduced vanadium content of the other samples suggested that product carbon material is also present.

Size analysis for these materials indicated that approximately 20 weight percent is larger than 200 mesh, with the remainder of the particles being substantially smaller than 5 microns. Several size fractions of sample 16:44 were also analyzed for ash, carbon, and metals and the results are shown in Table 10. The results shown in Table 10 indicate that the metal constituents are concentrated in the finer material. It is expected that the coarser material is Desulco. Analysis of the -400-mesh fraction also indicates the presence of a small amount of aluminum from erosion of the alumina refractory lining the reactor.

The sample collected at 16:44 was subjected to a number of bench-scale separations in attempts to remove the fine carbon product from the Desulco and metal fines. Magnetic separation, a variety of gravity separations with water, and a heavy liquid gravity separation $(S G=2.0$ ) were attempted. Only the heavy liquid separation provided a relatively clean carbon sample. 
Table 10. Analytical Results for Fine Carbon

Size Fractions from Run C-7 (16:44 Sample)

\begin{tabular}{|c|c|c|c|c|}
\hline & $\begin{array}{c}\text { Ash, } \\
\text { Weight \% }\end{array}$ & $\begin{array}{c}\mathrm{Fe}, \\
\text { Weight \% }\end{array}$ & $\begin{array}{c}\mathrm{Ni}, \\
\text { Weight \% } \\
\end{array}$ & $\begin{array}{c}\text { Al, } \\
\text { Weight \% }\end{array}$ \\
\hline $8 \times 100$ Mesh & 0.4 & -- & - & -- \\
\hline $200 \times 270$ Mesh & 1.8 & -- & -- & -- \\
\hline-400 Mesh & 16.3 & 6.5 & 1.7 & 0.14 \\
\hline
\end{tabular}

Microscopic examination of the clean material produced by heavy liquid separation showed particles which were obviously Desulco and particles similar to the polished, rounded sample removed from the bed. This float sample was analyzed for carbon content and found to contain 98.9 weight percent carbon with very little hydrogen or nitrogen and no detectable sulfur.

It is possible that this float sample is predominantly Desulco fines. We have found that vanadium content is a relatively sensitive indicator for Desulco, and the float fraction was analyzed for vanadium and iron content, yielding values of 744 and 3,012 ppm, respectively. This vanadium analysis is lower than in as-received Desulco and suggests the presence of some fine carbon. While this fine carbon might have been formed by gas phase nucleation, it seems more probable that this material is predominantly pyrolytic carbon which deposited and was then eroded by the action of the fluidized bed.

\section{Pyrolytic Carbon from Heat Transfer Surfaces}

As noted above, a thick layer of pyrolytic carbon formed on the heat transfer surfaces in the carbon formation reactor. At some points in the reactor, the pyrolytic carbon was so thick that gas flow through that part of the unit could not have been possible. To more fully understand the causes of pyrolytic carbon formation and its effect on the materials of construction of this unit, an analysis of this carbon was undertaken.

When the carbon reactor was emptied, several types or morphological forms of pyrolytic carbon were observed. Very close to the Incoloy $800 \mathrm{HT}$ surfaces, shiny flakes of carbon approximately $1 / 16$-inch thick were observed. At welds and on 316 stainless steel surfaces, dull black or grey flakes were found. Also, large, coke-like granules formed a very black cake at the thickest parts of the carbon deposit.

Analytical data for these pyrolytic carbon samples are reported in Table 11. The samples are very high in the elements which make up Incoloy and stainless 
steel. It seems likely that the formation of pyrolytic carbon was leading to deterioration of the heat transfer surfaces, possibly by carburization.

Table 11. Analytical Results for Forms of Pyrolytic Carbon

\begin{tabular}{|c|c|c|c|c|c|}
\hline & $\begin{array}{c}\text { C, } \\
\text { Weight \% }\end{array}$ & $\begin{array}{c}\text { Fe, } \\
\text { Weight \% }\end{array}$ & $\begin{array}{c}\text { V, } \\
\mathrm{ppm}\end{array}$ & $\begin{array}{c}\mathrm{Ni}, \\
\mathrm{ppm}\end{array}$ & $\begin{array}{c}\text { Cr, } \\
\mathrm{ppm}\end{array}$ \\
\hline Shiny Flakes & 98.5 & 0.37 & N.D. & 390 & 1,300 \\
\hline Black/Grey Flakes & 97.0 & 1.79 & N.D. & 6,000 & 7,000 \\
\hline Coke-Like Granules & 97.0 & 1.29 & 36 & 1,300 & 860 \\
\hline
\end{tabular}

In an attempt to confirm this idea, a large piece of mixed pyrolytic carbon showing the imprint of a glow bar tube on one side was analyzed for spatial distribution of metals by SEM/EDX. These spectra are shown in Figure 46. Here it can be seen that at the inner radius or surface which is touching the glow bar muffle (part a), levels of $\mathrm{Cr}, \mathrm{Fe}$, and $\mathrm{Ni}$ are elevated relative to the interior of the carbon particle (part b). A photograph of this pyrolytic carbon fragment is shown in Figure 47, and the analysis locations are indicated. This supports the conclusion that glow bar muffles are deteriorating because of carburization, followed by erosion of the metal surface.

The coke-like granules were also analyzed by X-ray powder diffraction. The diffraction pattern exhibited the sharp (002) reflection of crystalline graphite at about $26^{\circ} 2 \theta$ (Cu $\mathrm{K} \alpha$ radiation). The pattern also exhibited peaks from amorphous $\mathrm{X}$-ray scattering similar to those reported for carbon black by Wertz. ${ }^{25}$

\section{MATERIALS PERFORMANCE RESULTS}

With the exception of the Incoloy $800 \mathrm{HT}$ used in the glow bar muffle tubes, all materials of construction performed quite well. At the high temperature to which the glow bars were heated $\left(>2,000^{\circ} \mathrm{F}\right)$, the Incoloy was degraded by carburization. Stainless steel fins welded to the muffle tubes were also severely degraded. Incoloy $800 \mathrm{HT}$ was the best material available for this application, yet it did not perform up to expectations and resulted in eventual shutting down of carbon reactor operations because of safety concerns. 
a)

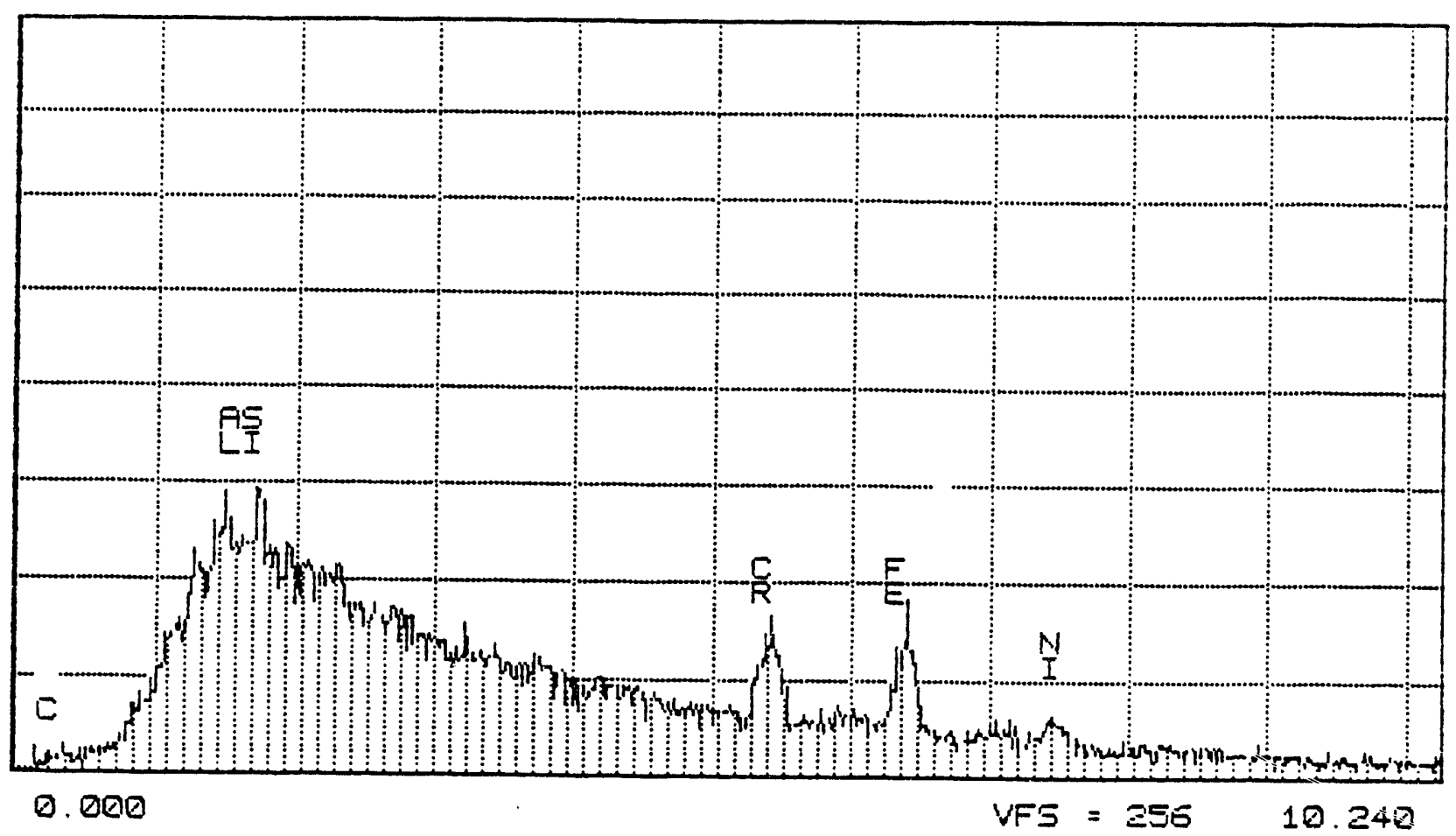

b)

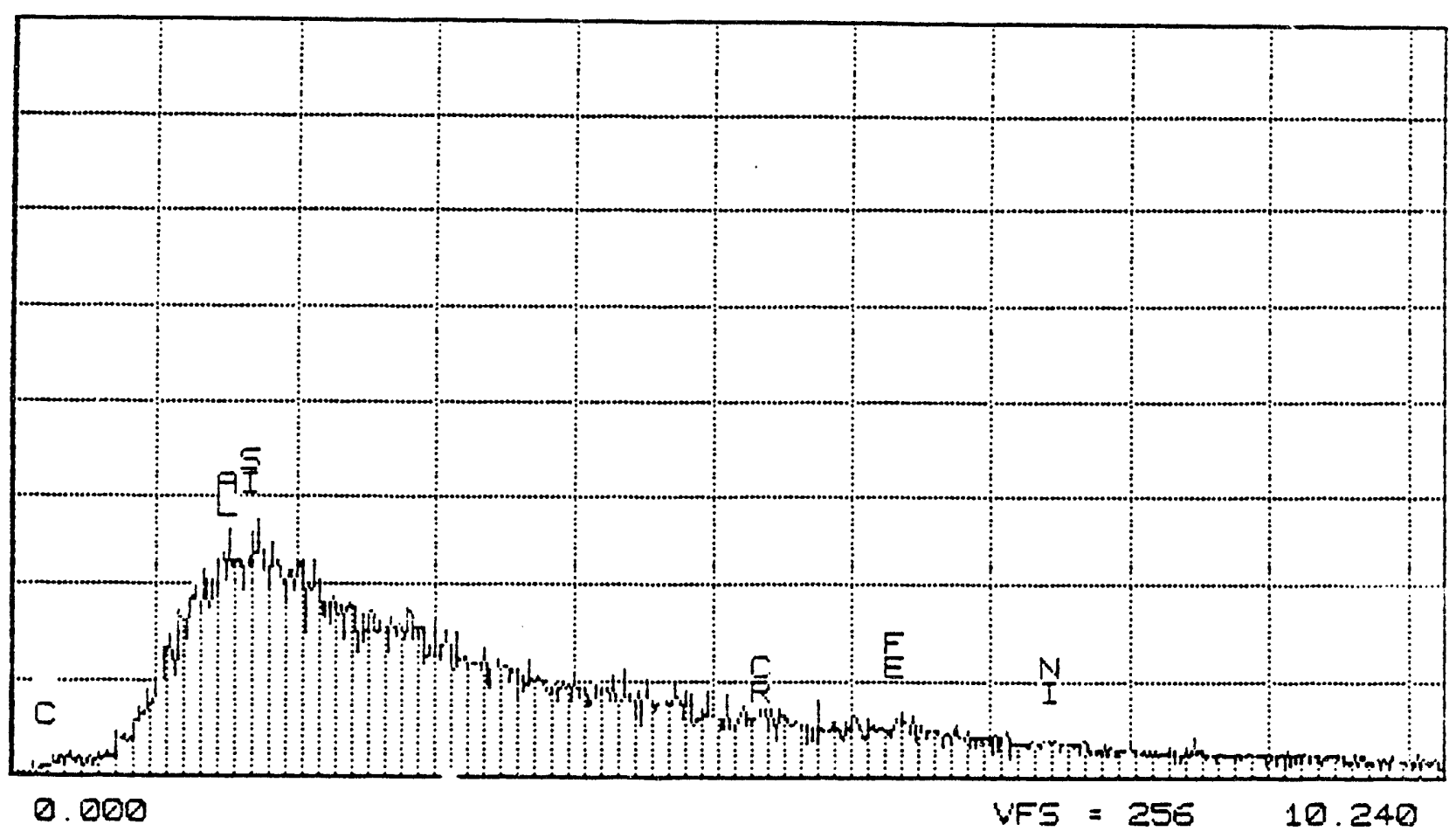

Figure 46. Energy dispersive $X$-ray spectra for a) pyrolytic carbon taken from the glow bar muffle surface and b) pyrolytic carbon roughly 1 inch from the glow bar muffle surface. 


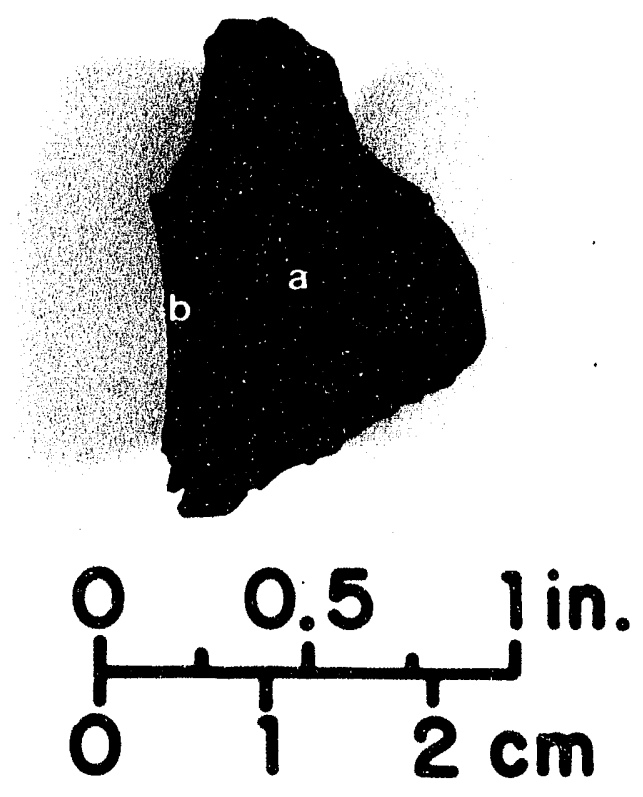

Figure 47. Photomicrograph of pyrolytic carbon fragment showing analysis locations for SEM/EDX. 


\section{DISCUSS!ON}

In this chapter, the results described above for individual runs will be drawn together so that conclusions can be drawn about the performance of individual systems and of the overall PRU.

\section{GAS SEPARATION SYSTEM PERFORMANCE}

The gas separation membrane utilized in this project gave essentially trouble free performance. Performance met or exceeded design specifications for virtually all operating conditions utilized. The requirement of protecting the membrane from liquid water was easily achieved by cooling to condense water and then reheating above the dew point. Problems were encountered with the proportional integral derivative (PID) controller on the circulation heater used to reheat the membrane feed gas. On several occasions, the feed gas temperature reached levels well above the maximum tolerance specified by the membrane manufacturer, but this did not appear to result in significant degradation of membrane performance.

The membrane required little or no operator attention except during start-up. During start-up, when the recirculating gases were essentially pure hydrogen, it was necessary to use a needle valve to generate back pressure for the membrane permeate. If this was not done, nearly all of the gas feed to the membrane would report to the permeate stream, starving the carbon formation side of the process. As methane content in the gas increased because of char gasification or bottled methane injection, the back pressure could be reduced by opening the needle valve.

\section{METHANATION SYSTEM PERFORMANCE}

During early runs, considerable difficulty was experienced in feeding and discharging solids from this unit. In particular, the valves employed in lock hoppers experienced severe leakage and various parts of the feeding and discharging systems plugged. The problems were in large part eliminated by installing pressurized feed and discharge systems and changing the discharge from the original J-valve configuration to a bed overflow. In spite of the improvements made during this project, further improvements in reliability and reproducibility of solids handling could still be made.

The methanation reactor system was designed to achieve equilibrium methane content in the product gas. This level of methiane content (roughly 40 volume percent) was never achieved during PRU operation. Equilibrium methane content was observed in bench-scale studies in a mass transfer limited fixed-bed unit. In these studies, $80 \mathrm{~g}$ of char was reacted with 4 standard liters per minute (sIm) of hydrogen for about 4 hours. Equilibrium methane content was obtained during the first 30 to 60 minutes of the run. For a time of 45 minutes, this corresponded to $0.0277 \mathrm{lb}$ char $/ \mathrm{ft}^{3}$ hydrogen. 
In the PRU methanation unit as originally designed, 50 pounds/hour of char was reacted with $55 \mathrm{scfm}$ of hydrogen with a mean residence time of about 45 minutes. This corresponded to $0.0152 \mathrm{lb}$ char/ $/ \mathrm{ft}^{3}$ hydrogen. Given that this ratio was much less than that used in the bench-scale unit, it was not surprising that methane concentration in the exit gas was lower than the equilibrium value.

After modification of the unit to operate with a bed overflow, char feed rates of 20 to 60 pounds/hour were tested with a gas flow rate in the range of 40 to 70 scfm. For example, test period No. 2 of Run M-10 was run at 20 pounds/hour and the calculated mean residence time was then 42 minutes. The flow rate in this test was targeted at $65 \mathrm{scfm}$ for a ratio of $0.0051 \mathrm{lb}$ char $/ \mathrm{ft}^{3}$ hydrogen. Again, this ratio was much lower than that used in bench-scale tests. Table 12 lists char/hydrogen ratios for each of the test periods in Run M-10. These values are not averages of actual data but are based on the target values for the tests. Also included are mean outlet gas methane concentrations, mean char conversions calculated by mass balance, and char conversions from char analysis.

Table 12. Char/Hydrogen Ratios and Other Pertinent Data from Run M-10

\begin{tabular}{|c|c|c|c|c|}
\hline Test & $\begin{array}{c}\text { Char/ } \\
\text { Hydrogen }\end{array}$ & $\% \mathrm{CH}_{4}$ Out & $\begin{array}{c}\text { Char Analysis } \\
\text { Carbon } \\
\text { Conversion } \\
\end{array}$ & $\begin{array}{c}\text { Gas Analysis } \\
\text { Carbon } \\
\text { Conversion } \\
\end{array}$ \\
\hline $1274-32^{\mathrm{a}}$ & 0.0277 & 40 & 0.509 & -- \\
\hline M-10 No. 1 & 0.0078 & 14.0 & 0.353 & 0.316 \\
\hline Mi-10 No. 2 & 0.0051 & 8.1 & 0.364 & 0.317 \\
\hline M-10 No. 3 & 0.0093 & 11.1 & 0.240 & 0.289 \\
\hline M-10 No. 4 & 0.0151 & 16.1 & 0.238 & 0.304 \\
\hline M-10 No. 5 & 0.0250 & 19.8 & 0.232 & 0.298 \\
\hline
\end{tabular}

a Bench-scale test described in Reference 4.

Table 12 also includes results of a bench-scale test conducted at conditions similar to those employed in the PRU. Residence time in the bench-scale unit was 4 hours. Results reported in the Task 3 topical report ${ }^{4}$ indicated that most char conversion occurred during the first 30 to 60 minutes of the bench-scale run. However, conversion did continue at a slow rate after this time period, and over the course of 4 hours, this slow reaction could have produced significant additional conversion. Also, temperature control in this bench-scale unit was poor, and the char was exposed to substantially higher temperatures than $1,400^{\circ} \mathrm{F}$ during the early part of the test. These factors probably accounted for the higher carbon conversion observed in bench-scale testing. 
In none of the cases listed in Table 12 did PRU carbon conversion or product methane content reach the levels observed in the bench-scale unit. Even in Run M-10 test period No. 5 where the char/hydrogen ratio was almost as high as in the bench-scale unit, conversic n and outlet gas content were much lower. It is apparent from the PRU test results that the reactor did not perform as an equilibrium reactor and did not yield methane production rates as high as observed in the bench-scale tests.

Appendix $B$ describes data analysis and a redesign of this reactor using kinetic data and a fluid-bed design equation (bubbling bed model). The kinetic parameters were extracted from Run M-10 data. With this procedure, the bed depth is $594 \mathrm{~cm}$ or $19.4 \mathrm{ft}$. Utilizing the void fractions and char bulk density, we can estimate the bed inventory as $8,740 \mathrm{~g}$ or $19.3 \mathrm{lb}$. The mean residence time is 23 minutes. Of course, this bed would be impractically tall, but the calculation does provide an indication of the reactor volume required.

So, the results of applying design parameters in the PRU suggest that our reactor was approximately the correct diameter ( 5 inches) but our gas flow rate was too high and our bed height (and volume) was much too low. Our operating experience indicates that with these bed dimensions, we will observe poor mixing and bypassing. The bypassing problems might be eliminated by relocating the feed so that fresh char is delivered to the grid region through the wall of the bed. However, considerations of solid properties indicate that solids mixing will still be poor, as discussed below.

Geldart has proposed a classification system for powders relative to fluidization. $^{23}$ This classification is based on the observation that particulate solids of differing size distribution and density produce very different types of fluidization. Most of the literature on fluidization deals with group A powders exemplified by fluid catalytic cracking catalyst. These materials are easily fluidized and conform to many of the common assumptions of two-phase fluid-bed models. In slugging beds, these materials produce classical axisymmetric slugs which are bullet shaped and have a layer of solids between the slug and the wall.

The coal char used in this project is a border line group B-D powder. These materials are relatively coarse and difficult to fluidized. Particle size segregation is usually observed. In slugging beds, a type of slug called a square slug is observed. Regions above and below the square slug are not truly fluidized in that the gas velocity may be lower than the minimum fluidization velocity. This is the type of slug that we have observed in our cold flow model for methanation. In any system where square slugs form, solids mixing will be poor. Geldart suggests that square slugs can be eliminated by roughening the walls of the fluid bed, and perhaps this approach would allow us to operate a high H/D bed with reasonable mixing. Baffles might also be used to improve mixing. 
Another approach towards processing group B-D materials is to use an inclined fluid bed. This type of bed was used for mild gasification of coal in the companion project reported by Merriam and coworkers of WRI. ${ }^{15}$ Advantages of this type of bed are that the solids are in plug flow which requires a smaller reactor volume, $H / D$ ratios are low, and gas velocities only slightly above minimum fluidization are required. The solids are also exposed to a higher mean hydrogen partial pressure in this arrangement.

\section{CARBON FORMATION SYSTEM PERFORMANCE}

The carbon formation reactor system was by far the most important and highest risk part of the CTC PRU. This reactor was designed with more unknowns that any other part of the plant. Our operating experience indicates that the heat transfer tubes are a very demanding materials application. It will be difficult to find materials of construction which are suitable for this severe, high temperature environment. However, operational results do indicate that methane can be decomposed to produce fine carbon particles which are entrained and to produce a coating of carbon on seed carbon particles. Conversions were very low. We attribute this to the fact that the observed heat transfer coefficients were much lower than the values assumed in the design and to the formation of a pyrolytic carbon scale on the heat transfer surfaces.

Appendix $\mathrm{C}$ presents a detailed heat transfer coefficient calculation using correlations available in the literature. This calculation indicates that an overall heat transfer coefficient of $40 \mathrm{Btu} / \mathrm{hr}-\mathrm{ft}^{2}{ }^{\circ} \mathrm{F}$ could have been obtained. This value is substantially higher than that observed at any time during PRU operation. There may be several reasons for this. First, the value of $U$ assumed in the original design and the equations used in the modified design are based on data for group A powders. The seed carbon which we utilized was a group B powder, and very little is known about heat transfer in group B or D powder systems. Also, a great deal of pyrolytic carbon was deposited on the heat transfer surfaces which certainly reduced the heat transfer coefficient. Finally, because some of this pyrolytic carbon eventually was attrited from the tubes, the particles in the bed were much coarser on average than intended.

\section{INTEGRATED SYSTEM PERFORMANCE}

The results of integrated runs described above indicate that in a general sense the integrated system performed well. However, there are several overall system performance topics which must be discussed.

The first among these is heat losses. Heat losses were much higher than design for virtually every unit operation in the process. This necessitated oxygen injection in the methanation reactor, redesign of the carbon formation reactor, and installation of a preheater on the carbon formation reactor. Another manifestation of 
not lases was the poor performance of the process loop heat exchangers. White thess units were trouble free to operate, design approach temperatures were anteres. For future operation, it would be desirable to modify these units to insirs the riphest level of thermal efficiency possible.

4 The: problem in overall system performance was flow rate instability. This vas sasas oy the intermittent nature of char feeding to the methanation reactor ar $=$ the memmitent use of process gas in J-valve operation. This also resulted in arys flumizions in methane reactor product gas composition. The problem was axises to some extent by elimination of the J-valve but not completely. The acuustion of good data for scale-up depends upon attaining steady state sroitons or fairty long periods of time so that meaningful numbers can be zetared. Whith the flow rate instability observed in PRU tests, this type of data sariox se obtained. I..pplementation of a continuous char feeding and discharging syse- such as screw feeders would eliminate this problem. Another possibility is I comar amounts of char with a higher frequency.

Operation of the system was also made more difficult by the high degree of cocc coupling. By this it is meant that the two process loops (char methanation aro carbon formation) were so highly coupled that conditions in one loop could not se arered without substantially changing conditions in the other loop. For a PRU scaie system, this does not provide enough flexibility for fine tuning of the process conditions and creates a situation where an upset in one loop generates an upset $n$ the other loop. To avoid this situation in future PRU studies, a gas accumulation pressure vessel might be installed for accumulation of gases from both reactors. This vessel would have the capacity to hold something like 15 minutes worth of process gas requirements at a slightly higher pressure than that of the membrane feed. If a process upset occurred, this gas could be regulated out of the accumulator to the membrane, supplying both reactors with adequate feed gas for fluidization and resulting in damping of process upsets and flow rate fluctuations. Tinis accumulator would also provide the flexibility needed to fine tune the individual process loops during integrated operation. The accumulator would probably not be necessary in a process demonstration or commercial scale system.

\section{PRODUCT QUALITY}

The amount of carbon produced was much lower than the design called for. This was caused by problems in achieving adequate heat transfer probably due to scale formation and lack of adequate gas residence time at temperature in the carbon reactor. The product that was collected indicates that the production of fine carbon, the growth of seed carbon, and the formation of pyrolytic carbon all occurred in the carbon formation unit. These carbons were contaminated by metals, iron and nickel, due to erosion and corrosion of incoloy and stainless steel, as discussed below. Therefore, these products were not evaluated against the specifications for any of the proposed applications. A radical change in the design 
between tensile values at temperatures above $2,000^{\circ} \mathrm{F}$ decreases considerably in addition to the tensile strengths decreasing. At $2,100^{\circ} \mathrm{F}$, the tensile strength decisively decreases to approximately 1,200 psi. The temperature at which this sharp decrease in strength occurs correlates well to the high temperature, solution annealing heat treatment that Inco International uses for dissolving precipitates and homogenizing the material. The dissolution of the aluminum-titanium carbide precipitates at this temperature would explain the large decrease in strength observed.

High Temperature Tensile Data for Incoloy $800 \mathrm{HT}$

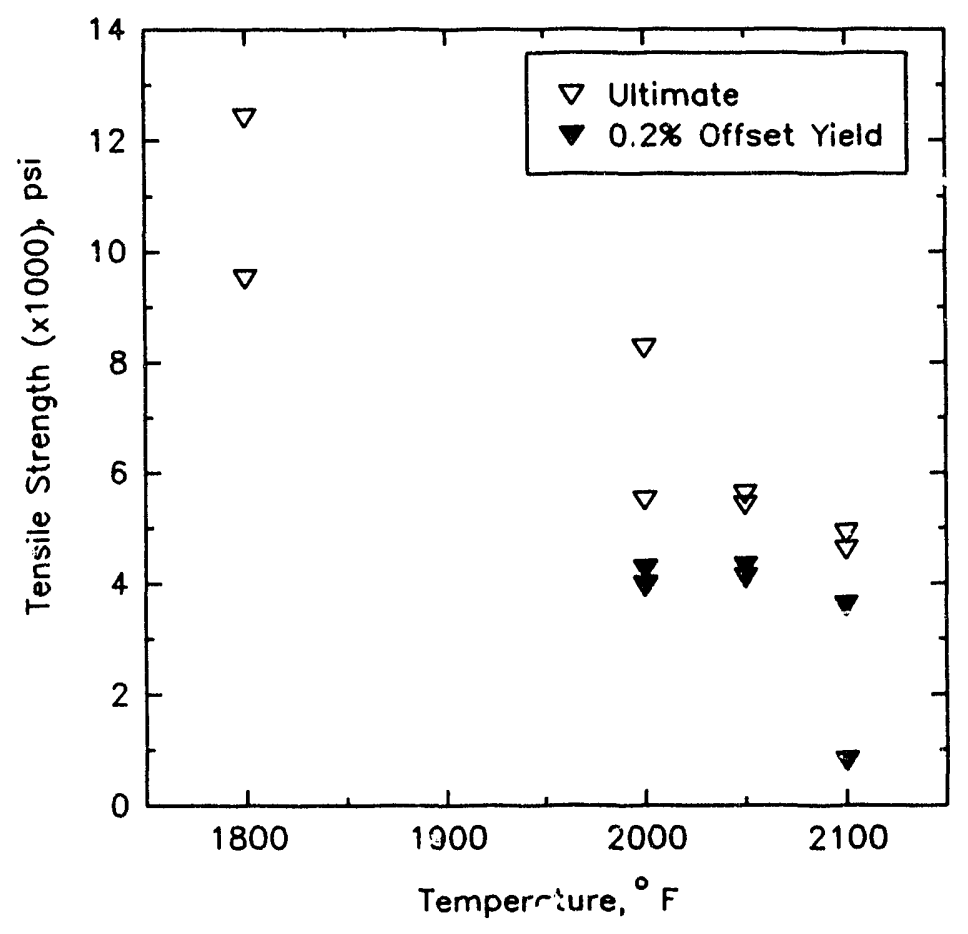

Figure 48. High temperature tensile strength of Incoloy $800 \mathrm{HT}$.

In an effort to determine the influence of time at temperatures above $2,000^{\circ} \mathrm{F}$, test samples were heated to the target temperatures of $2,000,2,050$, and $2,100^{\circ} \mathrm{F}$ for up to 10 hours. Load was set at half the yield stress once temperature equilibration had been attained. Figure 49 shows the results of the three tests recorded as stroke as a function of time, which indicates the relative degree of sample creep at temperature. The rate of creep can be seen to increase as the temperature is increased over this range. The steady state creep rate in the $2,000^{\circ} \mathrm{F}$ test occurs up to 17,000 seconds before a transition develops into accelerated creep. This steady state time decreases to zero time or the start of the test for the $2,100^{\circ} \mathrm{F}$ temperature, showing instability of the material. 
These results demonstrate the unsuitability of Incoloy $800 \mathrm{HT}$ for use at the high temperatures required in the carbon formation system. Typically glow bars were operated at $2,050^{\circ} \mathrm{F}$, and from a heat transfer standpoint, it would have been desirable to go to even higher temperatures. Also, the glow bar muffle tubes were experiencing severe carburization during PRU operation. This is quite consistent with the low carbon content of the as-received material and the instability shown to occur at high temperatures.

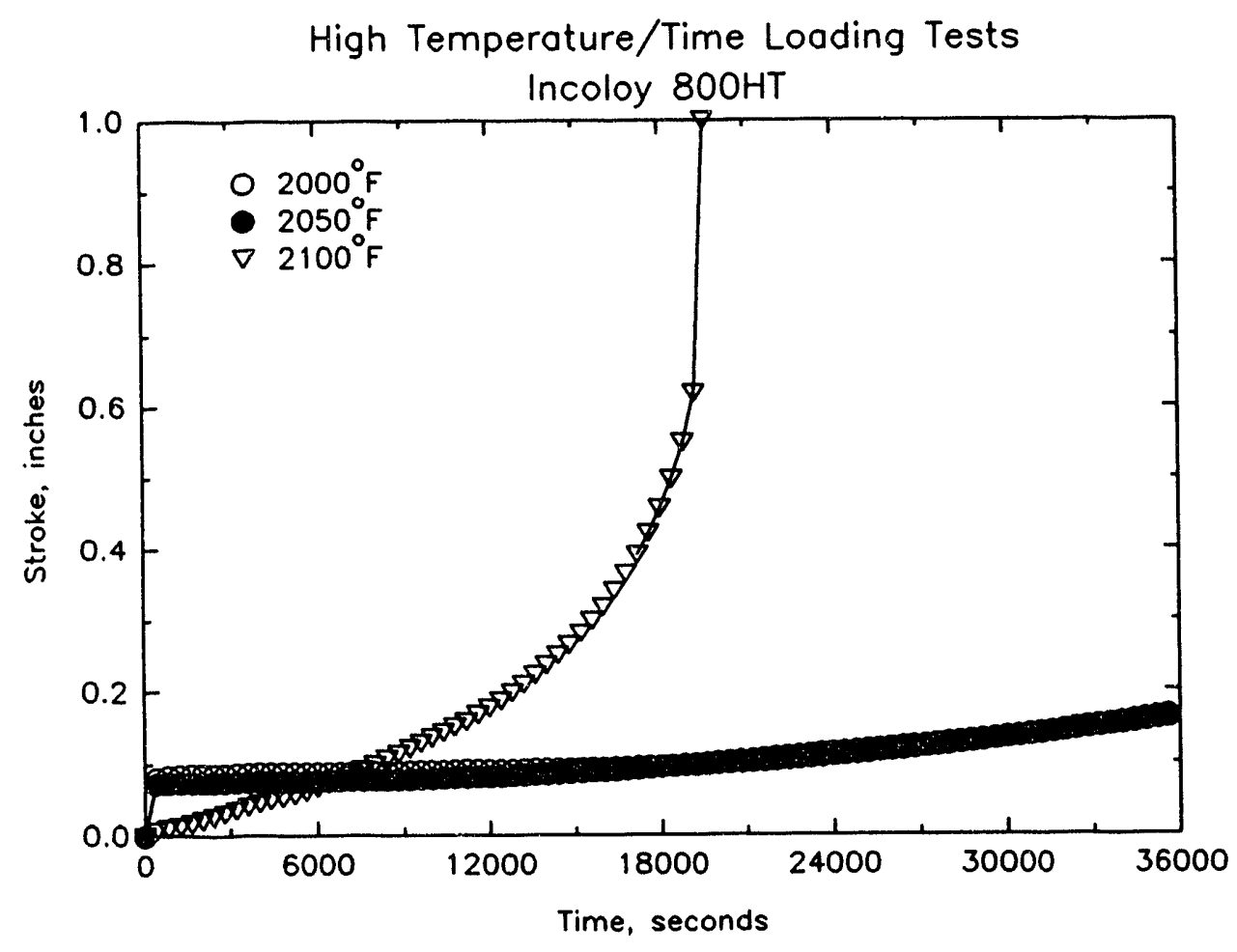

Figure 49. Results of high temperature creep measurement for Incoloy $800 \mathrm{HT}$.

\section{PERFORMANCE OF CONTROL SYSTEM AND INSTRUMENTATION}

The PRU was completely computer controlled, utilizing a personal computer. The major instrumentation systems were the gas analysis system and the instruments used to monitor temperature, pressure, and flow.

\section{Computer Control System}

The computer control system based on Genesis software performed well and controllability was always acceptable. In particular, in the most demanding control 
applications such as emergency shutdowns and control of the carbon reactor glow bars, the system functioned well. Data logging was also performed well, as demonstrated by the fact that virtually all of the data presented in this report were logged by the computer. Our experience with this completely computer controlled system has suggested several modifications which might be made in the future to obtain even better control and to increase the ease of data analysis.

Control of the PRU operation was hindered by dependence on a single computer. Our experience suggests that distributing control for each major subsection of the plant to a small process logic controller (PLC), supervised by a main computer, would allow continuation of process control even if the supervisory computer were to go down or malfunction. This supervisory computer would be backed up by a second computer whose main function during normal operation would be to log data. Emergency shutdown could be decoupled from the supervisory computer to improve emergency system reliability while allowing access to the supervisory computer for software modification or repair without requiring total plant shutdown.

The PRU operating experience also indicates that decision making was hindered by a lack of information about the runs. This occurred because procedures for properly analyzing data were not developed until quite late in the PRU test program. In order for decisions about PRU modifications and test conditions to be made with the most up-to-date information, it is desirable to have much of the data analysis automated and on-line. The data logging computer could perform much of this automated analysis so that engineers running the plant would have analyzed data even during the middle of a PRU run. This might require that the data logging computer delegate some of the task to a third computer which would periodically perform data analysis using an automated spreadsheet program or features of the Genesis software package.

\section{Instrumentation}

Temperature and pressure sensing instruments worked well and were generally trouble free. The only exception might be the thermocouples used to measure glow bar temperatures. The purpose of these thermocouples was to insure that the muffle tube inside wall temperature did not exceed the high temperature limit for this material. However, the thermocouples were placed inside of the cylindrical glow bars and may not have actually measured the muffle tube inside wall temperature.

For operation of fluidized bed reactors, accurate knowledge of feed gas flow rate is essential. An accurate measurement is required so that flows are kept at a level where good fluidization is maintained but bed entrainment is within acceptable limits. Also, for material balance calculations on the reactors, accurate flow data are required. During the PRU operation, problems with the turbine flowmeters were 
frequently encountered. The meters were very sensitive to the presence of condensable liquids and solid particles. The meters also required a great deal of calibration to maintain what accuracy they had. It was apparent to the PRU operators that turbine flowmeters were probably not the best flow measurement device for this application. Because of the need for highly accurate flow data, a better approach might have been to utilize two or more flowmeters, each based on a different measuring technique. With this redundancy, the operators could always be confident in their flow rate information.

Analysis of gas compositions was also very important for process operation and for analysis of the results obtained in the PRU. The mass spectrometer system utilized in this project generally performed well and provided accurate analysis data. However, on occasion the inlet to the unit would become plugged with condensable material or fine solids which required a shutdown for a period of about one hour. Because of the importance of gas analytical data, perhaps some redundancy could have been included in the gas analysis system. In particular, having continuous methane monitors on the most important gas streams in addition to mass spectral analysis seems desirable. These gas streams would include:

- Methane reactor product gas.

- Carbon reactor feed gas.

- Carbon reactor product gas.

\section{SAFETY}

The PRU was operated in an extremely safe manner. No accidents involving explosive or poisonous gases occurred. In particular, the automated emergency shutdown system based on explosive gas monitors worked well. On several occasions leaks of hydrogen into the process area occurred and were detected by the gas monitors which automatically initiated shutdown and purging of the unit. Alarms and limits set on the computer control system also performed their function well. Operators were alerted to potential problems with a reasonable time for response. A lightning protection system was installed on the building, which apparently worked well, as did the flare system and emergency power system.

The good safety record of PRU operations indicates that the CTC process can be performed in a safe manner. 


\section{CONCLUSIONS}

The design, construction, and operation of a 50 pound/hour continuous process research unit (PRU) for the char-to-carbon process, based on very limited batch test data from bench-scale reactors, were a major task which was successfully accomplished.

The PRU was operated for about one year, completing 35 runs covering about $\mathbf{8 0 0}$ hours of operation. The PRU operation provided the proof of concept for the CTC process. Mild gasification char was successfully converted to methane in the methanation reactor, and after gas separation in a membrane, it was decomposed to carbon in the carbon formation reactor. The two reactions occurred at designed temperature and pressure conditions.

The percent conversion was well below the design in the methanation reactor, mostly due to the lack of adequate residence time at proper temperature. Only about 25 to 35 percent conversion of char to methane was obtained in the methanation reactor, while the design called for 70 to 75 percent conversion. This resulted in 15 to 20 percent methane in the exit gas instead of 35 to 40 percent.

The membrane separation system performed extremely well, requiring no attention and recovering hydrogen gas with less than 4 percent methane and producing methane gas with 60 percent and more methane.

The performance of the carbon reactor was not satisfactory. Only a small fraction of the methane gas cracked, the concentration decreasing generally by 10 to 15 percent. Lack of enough gas residence time at proper temperature was the primary reason. This in turn was caused by poor heat transfer due to scaling of the heat transfer surface.

An important reason for not attaining the desired temperatures in the reactors and heat exchangers was that heat losses were significantly higher than allowed for in design. The fluidization quality in the reactors was also poor, as was seen by the cold flow models.

The carbon product was contaminated by chromium, iron, and nickel metals due to erosion and corrosion of metal tubes used as muffle for the glow bars.

A materiais of construction problem led to the poor performance of the carbon reactor and its shutdown due to safety concerns.

Other systems, including three cyclones, baghouse, heat exchangers, and compressors, worked well. The solids feeding and discharging systems had to be modified. Most of the instruments, with the exception of turbine flowmeters, worked well. 
The plant is highly computerized for data logging, as well as process control. This system worked well and was primarily responsible for the safe operation of the plant involving explosive and toxic gases. 


\section{RECOMMENDATIONS}

It is recommended that the PRU test program be continued, after the required modifications, to accomplish the remaining goals viz.

- Process optimization.

- Production of enough product for market evaluation.

- Development of scale-up data for PDU design.

Specific recommendations for the PRU modification are to:

- Develop, design, and install an alternative carbon formation system based on existing commercial technology and aimed at producing only fine carbon. A modified thermal black type reactor or a plasina reactor are the obvious candidates.

- Modify the methanation reactor to provide longer residence time and better fluidization, along with continuous feed and discharge systems.

- Other minor modifications would be made in the area of instrumentation and computer control to improve on-line data analyses capability and to separate emergency shut-down function from normal operation. 


\section{REFERENCES}

1. Cha, C. Y., Jha, M. C., Breault, R. W., and Merriam, N. W., "Advanced Concept for the Production of Coproducts", Proceedings of the 8th Annual Gasification and Gas Stream Cleanup Systems Contractors Review Meeting, Morgantown, West Virginia, May 1988, pp. 695.

2. Cha, C. Y., Merriam, N. W., Jha, M. C., and Breault, R. W., Topical Report for Task 1: Literature Survey and Market Assessment, "Development of an Advanced, Continuous Mild Gasification Process for the Production of Coproducts", Contract No. DE-AC21-87MC24268, January 1988.

3. Merriam, N. W. and Cha, C. Y., Topical Report for Task 2: Mild Gasification Tests, "Development of an Advanced, Continuous Mild Gasification Process for the Production of Coproducts", Contract No. DE-AC21-87MC24268, April 1989.

4. Jha, M. C. and McCormick, R. L., Topical Report for Task 3: Bench-Scale Char Upgrading and Utilization Study, "Development of an Advanced, Continuous Mild Gasification Process for the Production of Coproducts", Contract No. DE-AC21-87MC24268, August 1989.

5. Jha, M. C. and Cha, C. Y., "Mild Gasification of Western Subbituminous Coal: Product Recovery and Upgrading", Proceedings of the 6th Annual Pittsburgh Coal Conference, Pittsburgh, Pennsylvania, September 1989, pp. 765.

6. McCormick, R. L. and Jha, M. C., "Characterization of Mild Gasification Char for Methane Production", Proceedings of the 7th Annual Pittsburgh Coal Conference, Pittsburgh, Pennsylvania, September 1990, pp. 103.

7. Jha, M. C., McCormick, R. L., and Berggren, M. H., "Upgrading of Char from Mild Gasification", Proceedings of the 9th Annual Gasification and Gas Stream Cleanup Systems Contractors Review Meeting, Morgantown, West Virginia, June 1989, pp. 349.

3. Jha, M. C., McCormick, R. L., and Hogsett, R. F., "Upgrading of Char from Mild Gasification", Proceedings of the 10th Annual Gasification and Gas Stream Cleanup Systems Contractors Review Meeting, Morgantown, West Virginia, August 1990, pp. 572.

9. Woessner, P. W. and Jha, M. C., "Coal-Derived Pure Carbon: A Potential Premium Fuel for Industrial Power Generation", presented at the 1990 Industrial Power Conference, St. Louis, Missouri, October 1990. 
10. Jha, M. C. and Woessner, P. W., "A Process for the Production of ValueAdded Coproducts from Coal and Other Carbonaceous Materials", U. S. Patent Application, Ser. No. 354,606, May 22, 1989.

11. Jha, M. C. and McCormick, R. L., "A Process for Upgrading Mild Gasification Char", Record of Invention Submitted to DOE Patent Office, Oak Ridge, June 1990.

12. McCormick, R. L., Jha, M. C., and Hogsett, R. F., "A Continuous, Indirectly Heated Process for the Production of Carbon and Hydrogen from Hydrocarbons", U. S. Patent Application Ser. No. 584,594.

13. Jha, M. C. and McCormick, R. L., "Process for the Manufacture of Activated Carbon from Coal by Mild Gasification and Hydrogenation", U. S. Patent Application Ser. No. 571,794.

14. Hogsett, R. F., McCormick, R. L., and Jha, M. C., "Char-to-Carbon (CTC) Process, Including Intermediate Gas Separation Step", Record of Invention Submitted to DOE Patent Office, Oak Ridge, October 1990.

15. Merriam, N. W., Cha, C. Y., Kang, T. W., and Vaillancourt, M. B., Topical Report for Task 4. Mild Gasification Tests, "Development of an Advanced, Continuous Mild Gasification Process for the Production of Coproducts", Contract No. DE-AC21-87MC24268, December 1990.

16. Jha, M. C. and Hogsett, R. F., Topical Report for Task 4.6. Economic Evaluation, "Development of an Advanced, Continuous Mild Gasification Process for the Production of Coproducts", Contract No. DE-AC2187MC24268, October 1991.

17. Ralph M. Parsons Company, Topical Report for Task 4.7: Preliminary Engineering Design and Cost Estimate for a 20 Ton/Day Coal Mild Gasification and Product Upgrading Process Development Unit, "Development of an Advanced, Continuous Mild Gasification Prccess for the Production of Copioducts", Contract No. DE-AC21-87MC24268, September 1991.

18. Chen, C.-J. and Back, M. H., "The Simultaneous Measurement of the Rate of Formation of Carbon and of Hydrocarbon Products in the Pyrolysis of Methane", Carbon 17, 175 (1979).

19. Wen, C. Y. and Yu, Y. H., "Generalized Method for Predicting the Minimum Fluidization Velocity", AlChE Jour. 12, 610 (1966).

20. Naumann, E. B., Chemical Reactor Design, Wiley, New York, 1987. 
21. Grace, J. R., "Fluid Beds as Chemical Reactors" in Gas Fluidization Technology, Geldart, D., Editor, Wiley, New York, 1986.

22. Grace, J. R., "Fluidized-Bed Hydrodynamics" in Handbook of Multiphase Systems, Heston, G., Editor, Hemisphere, Washington, 1982.

23. Geldart, D., "Characterization of Fluidized Powders" in Gas Fluidization Technology, Geldart, D., Editor, Wiley, New York, 1986.

24. Grace, J. R., "Fluidized-Bed Heat Transfer" in Handbook of Multiphase Systems, Heston, G., Editor, Hemisphere, Washington, 1982.

25. Wertz, D. L., "Amorphous X-ray Scattering in Coals and Devolatilized Coal ByProducts", Powder Diffraction $\underline{3}$ (3) 153 (1988). 


\section{APPENDIX A}

OPERATION METHOD DETAILS 


\section{PRE-RUN MAINTENANCE}

A list of maintenance items; was performed on the day before a scheduled start-up. Our experience has silown that completion of these maintenance items increases the probability of obtaining a trouble free run. The following list of tasks was performed on the day before a scheduled start-up:

- Verify operation of and clean any non-operating flowmeters.

- Clean and check filters at lock hopper vents (6), condenser (2), membrane (2), and methane compressor (4).

- Clean all filters on gas analysis sample lines.

- Check mass spectrometer inlet.

- Clean emergency vent solenoid valve and close ball valves to isolate. Open manual bypass.

- Remove and clean methane reactor check valve.

- Flush and drain compressor condenser drain systems. Blow dry to prevent freezing.

- Make sure outside drains are open and clear.

- Blow solids out of lines between carbon reactor and compressor.

- Blow solids out of lines between condenser filters arid compressor.

- Check and fill char feed hopper, note char lot number.

- Check the status of hydrogen and nitrogen supply systems.

\section{PRE-START-UP CHECKS}

After completion of the pre-run maintenance, the following checks are made immediately before start-up:

- Check to see that uninterruptible power supply is on.

- Verify the utility supply (instrument air, water, and powei).

- Turn on master circuit breaker in I/O rack, check all fuses. 
- Check zero and span of combustible gas detectors.

- Turn on process gas analyzer (mass spectrometer).

- Activate emergency generator circuits to provide backup power.

- Drain water from flare and close drain valve.

- Check that the nitrogen tank is off and that the block valves inside are closed.

- Check that the hydrogen tank is off and the six block valves inside are off.

- Insure that all filters are blocked in at both filter stations and at the methane compressor.

- Insure that bypass line around first set of filters is closed.

- Drain water from all four filters.

- Close doors and secure the area.

- Perfc $n$ initial check of motor control center:

- Put area lights in auto position.

- Check all circuit breakers in lighting panels.

- Insure that all high voltage circuits are off.

- Put all heater controllers in off position.

- Insure that both air handlers are on.

- Close bypass valves around membrane.

- Verify that the main block valve on the membrane permeate is closed and block valves to the needle valve are open.

- Set the position of the needle valve on the membrane permeate (1/4 turn).

- Open the shutters on the PRU upper floor.

- Check the oil level in both compressors.

- Close the compressor condenser bleed valves.

- Close the cooling water drain valves at the compressors. 


\section{START-UP PROCEDURE}

After completion of all pre-run maintenance and pre-start-up activities, the PRU is ready to be started. Development of start-up procedures was one important objective of this development program, and by the end of the program, smooth start-ups were routinely obtained. Start-up procedures varied slightly, deperiding upon whether the entire integrated system was being operated or if only one of the reactors was being operated. A general start-up procedure for the integrated system is described here.

\section{Computer Start-up}

The PRU was completely computer controlled, as described in the preceding chapter. The control computer also logged data. The following is a check list for starting the control computer and software program.

- Log computer into Runtime version of Gellesis.

- Bring up the PDU screen (Macro <Alt+1>).

- Reset emergency shutdown (ESD) and soft shutdown (SSD) in software $(<\mathrm{F} 2><$ Run $>$ Tab $<1>)$ and the $1 / O$ rack.

- Toggle heater controllers (Macro <Alt+F1>). Check to see that all heater controllers are in manual and at zero percent power.

- Toggle all other controllers (Macro <Alt+F2>):

- $\mathrm{CP}-101=100 \%$ open in manual.

- $\quad$ CP-102 $=100 \%$ open in manual.

- Make-up $\mathrm{H}_{2}=0 \%$ open in manual.

- Bleed gas $=100 \%$ closed in manual.

- Methane back pressure $=0$ psi in auto.

- Condenser $=100^{\circ} \mathrm{F}$ in auto.

- Toggle air solenoids (Macro <Alt+F4>).

- Check I/O rack fuses and power to all circuits and correct logic state.

These controls were toggled to insure that they were in the desired position for start-up and not at some intermediate position resulting from the previous shutdown.

\section{Nitrogen Purge and Heater Start-up}

After starting the control computer, the system is purged with nitrogen to remove air, and heating of the unit is initiated. 
- Open the nitrogen inlet valve (FV 4101A) and tag in manual.

- Turn on gas sample line vacuum pumps.

- Close the manual purge ball valve (MPBV 001).

- Turn the nitrogen tank on.

- Open the system purge block valve and set the regulator to 20 psi. Regulate flow so that membrane check valve clicks steadily.

- Open the inlet/outlet/enclosure purge block valve and set the regulator to $10 \mathrm{psi}$. Start nitrogen purge to all three screws. Start nitrogen purge to the carbon reactor glow bar enclosures.

- Flush the vent system with nitrogen for 2 minlites.

- Establish nitroger. nurge to the flare. Set the flowmeter to greater than $50 \%$.

- Light the flare.

- Initiate system power in the motor control center:

- Turn SCR-101 and 102 main breakers on and set SCR-101 and 102 switches to auto.

- Turn on power to compressors CP-101 and CP-102.

- Verify power to screw conveyors.

- Turn on main breaker to transformer and then turn on main breaker from transformer to the SCR-103 cabinet. Put SCR-103 in auto.

- Set HT1 heater control (methanation feed gas) at about $6 \%$. This will give a temperature of about $800-1,000^{\circ} \mathrm{F}$.

- Set HT2 heater control (membrane feed gas) at about $2 \%$. This will give a temperature of about $300^{\circ} \mathrm{F}$.

- Gradually increase V105 heater control (carbon reactor glow bars) output to $20 \%$.

- Continue to purge until the oxygen content is less than 0.5 mole percent at the vent. 


\section{Hydrogen Purge and System Pressurization}

After purging oxygen from the system, nitrogen is then purged using hydrogen at moderate pressure.

- Turn hydrogen on at trailer, check that supply pressure is greater than 350 psi.

- With computer, turn $\mathrm{H}_{2}$ SUPLY to on position and visually check that the valve opened.

- Close nitrogen system purge valve (FV 4101A) and put tag in auto.

- Open the manual block valve on hydrogen supply line.

- Set hydrogen pressure on the supply line to $20 \mathrm{psi}$.

- Initiate checks of PRU area with the explosimeter to detect any hydrogen leaks.

- Flush the system with hydrogen until nitrogen content is $<5 \%$ at the system vent.

At this point, the system is ready for pressurization vith hydrogen:

- Turn on cooling water to both compressors and to membrane condenser E-102.

- Close the vent solenoid bypass valve and open solenoid block valves.

- Tag the vent solenoid valve (FV-3101C) in auto.

- Open the manual purge ball valve (MPBV 001).

- Set metharle reactor back pressure regulator to $290 \mathrm{psi}$ (yielding $300 \mathrm{psi}$ in the reactor).

- Gradually increase methanation system pressure to $80 \mathrm{psi}$ using pressure regulator on the hydrogen supply.

- When hydrogen pressure reaches $80 \mathrm{psi}$, turn on the hydrogen compressor (CP-101).

- Set CP-101 flow control for a suction inlet pressure of 80 psi in auto. Pressure in the hydrogen loop should reach about 300 psi with the membrane permeate valve at the correct setting. 
- After the methane reactor and hydrogen loop pressure reach the set point, the pressure in the methane loop (carbon reactor) will start to increase. When it reaches about $70 \mathrm{psi}$, turn on the methane compressor (CP-102).

- Be prepared in advance to switch the hydrogen supply system off and go to the hydrogen make-up system. If this is not done in a timely manner, the methane loop will overpressure and one of the pressure safety valves will vent to the flare.

- Allow pressure in methane loop to advance to 80 to 90 psi and then switch to the hydrogen make-up system.

- Use Macro <Alt+F3> to turn on the four history blocks to begin logging of data.

- At this point, the start-up is essentially complete. All that remains is to heat the reactors to the desired temperature levels and adjust the flow controls as methane production and decomposition begins.

\section{SHUTDOWN}

In an emergency, the unit can be shutdown by simply pressing the emergency shutdown button on the $1 / O$ rack or in the PRU area. To take a controlled shutdown, which minimizes the maintenance and cleanup that must be performed before another run is attempted, the following procedure was employed:

- Turn off the methane reactor and carbon reactor heaters (HT-101 and V105 TC). Put control set points at $0^{\circ} \mathrm{F}$.

- Put the membrane heater in manual and set HT2-TC tag to about $25 \%$.

- Put SCR-101 and 103 in the off position in MCC and turn off the main breakers in MCC.

- Shut off the hydrogen supply by closing Tag H2 SUPLY on the computer.

- Back off the four hydrogen pressure reguiators and close the four hydrogen block valves.

- Take the hydrogen trailer off line and record tank status.

- Shut off the methane compressor (CP-102).

- Close the manual purge block valve (MPBV 100). 
- Bleed gas out of the system by closing the block valves on both sides of the vent solenoid (FV-3101C) and then slowly opening the bypass valve. Adjust the bypass valve to maintain about a 6-foot long flame from the flare. At end of the bleed sequence, open the bypass valve fully.

- When the pressure in carbon reactor drops to $90 \mathrm{psi}$, slowly lower pressure in the hydrogen loop by lowering the setting on the methane reactor back pressure regulator.

- When the pressure in the methane reactor drops to $90 \mathrm{psi}$, set the methane reactor back pressure regulator to 0 psi ( $100 \%$ open).

- Shut off the membrane heater (HT2). Put temperature controls at $0^{\circ} \mathrm{F}$ and put SCR-102 in MCC in the off position. Shut off the main breaker in MCC.

- When the pressure at the methane compressor suction drops to 5 to $10 \mathrm{psi}$ (less than 30 psi discharge pressure), push the black SSD button. This will shut down the hydrogen compressor.

- Initiate nitrogen purge cycle by opening FV $4101 \mathrm{~A}$ and set the purge pressure to about 40 psi.

- Purge with nitrogen until hydrogen concentrations drop to less than $5 \%$ at all sample points. It may be necessary to open the bypass line around the first set of filters in the membrane loop to achieve gas flow through this part of the system if the filters have become plugged with char or volatiles.

- Turn off all main breakers in MCC.

- Turn off all cooling water.

- Open cooling water drain valves at the compressors.

- Open drain valves on both compressor condenser systems.

- Turn the heat trace system on for the outside lines.

- Shut off the nitrogen system.

- Turn off the flare.

- Turn off the instrument air dryer and air compressor. 
APPENDIX $\mathbf{B}$

METHANATION REACTOR DATA ANALYSIS AND MODELING 
A different design approach would be to use kinetic data and a fluid-bed design equation. In this approach, the char and gas conversions are specified as well as the char feed rate. A material balance is then used to estimate the gas flow rate requirement. After this calculation is completed, the velocity is specified and used to determine the reactor diameter, given the flow rate estimated above. Then a fluid-bed design equation and the kinetic data are used to estimate the required bed height. This lequires computation of a bubble to dense phase mass transfer coefficient from empirical correlations. Finally, freeboard and entrainment calculations can be conducted. For gas-solid reactions, this is an iterative calculation which has been described in the literature. ${ }^{21}$

To further evaluate the performance of the methanation unit, material balance and fluid bed design equations will be used to extract crude kinetic parameters from Run $\mathrm{M}-10$ data. These kinetic parameters will then be used to design a new reactor which will achieve specified char and gas conversion. A carbon balance on this system is:

$$
x_{c}=\frac{y_{0} Q_{0}-y_{i} Q_{1}}{F_{c}}
$$

Where: $X_{c}=$ Fractional carbon conversion.

$y_{i}=$ Mole fraction of methane in feed.

$y_{0}=$ Mole fraction of methane in product.

$Q_{i}=$ Inlet gas flow rate.

$Q_{0}=$ Outlet gas flow rate.

$F_{c}=$ Feed raie of carbon in char.

The outlet gas flow rate is determined from a hydrogen balance (neglecting hydrogen present in the char):

$$
Q_{i}\left(1+y_{i}\right)-Q_{0}\left(1+y_{0}\right)
$$

Geldart ${ }^{21}$ has presented an analytical solution to the two-phase bubbling bed model for irreversible first order reactions:

$$
\frac{P_{o}}{P_{i}}=\exp \left[\frac{-K Y\left(1-e_{b}\right)\left(1-e_{m}\right)}{Y+K\left(1-e_{b}\right)\left(1-e_{m}\right)}\right]
$$


Where: $P_{i}=$ Hydrogen partial pressure in feed.

$P_{0}=$ Hydrogen partial pressure in product.

$\theta_{\mathrm{b}}=$ Bubble void fraction.

$e_{m}=$ Minimum fluidization void fraction.

$\mathrm{Y}^{\mathrm{m}}=$ Dimensionless mass transfer coefficient.

$\mathrm{K}=$ Dimensionless kinetic rate constant.

The minimum fluidization void fraction is usually assumed to be 0.5 . The dimensionless parameters and bubble void fraction are calculated. For the bubble void fraction, the bubble gas flow rate is first calculated:

$$
Q_{b}=\left(u-u_{m}\right) A
$$

Where: $\mathrm{u}=$ Gas velocity.

$u_{m}=$ Minimum fluidization velocity $=8.3 \mathrm{~cm} / \mathrm{s}$.

$A=$ Reactor cross-sectional area.

The bubble rise velocity is then estimated (for slugs): ${ }^{22}$

$$
u_{b}=0.35(g D)^{1 / 2}+\left(u-u_{m}\right)
$$

Where: $g=$ The acceleration of gravity.

$\mathrm{D}=$ The bed diameter.

Given these values:

$$
e_{b}=Q_{b} /\left(u_{b} A\right)
$$

The dimensionless mass transfer coefficient can be calculated from:

$$
Y=k_{g} a H / u
$$

Where: $k_{g}=$ Bubble to dense phase mass transfer coefficient

$$
-\frac{u_{m}}{3}+2\left[\frac{D_{m} e_{m} u_{b}}{\pi D}\right]
$$


$D_{m}=$ Molecular diffusivity of hydrogen.

$\mathrm{a}=$ Mean bubble surface area $=6 \mathrm{e}_{\mathrm{b}} / \mathrm{D}$.

$\mathrm{H}=$ Bed height.

The dimensionless kinetic rate constant is defined as:

$$
K=k_{r} H / u
$$

Where: $k_{r}=$ The intrinsic rate constant for a first order reaction.

Utilizing the gas analysis data and run parameters for Run $M-10$, the mass transfer coefficient, $k_{g}$, can be calculated and the intrinsic rate constant, $k_{r}$, can be estimated. The results of these calculations are shown in Table 13.

\section{Table 13. Kinetic and Mass Transfer}

Parameters Extracted from Run $\mathrm{M}-10$

\begin{tabular}{|c|c|c|c|}
\hline Test & $\begin{array}{l}\text { Conversion } \\
\text { to } \mathrm{CH}_{4}\end{array}$ & $\mathrm{k}_{g} \mathrm{~cm} / \mathrm{s}$ & $\underline{k}_{r}, 1 / \mathbf{s}$ \\
\hline 1 & 19.4 & 3.643 & 0.0382 \\
\hline 2 & 22.2 & 3.760 & 0.0418 \\
\hline 3 & 18.0 & 3.747 & 0.0608 \\
\hline 4 & 27.0 & 3.643 & 0.1058 \\
\hline 5 & 23.9 & 3.626 & 0.1463 \\
\hline
\end{tabular}

Here agreement in mass transfer parameters for the various test periods is seen to be good. Rate constants vary over a fairly wide range; however, given the fluctuations in outlet methane content and the intermittent nature of char feeding, the results are probably pretty good.

For design of a new reactor, we will use the following conditions:

$$
\begin{aligned}
& \mathrm{k}_{\mathrm{g}}=3.6 \mathrm{~cm} / \mathrm{s} \\
& \mathrm{k}_{\mathrm{r}}=0.1 \mathrm{l} / \mathrm{s} \\
& \mathrm{F}=50 \mathrm{lb} \mathrm{char} / \mathrm{hr} \\
& \mathrm{y}_{\mathrm{i}}=0 \\
& \mathrm{y}_{0}=0.4 \\
& \mathrm{X}_{\mathrm{c}}=0.65 \\
& \mathrm{~T}^{\circ}=1,400^{\circ} \mathrm{F} \\
& \mathrm{P}=300 \mathrm{psig}
\end{aligned}
$$


Solving the carbon balance yields

$$
Q_{0}=32.4 \mathrm{scfm}
$$

Solving the hydrogen balance yields

$$
Q_{1}-45.0 \mathrm{scfm}
$$

The average of these values will be used for further calculations:

$$
Q-38.7 \mathrm{scfm}
$$

Assuming a velocity of four times minimum fluidization:

$$
u=4 u_{m}-4(8.3)=33.2 \mathrm{~cm} / \mathrm{s}
$$

The cross-sectional area can then be calculated as $93.5 \mathrm{~cm}^{2}$, yielding a reactor diameter of $10.9 \mathrm{~cm}$ or 4.3 inches. 


\section{APPENDIX C}

CALCULATION OF CARBON REACTOR HEAT TRANSFER COEFFICIENT 
For the original design with horizontal heat transfer tubes, a heat transfer coefficient of about $30 \mathrm{Btu} / \mathrm{hr}-\mathrm{ft}^{2}{ }^{\circ} \mathrm{F}$ was assumed. For the modified design with vertical tubes, heat transfer coefficients were estimated using equations and correlations presented by Grace. ${ }^{24}$ The overall heat transfer coefficient, $U$, is given by:

$$
U=\frac{1}{1 / h_{g}+\frac{r_{0}}{K_{t}} \ln \left(r_{0} / r_{i}\right)+1 / h_{b}}
$$

Where: $h_{g}=$ Glow bar to inner tube wall film coefficient.

$h_{b}=$ Outer tube wall to bed film coefficient.

$r_{i}=$ Inner tube radius $=0.089$.

$r_{0}=$ Outer tube radius $=0.120$.

$\mathrm{K}_{\mathrm{t}}$ = Tube thermal conductivity $=10 \mathrm{Btu} / \mathrm{hr}-\mathrm{ft}-{ }^{\circ} \mathrm{F}$.

The glow bar to tube wall film coefficient, $h_{g}$, is assumed to be very large, so $1 / h_{g}$ is approximately zero. The bed to tube wall film coefficient is composed of radiant, conductive, and convective components which are additive:

$$
h_{\mathrm{b}}-h_{\mathrm{rad}}+h_{\text {conv }}+h_{\text {cond }}
$$

The radiant component may be estimated from:

$$
h_{\mathrm{rad}}=\frac{E_{\mathrm{b}} \sigma\left(T_{\mathrm{b}}^{4}-T_{\mathrm{s}}^{4}\right)}{\left[1 / E_{\mathrm{s}}+1 / E_{\mathrm{b}}-1\right]\left(T_{\mathrm{b}}-T_{\mathrm{s}}\right)}
$$

Where: $E_{b}=$ Emissivity of the bed.

$E_{s}=$ Emissivity of heat transfer surface.

$\mathrm{T}_{\mathrm{b}}=$ Bed temperature.

$T_{s}=$ Surface temperature.

$\sigma=$ Stephan-Boltzman constant $=0.1714 \times 10^{-8}$ Btu/hr- $-\mathrm{ft}^{2}-\mathrm{R}^{4}$.

Assuming a value of 0.6 for the heat transfer surface emissivity (a grey body), the bed emissivity may be estimated from: 


$$
E_{\mathrm{b}}=0.5\left(1+E_{\mathrm{s}}\right)=0.8
$$

We also assume a surface temperature of $1,900^{\circ} \mathrm{F}$ and a bed temperature of $1,600^{\circ} \mathrm{F}$. These values yield:

$$
h_{\text {rad }}=31 B t u / h r-f t^{2}-{ }^{\circ} F
$$

The convective component may be estimated from:

$$
h_{\text {conv }}=0.009 A r^{0.5} p p^{0.33} \frac{K_{g}}{d_{p}}
$$

Where:

$$
A r=\frac{g \rho_{g}\left(\rho_{s}-\rho_{g}\right) d_{p}^{3}}{\mu_{g}^{2}}
$$

$$
\begin{aligned}
& \mathrm{g}=\text { Acceleration of gravity. } \\
& \rho_{\mathrm{g}}=\text { Gas density. } \\
& \rho_{\mathrm{s}}=\text { Solid density. } \\
& \mathrm{d}_{\mathrm{p}}=\text { Particle mean diameter. } \\
& \mu_{g}=\text { Gas viscosity. } \\
& \mathrm{K}_{\mathrm{g}}=\text { Gas thermal conductivity. } \\
& \mathrm{Pr}_{\mathrm{r}}=\text { Prandtl number }=\mathrm{Cp}_{\mathrm{g}} \mu_{\mathrm{g}} / \mathrm{K}_{\mathrm{g}} \\
& \mathrm{Cp}_{\mathrm{g}}=\text { Gas heat capacity. }
\end{aligned}
$$

Substituting appropriate physical properties yields:

$$
\begin{aligned}
& \text { Ar }=226 . \\
& \operatorname{Pr}=0.273
\end{aligned}
$$

$$
h_{\text {conv }}=11.2 B t u / h r-f t^{2}-{ }^{\circ} \mathrm{F}
$$


For the conductive component:

$$
h_{\text {cond }}=\left(1-e_{b}\right)\left[\frac{\rho_{s}\left(1-e_{m}\right) C p_{s} K_{e f f} f_{b}}{1-e_{b}}\right]^{1 / 2}
$$

Where: $e_{b}=$ Bubble void function.

$e_{m}=$ Yoid fraction at minimum fluidization.

$\mathrm{Cp}_{\mathrm{s}}=$ Solid heat capacity.

$\mathrm{K}_{\text {eff }}=$ Bed effective thermal conductivity.

$f_{b}=$ Bubble frequency.

The effective thermal conductivity is assumed to be about $0.14 \mathrm{Btu} / \mathrm{hr}-\mathrm{ft}-{ }^{\circ} \mathrm{F}$ based on data and correlations presented by Grace. ${ }^{24}$ A bubble frequency of about 10 can be estimated by trial and error utilizing the bed geometry, particle properties, and design gas flow rate. Substitution of physical property values yields:

$$
h_{\text {cond }}=5 B t u / h r-f t^{2}-{ }^{\circ} \mathrm{F}
$$

These component values sum to yield an overall film coefficient:

$$
h_{\mathrm{b}}-31+11+5=47 \mathrm{Btu} / \mathrm{hr}-\mathrm{ft}^{2}-{ }^{\circ} \mathrm{F}
$$

And an overall heat transfer coefficient:

$$
U=40 \mathrm{Btu} / \mathrm{hr}-\mathrm{ft}^{2}-{ }^{\circ} \mathrm{F}
$$




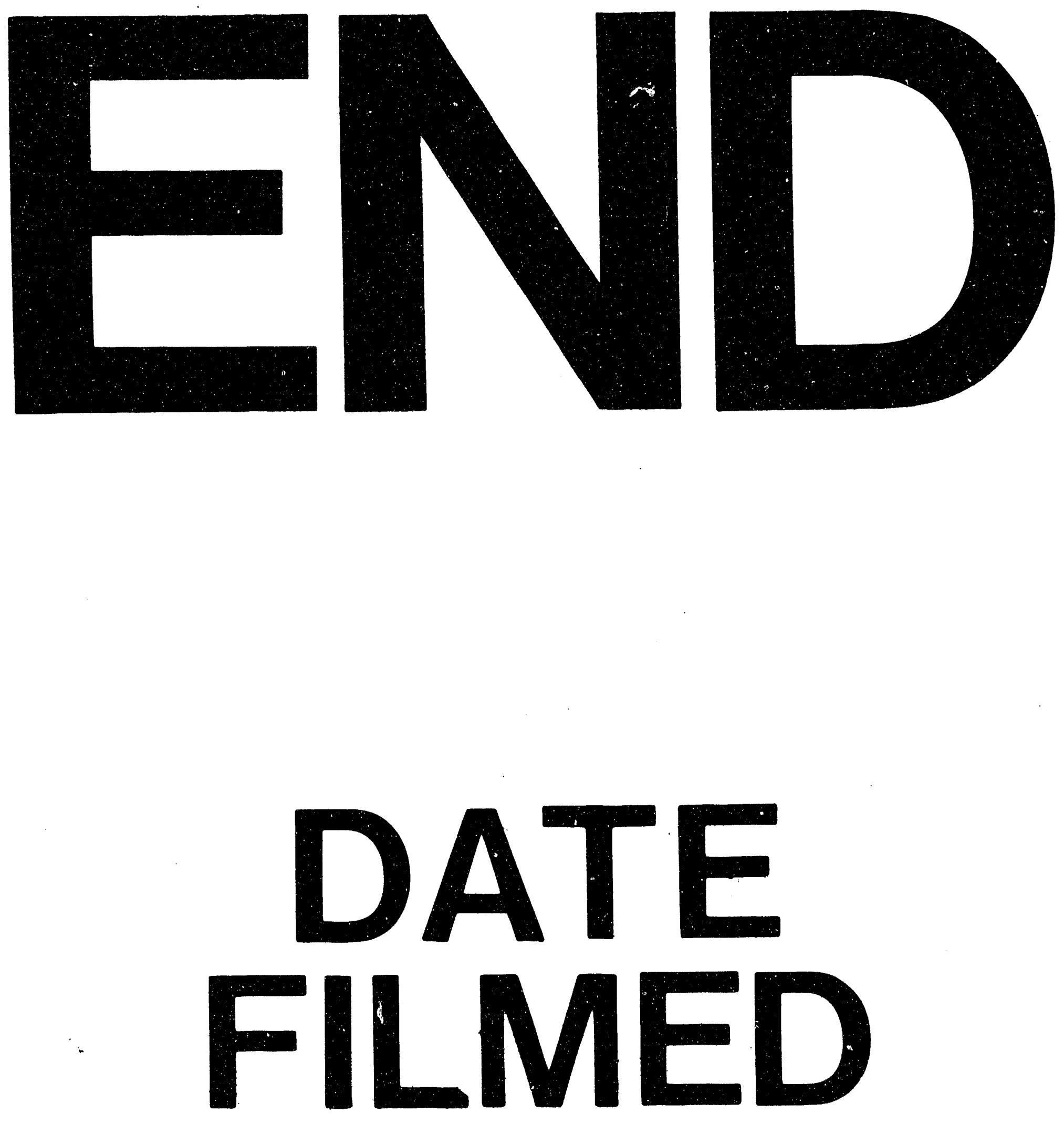

1

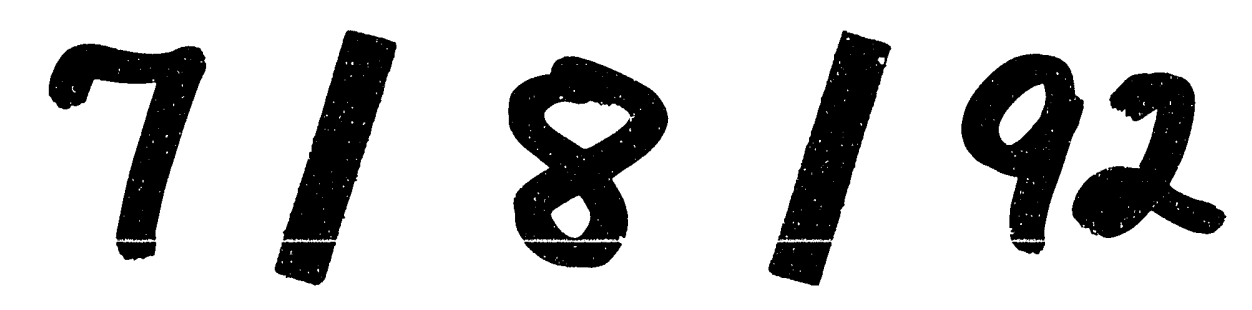


